Florida International University FIU Digital Commons

FIU Electronic Theses and Dissertations

University Graduate School

6-28-2017

\title{
The Diffusion of Social Media in Nonprofit Organizations
}

Elvis Asorwoe

Florida International University, easor001@fiu.edu

DOI: $10.25148 /$ etd.FIDC001925

Follow this and additional works at: https://digitalcommons.fiu.edu/etd

Part of the Public Administration Commons

\section{Recommended Citation}

Asorwoe, Elvis, "The Diffusion of Social Media in Nonprofit Organizations" (2017). FIU Electronic Theses and Dissertations. 3471. https://digitalcommons.fiu.edu/etd/3471

This work is brought to you for free and open access by the University Graduate School at FIU Digital Commons. It has been accepted for inclusion in FIU Electronic Theses and Dissertations by an authorized administrator of FIU Digital Commons. For more information, please contact dcc@fiu.edu. 


\title{
FLORIDA INTERNATIONAL UNIVERSITY
}

\author{
Miami, Florida
}

\section{THE DIFFUSION OF SOCIAL MEDIA IN NONPROFIT ORGANIZATIONS}

\author{
A dissertation submitted in partial fulfillment of the \\ requirements for the degree of \\ DOCTOR OF PHILOSOPHY \\ in \\ PUBLIC AFFAIRS \\ by
}

Elvis Asorwoe

2017 
To: Dean John F. Stack, Jr.

School of International and Public Affairs

This dissertation, written by Elvis Asorwoe, and entitled The Diffusion of Social Media in Nonprofit Organizations, having been approved in respect to style and intellectual content, is referred to you for judgment.

We have read this dissertation and recommend that it be approved.

George Marakas

Shaoming Cheng

Nazife Ganapati

Susannah Bruns Ali

Sukumar Ganapati, Major Professor

Date of Defense: June 28, 2017

The dissertation of Elvis Asorwoe is approved.

Dean John F. Stack, Jr. School of International and Public Affairs

Andrés G. Gil

Vice President for Research and Economic Development and Dean of the University Graduate School

Florida International University, 2017 
(C) Copyright 2017 by Elvis Asorwoe

All rights reserved. 


\section{DEDICATION}

I dedicate this dissertation to my children, Sheena Abena Bubune Asorwoe and Shannon Kweku Mawudeka Asorwoe. 


\section{ACKNOWLEDGMENTS}

To the members of my dissertation committee, Dr. George Marakas, Dr. Shaoming Cheng, Dr. Emel Nazife Ganapati, and Dr. Susannah Ali, I am grateful for your time and direction throughout this process and my time at FIU. To my chair, Dr. Sukumar Ganapati, your guidance, patience, kindness, and understanding made this dissertation a success. I am sincerely grateful.

I would like to thank the President of United Way of Florida, Dr. Ted Granger, for providing great atmosphere and connections to all chapters of United Way and affiliated local nonprofit organizations in Florida. To the participants/interviewees and staff of all chapters of United Way and affiliated local nonprofit organizations in Florida, your insight made this dissertation a success. Thank you for inviting me into your offices to learn about the work of United Ways of America and all affiliated local nonprofits' community development contributions.

The financial support of the FIU Dissertation Year Fellowship (DYF) contributed to my development and ability to complete this dissertation successfully.

Lastly, I thank the Department of Public Administration, Florida International University and the resources of the FIU Writing Center, were instrumental in the completion of this dissertation. The GA/TA financial support received as a full-time student in the doctoral program is one of the greatest opportunity of a lifetime. 


\title{
ABSTRACT OF THE DISSERTATION
}

\section{THE DIFFUSION OF SOCIAL MEDIA IN NONPROFIT ORGANIZATIONS}

by

\author{
Elvis Asorwoe
}

Florida International University, 2017

Miami, Florida

Professor Sukumar Ganapati, Major Professor

Social media platforms have become important over the last decade for nonprofit organizations to communicate with stakeholders, engage with community, and connect with donors. Despite the significance, there is a wide gap in the research on social media adoption and use among community-based nonprofits. To fill this gap, this dissertation examines the diffusion of two popular social media platforms (Facebook and Twitter) among community-based nonprofit organizations affiliated with the United Way of America in Florida. The United Way is the largest federated organization of nonprofits and its primary focus is on education, income, and health.

Two questions guide this study: (i) What are the principal determinants of the adoption and use of social media in nonprofit organizations? and (ii) How do nonprofits use social media? The conceptual framework for the analysis comprises of three dimensions: technological, environmental, and organizational. These dimensions respectively draw upon three theories: diffusion of innovation theory, resource dependence theory, and institutional theory. As such, the 
hypothesis is that the adoption and use of social media is influenced by technological, environmental, and internal institutional factors. For the first question, I conducted a survey of nonprofits affiliated with United Way chapters in Florida, and then analyzed the results using multivariate regression analysis. For the second question, I scraped the Facebook pages of United Way chapters and conducted a content analysis of the posts. I also interviewed key officials in these organizations.

The regression analysis shows that technological indicators were significant for the adoption of social media, but were not so for social media use. The findings suggest that factors affecting the adoption and use of social media are distinctive. The content analysis shows that nonprofits predominantly use social media to organize and promote events and to collaborate with other organizations. The events and collaboration enhance the organizations' legitimacy and help with fundraising for targeted purposes. The study's policy implication is that nonprofits should engage social media specialists to enhance adoption and train the leaders about benefits of social media use. A federated organization like United Way could adopt best practices in encouraging the use of social media. 


\section{TABLE OF CONTENTS}

CHAPTER

PAGE

I. INTRODUCTION

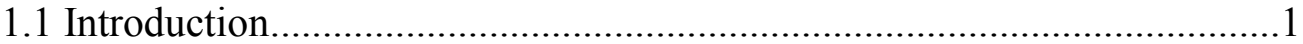

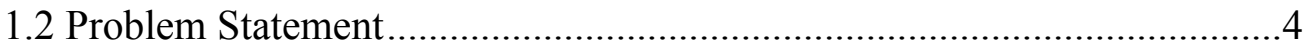

1.3 Purpose and Significance of the Study ......................................................

1.4 Conceptual Framework ............................................................................10

1.5 Research Questions and Hypotheses .......................................................13

1.6 Research Design and Methodology ..........................................................14

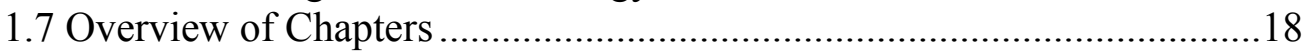

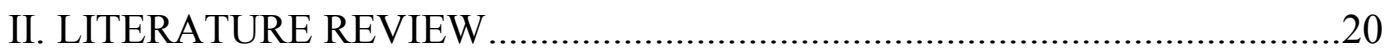

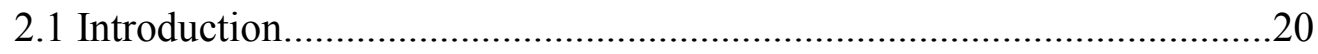

2.2 The Evolution of Social Media ................................................................21

2.3 Social Media Use among Nonprofit Organizations .................................26

2.4. Theories of Social Media Diffusion ........................................................34

2.5 Conceptual Model....................................................................................49

2.6 The Empirical Context: United Way .......................................................52

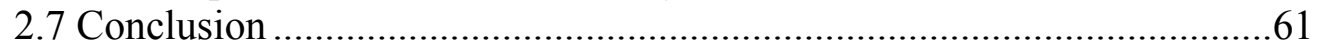

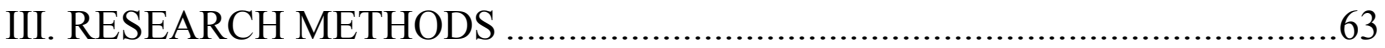

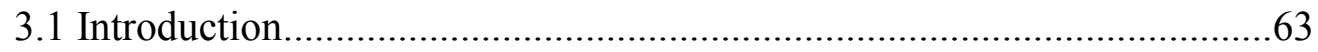

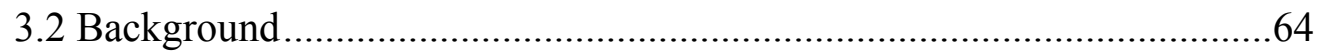

3.3 Quantitative Research Methodology ....................................................65

3.4 Qualitative Research Methodology .....................................................72

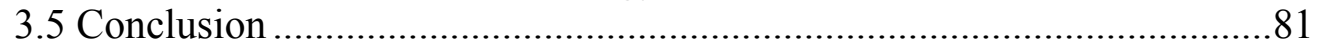

IV. DETERMINANTS OF ADOPTION \& USE OF SOCIAL MEDIA ...............82

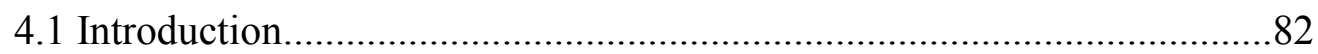

4.2 The Analytical Model and Variables .......................................................83

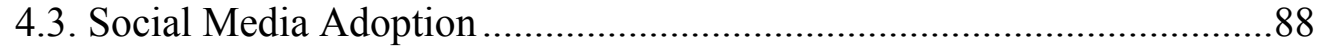

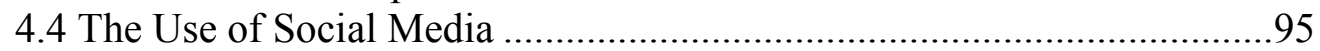

4.5 Summary Analysis of Social Media Adoption and Use .........................101

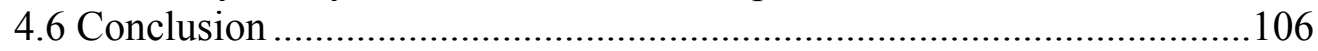

V. THE USE OF FACEBOOK

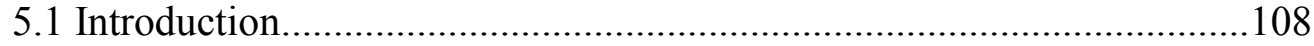

5.2 Types of Facebook Posts .....................................................................109

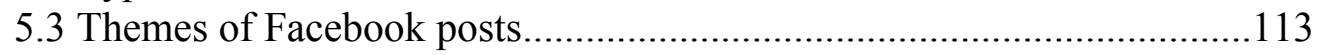

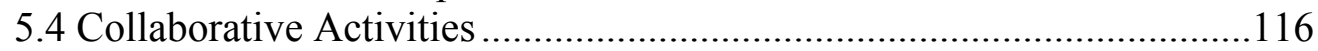

5.5 Dialogue and Community Building ......................................................123

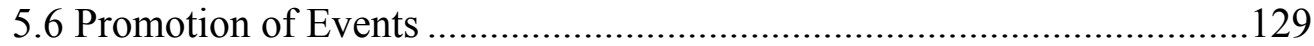

5.7 Leaders' views on Using Facebook: Interview Findings .........................138

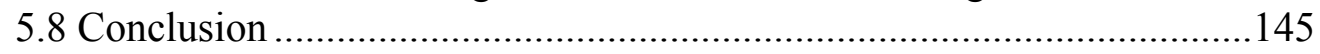




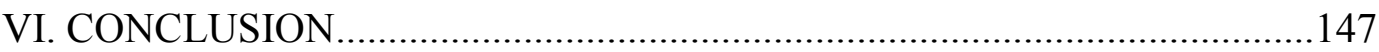

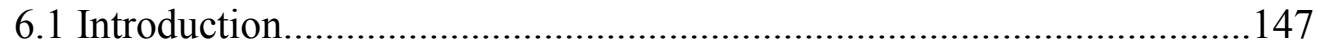

6.2 Research Context and Conceptual Framework.......................................148

6.3 Study's Findings and Contributions to Literature ……............................149

6.4 Implications for Policy and Practice....................................................156

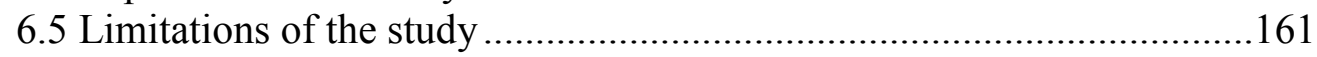

6.6 Recommendations for Future Research.................................................163

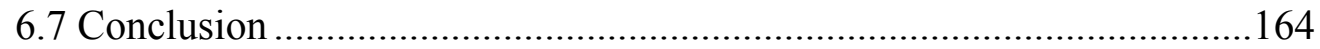

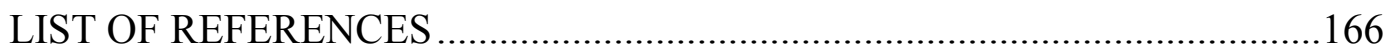

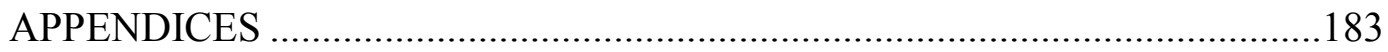

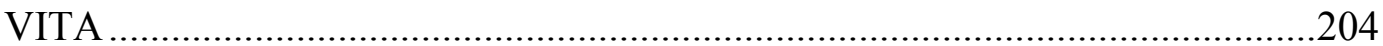




\section{LIST OF TABLES}

TABLE

PAGE

Table 1 Description of Variables

Table 2 Summary of United Way Facebook posts, July 2016- December 201674

Table 3 Selected United Way Chapters ………………………………..............

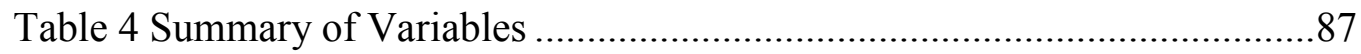

Table 5 Descriptive Statistics for Social Media Adoption....................................89

Table 6 Motivations for Adopting Social Media ..................................................90

Table 7 Summary of Regression Analysis of Adoption of Facebook ...............92

Table 8 Summary of Regression Analysis of Adoption of Twitter ....................94

Table 9 Descriptive Statistics of Social Media Use ………………....................96

Table 10 Motivations for Using Social Media....................................................97

Table 11 Summary of Logistic Regression, Facebook Use (Model 2a) .............99

Table 12 Summary of Logistic Regression, Twitter Use (Model 2b)...............101

Table 13. Summary of United Way Facebook posts, July-December 2016 .....110

Table 14. Profile of the selected United Way Chapters .....................................111

Table 15. Summary of Type of Posts (July 2016 to December 2016)..............113

Table 16. Themes of Facebook Posts …………………………………….....115

Table 17. Collaboration by United Way Chapters.............................................117

Table 18. Dialogue and Community Building by United Way Chapters ..........125

Table 19. Promotion of Events by United Way Chapters.................................131 


\section{LIST OF FIGURES}

FIGURE

PAGE

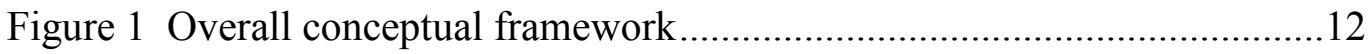

Figure 2 Full Conceptual Model …..................................................................50

Figure 3 Organizational Chart of United Way ...............................................54

Figure 4 Distribution of Selected United Way Chapters ................................... 76

Figure 5 Word Frequency Query of Facebook Posts ......................................114 


\section{LIST OF ACRONYMS AND ABBREVIATIONS}

$\begin{array}{ll}\text { AOL } & \text { American Online } \\ \text { BBS } & \text { Bulletin Board System } \\ \text { GDP } & \text { Diffusion of Innovation } \\ \text { ICT } & \text { Information and Communication Technology } \\ \text { IT } & \text { Information Technology } \\ \text { NAACP } & \text { National Association for the Advancement of Colored } \\ \text { People } & \\ \text { NCCS } & \text { National Center for Charitable Statistics } \\ \text { NP100 } & \text { Nonprofit Times 100 } \\ \text { RDT } & \text { Resource Dependence Theory } \\ \text { UWA } & \text { United Way of America }\end{array}$




\section{INTRODUCTION}

\subsection{Introduction}

Social media has become a pervasive technological force in the last decade, influencing the functioning of public and nonprofit organizations. In the context of electronic government (e-government), social media has become an important tool for open government initiatives, which include government transparency, accountability, and citizen co-production (Bertot, Jaeger, and Grimes, 2010; Lee and Kwak, 2012; Linders, 2012; Mergel, 2013). Research on social media in the nonprofit sector is still emerging, with extant research largely focusing on the social media use for public relations and information dissemination among large nonprofits (Nah and Saxton, 2012). This dissertation aims to contribute to the emerging literature by examining the diffusion of social media among local, community-based nonprofit organizations affiliated with United Way in Florida.

The nonprofit sector has a significant role to play in the American economy. It contributes to the societal well-being through various support services that include healthcare delivery, employment, education, and protection of the environment, plants and animals (Briones et al., 2011; Cho, Schweickartb and Haasec, 2014; GálvezRodriguez et. al., 2014; Grooters, 2011; Guo and Saxton 2014; Lovejoy and Saxton, 2012). The activities of nonprofit organizations have grown enormously over the last two decades in the country - there were nearly 1.55 million registered nonprofits in 2015 , contributing to about $5.3 \%$ of the nation's GDP (NCCS, 2015). They accounted for over $\$ 2.36$ trillion in revenues and over $\$ 5.47$ trillion in assets (NCCS, 2015). The nonprofit 
sector was remarkably resilient during the 2008-2011 economic recession-only a small share of nonprofits closed doors, and the overall employment in the sector had increased during this period (Brown et al., 2013; Wirtz, 2015). Government funding played an important role in the growth of non-profits, wherein the federal, state, and local government agencies have contracted with the non-profits to provide public services (Lecy and Slyke, 2012; Liu, 2016). At the same time, nonprofits have also to depend on funding through voluntary contributions.

The advent of new information and communication technology (ICT) like social media over the last decade has afforded new opportunities for nonprofit organizations to strategically utilize the ICT platforms to undertake core activities that directly impact their missions. Social media, also referred to as social networking, is a broad term for web-based platforms and services that enable two-way peer to peer communication. Users can develop public profiles and content, and connect with other peer groups on an online platform (Guo and Saxton, 2014; Lovejoy, Waters and Saxton, 2012). It is a core part of the rapidly evolving digital world, which enables instantaneous communications among community members in real time and location. It includes platforms like Twitter, Facebook, and YouTube. These are also referred to as Web 2.0 communication platforms that can be accessed on the go using any Internet connected device (e.g., computer, phablet, smartphone, smartwatch).

Social media use has grown exponentially over the last decade. According to Pew Research Center (2017), only 5\% of the American adults used some form of social media platform in 2005; the share increased to $69 \%$ in 2016. Concurrently, studies have shown the steady and substantial decline in the use of traditional media such as television, 
newspapers, radio and magazines as the means to brand and promote events by nonprofit organizations (Annenberg and Ketchum, 2008; Lumpp, 2014). The decline in the use of the traditional media is attributed to digital media such as website, email, social media, and text messages, which are relatively cheaper compared to traditional media (Guo and Saxton, 2014). Recent nonprofit literature has also emphasized the changing pattern of communication, branding, and advertisement as a result of the broader communication changes (Gálvez-Rodriguez et. al., 2014; Guo and Saxton, 2014).

In recent times, nonprofit organizations have increased ICT use for fundraising, advocacy, community engagement, and communication with stakeholders (Auger, 2013; Cho, Schweickartb and Haasec, 2014; Suárez, 2009). Large and well-established nonprofits like the American Red Cross, Oxfam, and American Cancer Society have relied on ICT tools like social media to undertake various activities, especially raising funds (Grooters, 2011). A recent study showed that nonprofit organizations spent an average of 4 cents on digital advertising for every \$1 raised in 2015 (Hrywna, 2016). Over 70 percent of the advertising budgets were geared towards new donor acquisition, increasing the number of new donors added to the pool of regular donors with monthly online revenue up by 24 percent and one-time giving up by18 percent (Hrywna, 2016).

There are few extant studies focusing on how nonprofit organizations can better use ICT to meet their organizational needs (Saxton and Waters, 2014; Saxton et al., 2015). Studies exploring the adoption and use of social media among local nonprofit organizations is even sparser. Although local nonprofits play a crucial role in the development of deprived communities across the country, social media activities in these smaller nonprofits have not captured the attention of scholars (Brown and Troutt, 2004; 
Bryce, 2006; Grønbjerg and Paarlberg, 2001). My study builds upon the limited studies on the adoption and use of social media in nonprofit organizations (e.g. Lovejoy and Saxton, 2012, Schneider, 2003; Waters et al., 2009). It contributes to the literature on the use of ICT, particularly social media, among community-based nonprofit organizations.

\subsection{Problem Statement}

Research on social media and the nonprofit sector is still emerging and is in its infancy. The existing research exploring technology and nonprofit organizations cut across multiple disciplines such as communication, management, public administration, and information systems. The research on diffusion of information technology in nonprofit organizations dates back to over three decades (Burt and Taylor, 2003;

Salamon, 1992, 1995. 2002; Salamon and Geller, 2007; Salamon, Sokolowsky and List, 2003; Santos, 2003). However, the adoption of information technology processes like Enterprise Resource Programs (ERPs) has been slow, in part, due to the cost of implementation, including expertise and cost of infrastructure (Brainard and Siplon, 2004; Salamon, 1992, 1995, 2005; Salamon and Geller, 2007). Unlike the traditional information technology solutions, social media use has grown exponentially in the last decade and become a popular communication medium. The advent of social media has changed the trajectory of the adoption and use of ICT in the nonprofit sector (Avery, 2010; Child and Gronbjerg, 2007).

Even though social media use has proliferated widely, nonprofits face the challenge of how to integrate social media applications into their organizational activities (Neff and Moss, 2011; and Safko, 2010). Nonprofit organizations could have limited 
resources such as knowledge, time, money, equipment, and personnel for dealing with social media (Alexander et al., 2010; Lord, 2009). Waters et al. (2009) and Young (2010), for example, highlight how time could be a constraint on social media use in nonprofit organizations. Schneider (2003) showed that there are hardware and software infrastructure challenges facing the nonprofit sector in the adoption and use of various information and communication technology platforms (Brinkerhoff, 2002; Eng, 2012; Gazley, 2010; Waters and Bortree, 2010).

The Dartmouth Center for Marketing Research at the University of Massachusetts conducted longitudinal studies on the use of social media among large nonprofit organizations in the United States (Young, 2012). The Dartmouth studies show that nonprofit organizations outpace public and private agencies in the adoption and use of social media for various types of activities. Nonprofits outnumbered public and private organizations by $97 \%$ in the adoption of social media (Young, 2012). A similar survey of 459 nonprofits undertaken in 2010 showed that a large majority (83\%) were using social media technologies for communication, community engagement and fundraising (LaCasse, Quinn, and Bernard, 2010; Young, 2012). The Dartmouth studies show how social media has become the central medium of communication and fundraising tool for large nonprofit organizations in the United States (Young, 2012).

Indeed, the early literature on adoption and use of social media among nonprofits has focused mainly on the so called Nonprofit Times 100 organizations (NPT100). These NPT100 organizations are similar to Fortune 500 companies. They have a large number of employees, huge budgets, significant assets, and several offices across the United States. Over $80 \%$ of these organizations have an entire department dedicated solely to the 
social media activities (Saxton et al., 2015; Waters, 2009). Large nonprofits could thus commandeer the resources better than the small, community-based nonprofits. Some scholars have even argued that there is a digital divide within the nonprofit sector between large nonprofits and smaller nonprofits (Fryer and Granger, 2008; McNutt and Menon, 2008).

Small, locally oriented community-based nonprofit organizations do not typically have the resources of the large nonprofit organizations. The small nonprofits rely on the generous gifts and donations from philanthropies to undertake various activities to improve the living conditions of communities (Smith, 1993). While the number of these community-based nonprofits has increased, the sources of income are shrinking, with limited grants from various levels of government and decrease donations from private individuals. Nonprofits need to devise new strategies using ICT tools like social media that will increase their income and reduce their overhead costs of operating so that organizations can divert more funds to programs and activities that directly impact the communities (Behn, et al., 2010; Edwards and Hoefer, 2010; Handy, 2010; Lampkin and Boris, 2002). Nonprofits undertake fundraising activities to solicit funds from donors. Other events include grants from recognized private foundations and government institutions. Studies show that on average, nonprofit executives spend substantial time on fundraising activities than on activities that directly impact the community needs (Lord, 2009). Thus, fundraising events are among the major activities of the community nonprofit organizations' management and leadership.

The literature on nonprofits has largely neglected how community-based nonprofit organizations could adopt and use social media effectively. Only a few 
practical guidebooks have been published over the last few years on how communitybased nonprofits could capitalize their operations using social media (Asencio and Sun, 2015; Kanter and Fine, 2010; Mansfield, 2012). Some of the studies serve as a guide for practitioners on how to use social media effectively in order to undertake more activities

with limited resources (Handley and Chapman, 2011; Mansfield, 2011). This dissertation study aims to fill the literature gap by focusing on the factors that influence the adoption and use of social media in locally focused nonprofits. The diffusion of social media among nonprofits is important to study since the widespread growth of social media has fundamentally influenced nonprofit organizations' communication and management practices. Nonprofits use social media platforms to promote and maintain their programs and services by reaching out to new constituents through cyberspace (Krestalude, 2011; Zorn, Flanagin, and Shoham, 2011). The social media use can enhance the nonprofit organizations' service delivery and the mobilization of their clients and supporters.

\subsection{Purpose and Significance of the Study}

Many nonprofits have come to rely on various forms of technologies to attract donors and connect with clients and stakeholders. Social media has become the mainstay for networking in nonprofit organizations (Saxton et al., 2015; Zorn et al., 2011). Nonprofit organizations use social media to facilitate community and stakeholder engagement (Saxton, et. al., 2015). Social media is a low-cost method to engage current and potential stakeholders through sharing of information in real-time (Mansfield, 2011; Young, 2010; Gálvez-Rodriguez, et. al., 2014). 
In the above context, the goal of this dissertation is to examine the principal determinants of adoption and use of social media platforms in nonprofit organizations in the United States. Two principal questions guide this study. The first question is: What are the principal determinants of adoption and use of social media in nonprofit organizations? This question aims to uncover the enablers and barriers in the adoption of social media. The second question is: How do nonprofits that have adopted social media use it? This question aims to explore the different uses of social media by communitybased nonprofits.

Several social media platforms have become popular over the last decade and are evolving rapidly. Facebook and Twitter are among the most popular among these platforms. Hence, this study focuses on the adoption and use of these two platforms. Facebook is a platform for sharing events, multimedia, and news instantaneously within a community of friends. Twitter is a microblogging site that is also popular for instantly relaying news and multimedia (President Donald Trump's twitter use has especially drawn political attention to the site).

Extant studies have focused on how social media like Facebook and Twitter can be used by nonprofit organizations in specific contexts. Nonprofits have used Facebook and Twitter for advocacy and engaging stakeholders (clients as well as donors) (Waters et al. 2009) and for educating and training volunteers (Briones et. al., 2011). The nonprofits have also used Facebook and Twitter to disseminate information and to coordinate response mechanisms following the 2010 Haiti earthquake (Bird, Ling, and Haynes, 2012; Takahashi, Tandoc, and Carmichael, 2015), the 2011 Japanese tsunami and 
earthquake (Acar and Muraki, 2011), the 2015 California wildfire crisis (Brengarth and Mujkic, 2016), etc.

Despite the use of Facebook and Twitter in various circumstances, there is no systematic study of the diffusion of social media among community-based nonprofits (Graddy and Morgan, 2006). The diffusion is important to study to understand why nonprofits adopt or use social media and to address the barriers they face. Adoption refers to the organizational decision to embrace and implement social media. Use refers to the set of activities that the nonprofits use the social media to achieve their mission. Despite the advantages of social media, nonprofit organizations face internal and external organizational challenges in adopting and using social media.

The study is significant for two important reasons. First, as already explained before, research on the adoption and use of social media in community-based nonprofit organizations is limited. Extant research has mainly focused on large nonprofit organizations. Hence, this study fills an important gap in the literature on social media and nonprofit organizations. This study focuses on nonprofit organizations operating under the umbrella of the Florida chapter of the United Way of America. The United Way is the largest federation of nonprofit organizations in the United States. Its mission is to advance the common good by mobilizing other locally engaged nonprofits. It mainly focuses on three areas: education, income and health.

Second, this study focuses on the organizational, environmental, and technological factors affecting the adoption and use of social media among nonprofit organizations. Although some studies have focused on the adoption and use of broader information and communication technology (ICT) by nonprofits, social media is a newer 
phenomenon that emerged only over the last decade. Hence, this study is timely in analyzing the adoption and use of social media, which is evolving rapidly. Facebook and Twitter are the most popular platforms that have emerged during this period.

\section{$\underline{1.4 \text { Conceptual Framework }}$}

Rogers (2003) seminal diffusion of innovation theory is significant for the adoption and use of a new technology like social media among nonprofits. He identified five stages of adopting an innovative technology. They are: knowledge, persuasion, decision, implementation, and confirmation stages. In the knowledge stage, the user is exposed to the technological innovation. At this stage, the individual or the organization has limited information about the innovation to make a decision on whether or not to adopt the innovation. The persuasion stage occurs when the individual or the organization develops an interest in the innovation and explores the innovation further.

The third stage of the adoption process is the decision-making. At this stage, the individual or the organization either adopts the innovation or rejects the innovation (Rogers, 2003). The decision-making stage is the stage where the individual weighs all the benefits and disadvantages of the innovation. The fourth stage is the implementation stage where the individual employs the innovation or use the innovation. The use depends on the contextual situation of the individual. The final stage of the adoption process is the confirmation stage where the decision to use the innovation is finalized (Rogers, 2003).

Rogers' diffusion of innovation theory additionally identified five factors that are critical during the the decision stage in order to adopt or not to adopt a technology (Rogers, 2003). These five factors are: relative advantage (using the new technology over 
the old one), compatibility (with existing organizational practices), ease of use (the degree to which the innovation is difficult to understand and use), observability (the benefits of the new technology), and trialability (the degree to which an innovation can be experimented with on a limited basis). Social media would arguably be adopted by nonprofits if the technology provides a relative advantage, is compatible with organizational activities, is less difficult to use, and its benefits are palpable. The trialability is not considered a significant barrier since the social media platforms (especially Facebook and Twitter) can be accessed costlessly and are widespread. Hence, the study examines how the first four decision making characteristics, i.e., relative advantage, compatibility, ease of use and observability influence the adoption and use of social media among nonprofit organizations.

While the diffusion of innovation is central to the adoption of a new technology, two additional theories are central to how organizations adopt new technologies. Whereas the diffusion of innovation deals centrally with the technological characteristics, the two additional theories deal with the external environmental and internal organizational factors in the adoption and use of social media in nonprofit organizations The conceptual framework is schematically represented in Figure 1. Thus, the theoretical framework of this study brings together the three dimensions - technological, environmental, and organizational factors - for examining the diffusion of social media in nonprofit organizations. The diffusion of innovation theory (Rogers, 2003) deals with the technological dimension; resource dependence theory (RDT) (Pfeffer and Salancik, 1978) deals with the environmental factors; and institutional theory (DiMaggio and Powell, 1983) deals with the organizational factors. 
Resource dependency theory (RDT) broadly explains the interdependence between organizations and their external environments (Pfeffer and Salancik, 1978). Organizations need access and control over their resources, which are often managed by other agencies in the environment. Organizations need to strategize accordingly for their survival. For example, organizations could form coalitions to gain control over external resources. Nonprofits are especially vulnerable to the external environment, as they are dependent on government, philanthropic, and other funding sources for their survival. The adoption and use of social media can assist nonprofits to gain access and control over external resources such donors. In other words, social media should benefit nonprofits in fundraising and build a public coalition to support community activities.

Figure 1 Overall conceptual framework

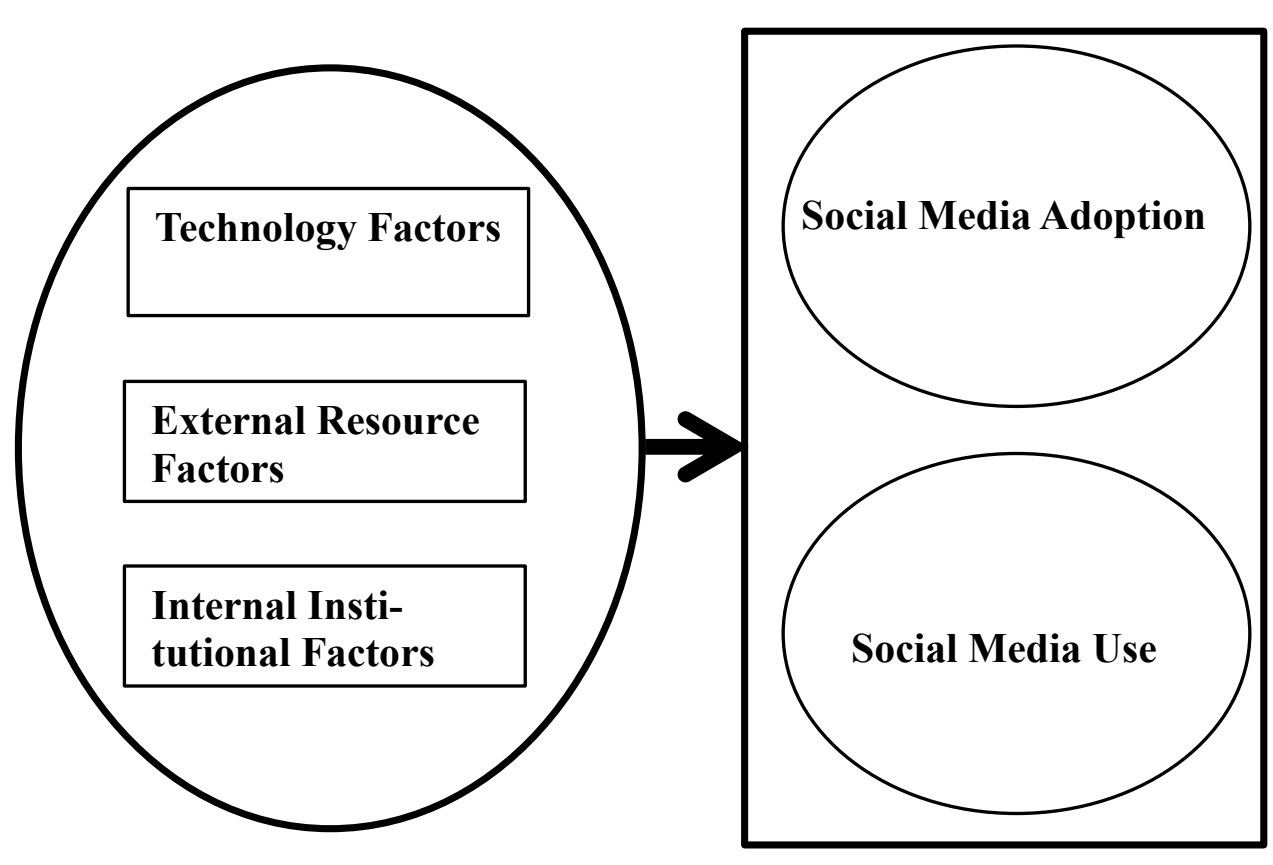


Institutional theory considers how internal organizational structure influences the behavior of organizations in the social fabric. The internal structure of organizations, including the asset size, the number of staff, income and leadership characteristics all play a major role in organizational activities. These internal organizational structures become "authoritative guidelines for social behavior" of the organization. Institutional pressures such as legal mandates, peer pressure, participation in networks, and donor pressures could influence nonprofit organizations to adopt innovations, including social media. These institutional pressures (coercive, mimetic, or normative) could result in isomorphic structural forms within an organization and spread similar management practices (DiMaggio and Powell, 1983).

Two aspects of the internal organizational structure are significant for technology adoption, namely organizational complexity and bureaucratic control, which have an active and adverse impact respectively on the adoption of innovation (Damanpour, 1991; Damanpour and Gopalkrishnan, 1998). Research also highlights the influence of leadership in the adoption and use of technology in nonprofit organizations (Zorn et. Al., 2011). Organizational complexity (e.g., organizational size and revenue) and technological support regarding staff and senior management (e.g. technology champion) could also be favorable to the adoption and use of social media in nonprofit organizations.

\subsection{Research Questions and Hypotheses}

This study explores the role of the technology, the environment, and the internal organizational factors in the adoption and use of social media among community-based 
nonprofit organizations. The overall goal is to identify factors that influence the adoption and use of social media in community-based nonprofit organizations as well as how nonprofit organizations that have adopted social media use social media to connect with stakeholders. The research questions and hypotheses are as follows:

Q1: What are the principal determinants of adoption and use of social media in nonprofit organizations?

H1: This is an explanatory research question, based on a survey of communitybased nonprofit organizations affiliated with the United Way in Florida. Drawing on the conceptual framework, the hypothesis is that social media adoption and use is influenced by technological, environmental, and internal institutional factors. The social media platforms considered for this question are Facebook and Twitter, two of the common ones. A multivariate regression model is used to test the hypothesis.

Q2: How do nonprofits that have adopted social media use it?

$\mathrm{H} 2$ : This research question is an exploratory one, where the focus is on how organizations use Facebook, one of the most prominent social media platforms. The guiding hypothesis is that organizations use Facebook for disseminating information, organizing events, and raising public interest. Content analysis of selected United Way's chapters in Florida and interviews with key officials of the chapters are used for exploring the use of the Facebook.

\subsection{Research Design and Methodology}

The empirical context of the study is United Way of America's local chapters and affiliated community-based nonprofits in Florida. The United Way is the largest federated 
organization of nonprofits. The local chapter offices are autonomous, and decide on which programs to focus on. The United Way started in Denver in 1887 and has since expanded to over 40 countries with nearly 1,800 local chapter offices worldwide. In 2014, the United Way mobilized over 2.6 million volunteers across the world to undertake various forms of volunteering work to support communities. Nearly 9.6 million individuals and corporations across the globe donated over $\$ 4$ billion to United Way. As a federated organization, the structure allows for locally oriented community-based solutions with the mission to improve lives by mobilizing the "caring power of communities around the world to advance the common good" (www.unitedway.org). The affiliated nonprofits obtain funding from the United Way as well as other sources. United Way funds three types of activities—education, income, and health-related activities.

There are two principal reasons for choosing United Way affiliated nonprofits in Florida. First, the United Way affiliates form the largest network of locally oriented, community-based nonprofits. Each United Way affiliated nonprofit is autonomous, registered as a 501(c)3 nonprofit organization and governed by a local board of volunteers. As community-based organizations, the nonprofits can choose to engage in activities that are unique to their situations. In Florida, aside from undertaking activities related to United Way's mission, the local nonprofits also conduct various activities on disaster preparedness, response and recovery, environment, substance abuse treatment, child care, and youth empowerment.

Second, Florida is one of the states with high concentration of charitable nonprofit activities. With over 70,000 nonprofits, the state ranks fourth highest in terms of the number of registered nonprofit organizations in the United States (after California, New 
York, and Texas). There are 31 local United Way local chapters in the state. The chapters could be county wide or span across multiple counties. The age of the United Way chapters range between 25 years (e.g. Putnam county chapter founded in 1992) to over 90 years (e.g. the Miami-Dade and Pensacola county chapters were founded in the 1920s). These chapters partner with nearly 1,400 community-based nonprofit organizations.

To analyze the first question, all the nonprofit organizations affiliated with the United Way were administered an online survey instrument (using Qualtrics, an online survey method available through the university). I was fortunate to have the collaboration of the United Way of Florida's leadership in helping me administer the survey across all the nonprofits affiliated with the United Way chapters. The survey instrument consisted of twenty-one questions related to both the dependent and independent variables. The dependent variables are adoption (operationalized as the number of years since the social media platform was adopted) and use (operationalized as frequency of the social media use by the organization). The survey questionnaire focused on the adoption and use of Facebook and Twitter, the two most popular social media platforms.

The independent variables are drawn from the conceptual model elucidated before. That is, the independent variables are the set of technological, external environment, and internal organizational factors. The technological variables are relative advantage, compatibility, ease of use and observability, drawn from Rogers' diffusion of innovation theory. The external environmental variables consist of diversity of funding resources, generation of public awareness, donor requirements to adopt/use social media, and peer practice pressure to adopt/use the social media. The internal organizational variables are adopting/ using social media for fundraising, leadership champion for the 
technology, financial health of the nonprofit (i.e. revenue) and information technology related human resources (i.e. IT staff). All of the independent variables were Likert scale questions, specifically intended to capture the variable (operationalized on a scale of 1 to 5). Appropriate control variables are also included for the regression models. These control variables are: number of social media managers, social media consultants, sector of the nonprofit organization, the United Way funding share, the IT budget), and the total staff size. These variables were also gleaned from the survey.

To analyze the second question, the Facebook pages of the United Way chapters were scraped and then the pages were analyzed for their content. The Facebook posts of all the chapters were first scraped for the latest six months period of a year (January 1 , 2016 to December 1, 2016). The volume of posts provides a good indicator of the extent to which the chapters and their affiliated nonprofits use Facebook. The chapters were then ranked according to high, medium, and low volume of posts. Four chapters from each group (i.e. a total of 12 chapters) were then selected for undertaking the content analysis of the posts. Care was also taken to ensure that the chapters are geographically representative (e.g. rural and urban counties, coastal vs inland counties, and counties from the north, south, east, west, and central regions). NVivo, a qualitative analysis software, was used to conduct the content analysis. In this, the major themes of the posts were identified for how the nonprofit organizations utilize Facebook. The findings of the content analysis was also checked for their credibility, confirmability, and dependability through interviews with officials from the United Way chapters. Six officials were interviewed, each of whom were from the selected United Way nonprofits. 


\subsection{Overview of Chapters}

The dissertation chapters are organized in the following manner. The second chapter reviews the related literature on the United Way nonprofit organizations, the adoption and use of information and communication technology in nonprofit organizations and the adoption and use of social media in nonprofit organizations. The chapter provides a historical outline of the United of Way of America in the United States, including the origin and structure of the organization, its fundraising and fund distribution to member organizations, problems, and challenges confronting the organization, and the reforms implemented to eradicate various problems. The chapter further reviews the literature on social media platforms and their significance. The chapter highlights the adoption and use of information technology in nonprofit organizations, the use of social media in nonprofit organizations, diffusion of innovation theory, resource dependence theory, and institutional theory. Lastly, the chapter concludes with a consideration of the importance of social media in nonprofit organizations.

The third chapter explains the research designs and methods. This chapter outlines both the quantitative and qualitative research methods to answer the research questions and test the hypotheses. The chapter identifies the operationalization and the measurement of the dependent, the independent, and the control variables. Multivariate regressions analyses are used to test the hypotheses for the first question. Content analysis is used to examine the second question that explores how nonprofit organizations that have adopted social media use it to engage their constituents and connect with 
donors. The content analysis draws on Facebook posts of twelve selected nonprofit organizations. The data collection process is also given in this chapter.

The fourth chapter presents the results of the quantitative analyses of the multivariate regression models. The hypothesis is that the adoption and use of social media is influenced by technological factors, external resource factors, and internal institutional factors. The multivariate analyses examine if there are a statically significant relationships between the adoption/use of social media and the independent variables. Appropriate organizational demographic variables are used as control variables for completeness of the models. Two regression models are presented in this chapter with the first model focusing on the adoption and the second model focusing on the use of social media.

The fifth chapter presents the results of the qualitative analysis on the use of Facebook by twelve selected United Way chapters. The primary sources for the analysis are the Facebook posts and comments. Officials from selected nonprofit organizations were also interviewed to ensure that the results of the content analysis were valid. I analyzed the Facebook posts and the interviews using Nvivo 11 software to reveal the major themes.

The sixth chapter presents a conclusion of the study. It includes a summary of the study's findings, discussion of the implications of the study for public and nonprofit management, policy development, and strategies for the effective use of social media in nonprofit organizations. The chapter concludes with the need for strategic use of social media for the optimum benefits of nonprofit organizations. 


\section{LITERATURE REVIEW}

\subsection{Introduction}

As the goal of this study is to examine the diffusion of social media among community-based nonprofit organizations, this chapter provides a literature review on the nexus between social media and nonprofit organizations. The social media platforms are essentially new phenomena that have evolved rapidly with the spread of Internet since the 1990s. While there are several such social media platforms, Facebook and Twitter have emerged as the two popular platforms. Some studies show that nonprofit organizations outpace public and private agencies in the adoption and use of social media for various types of activities. However, these studies focus mainly on the large nonprofits. Hence, this dissertation study focuses on locally oriented, community-based nonprofits affiliated with the United Way in Florida.

The literature review also explains the conceptual framework of the study. The conceptual framework draws on three theories - diffusion of innovation theory by Rogers (2003), the resource dependence theory by Pfeffer and Salancik (1978) and institutional theory by DiMaggio and Powell (1983). The theories are important to consider since they underlie the choice of the explanatory variables for the diffusion of social media among the nonprofits.

The next section of this chapter is a review of the evolution of social media and its diffusion among nonprofit organizations. The subsequent section provides an explanation of the theoretical approaches constituting the conceptual framework of the study. After this, a background of the empirical context of the study, United Way of Florida, is given. 
The last section concludes with the principal gaps in the literature and the scope of this dissertation.

\subsection{The Evolution of Social Media}

Long before the Internet era, there were two modes for computer based social interaction during the 1970s. The two primary platforms were the Bulletin Board System (BBS) and CompuServe. BBS was an online meeting place, wherein users could communicate with a central system using modems (Digital Trends, 2016). BBS was textonly and continued to be a valuable form of social media until the late early 1990s, before the Internet began to spread worldwide (Edosomwan et al., 2011).

CompuServe was also one of the communication services that started in the 1970s alongside BBS. CompuServe was business-focused, using mainframe computers for communications. CompuServe later expanded its services to the public in the late 1980s. Just like BBS, CompuServe let users to share text files, read daily events and news on the network (Boyd, 2007). The concept of email started with CompuServe, with the introduction of discussion forums, where individuals interacted and chatted with thousands of members in the same forum on any issue. The discussion forum is the precursor to modern debate and group chats that are prevalent in today's social media platforms (Boyd, 2007).

American Online (AOL) was among the first firms to introduce the social media phenomenon in the late 1980s, which quickly became popular during the 1990s. It was a commercial precursor to the modern day social media platforms. AOL enabled members to create member communities where individuals could place their profiles online and 
share with other members in the community (Edosomwan et al., 2011). It had several advanced features that were not available in the early days of BBS and CompuServe. AOL launched its Messenger for email in 1989. The AOL email systems were more intuitive than the earlier systems, making AOL more accessible to lay people who did not have advanced computer training (Digital Trends, 2016).

The 1990s marked the growth of the social media platforms with the Internet boom. Vice President Al Gore had facilitated a legislation in 1993 to enable the commercial use of the Internet, which was mostly limited to the hallowed realm of university research until then. The period between 1995 and 2000, also referred to as the dot-com bubble, saw the rise of Internet-related companies and the concurrent rise of social media (Boyd, 2007; Digital Trends, 2016; Edosomwan et al., 2011). During the dot-com bubble, the stock market of the technology firms boomed across the industrialized world. Web browsers became the mainstay of internet communications with Mosaic, Netscape, and Microsoft's Internet Explorer. The browsers further expanded the commercial use of the Internet. Online blogs facilitated peer to peer discussions or and information sharing over the Internet browsers, often consisting of discrete, informal diary-style writings (Boyd, 2007; Digital Trends, 2016; Edosomwan et al., 2011). Amazon and eBay emerged as e-commerce sites for trading goods. Yahoo and Google became popular search engines. Peer to peer networking to share files (e.g. music files using Napster) became common among Internet savvy college students (Digital Trends, 2016). Several social media platforms also emerged during the period. They included: classmates.com, SixDegrees.com, craiglist.com, and match.com. Other specialized, niche social media sites like Asian Avenue, Black Planet and Mi Gente also 
emerged during this period. The dot com bubble eventually burst in 2000, when many of the Internet companies, including the social media platforms, closed doors or became transformed through consolidations and acquisitions (Boyd, 2007; Digital Trends, 2016; Edosomwan et al., 2011).

Modern day social media sites emerged after 2000, when social media took a different turn with Friendster, LinkedIn, Myspace and Facebook. Friendster began in 2002, which was tailored along the idea of "circle of friends" to connect peers each other online (it was a portmanteau of friend and Napster) (Boyd, 2007; Digital Trends, 2016; Edosomwan et al., 2011). Friendster became popular quickly with over three million registered members within the first year of its launch. However, Friendster was overshadowed by MySpace and eventually closed doors in 2015 (Digital Trends, 2016).

MySpace was another remarkably successful social media platform that became widely popular after its launch in 2003. Fashioned after Friendster, MySpace focused on connecting young adults through music and musical videos. It remained one of the most popular social media platform during the early 2000s. MySpace lost ground to Facebook later. Although MySpace still survives, it has become a niche platform for music lovers, after undergoing acquisition in 2011.

Facebook began in 2004 as a college campus-oriented networking site and was opened to the public in 2006. It remains the largest social media platform in the world, with over 1.94 billion active users. Several reasons account for the success of Facebook in the social media landscape. It is easy to use, easy to understand, and has features that any ordinary person can intuitively learn quickly. People can post items like text messages, pictures, and videos instantly (also called posts). It allows for one-to-many 
communication among a circle of friends. Users can post comments instantaneously with any Internet connected device (computer or smartphone). A user can also have many "friends", who generally follow the user's status updates and other posts. They could "like" the user or a post. The total likes give a sense of how large a user's following is. Besides Facebook, Twitter is another popular social media platform (launched in 2006), which has over 328 million active users. It is a micro-blogging site where users can write short messages (of up to 140 characters). The short messaging system allows users to reach a wide audience of "followers." The posted messages can be read quickly on the go using any mobile device. The messages are often retweeted so that messages can become viral, beyond the original set of "followers."

There are several other prominent social media platforms besides Facebook and Twitter. They include LinkedIn, Google+, Snapchat, Pinterest, etc. LinkedIn was launched in 2003, one year after Friendster was founded. The LinkedIn's idea of social media took a different direction, compared to other previous social media platforms by connecting professionals from diverse backgrounds. Today, LinkedIn remains a very viable social media platform, connecting over 450 million professionals across the globe.

Google + is an add on to the popular Google search engine and is distinctive from Facebook and Twitter. Google+ started as an additional layer on its gmail platform for emails. Google+ later introduced the Hangouts feature that allowed users to join live via video chats with other online friends (Digital Trends, 2016). Hangouts made Google+ more attractive because of the video feature which was not available on Facebook previously. Facebook later integrated the video feature into its platform. 
Snapchat and Pinterest are newer social media sites founded in 2011 and 2012 respectively. Snapchat is a photo sharing tool, whereby pictures can be shared over mobile devices for specified time durations. Pinterest is a tool for sharing ideas (e.g. recipes) using visual medium (users can "pin" photos that interest them). Other sites like Youtube, Tumblr, Foursquare, and Tinder launched in 2005, 2007, 2009, and 2012 respectively also feature social media properties. Youtube is a popular video sharing site that allows users to share multimedia. Tumblr is a blogging site where users can customize themes, create blog posts and allow other users to connect to their post through dashboard feed sharing. Foursquare is a location based service that facilitates local search and discovery of services using a mobile app. Founded in 2012, Tinder is a niche site for matching nearby people anonymously and connecting them for social "dating" if they are both interested.

Despite the emergence of the newer social media sites, Facebook has been the overwhelmingly popular platform that surpasses others in sheer size of its users. It has gained popularity by adding features that are found in competitors' sites. It added location based services through Facebook places feature. It acquired Friendster's patents in 2010; Gowalla (location based service) in 2011; Instagram (a photo sharing service), in 2012; and Whatsapp (secure mobile text messaging service) in 2014. All these features have enhanced the usage of Facebook. Twitter is the second popular site, even though its user base is not as large as Facebook. Twitter has especially caught political attention with several prominent politicians using the medium to directly reach their constituency. President Donald Trump has especially resorted to tweeting to deliver his message directly to his electoral base. Given the popularity of Facebook and Twitter, this study 
focuses on the diffusion of these two social media platforms among nonprofit organizations.

\section{$\underline{2.3 \text { Social Media Use among Nonprofit Organizations }}$}

Social media has become a strategic communication tool for organizations in public, private and nonprofit sectors. Social media has the ability to reach out to a large audience instantaneously with just a click of a button. Nonprofit organizations have embraced social media because of the relatively low cost to implement the platform. Social media offers more advantages than the traditional face to face or telephone communications. These traditional forms of communication involve high costs to reach a large audience and need to be synchronous. Social media provides a mechanism to broadcast messages instantaneously over a mobile device connected to the Internet. The messages are delivered in real time and place, but users need not be available at the same time and place.

Although the use of social media is widespread across all organizations, studies exploring the practical use of social media by public and nonprofit organizations are limited to large scale organizations. Typically, the studies focus on Nonprofit Times 100 organizations, which are akin to the Fortune 500 companies listed in the private sector. Such studies exploring the use of social media show that social media platforms are useful for three main purposes (Waters and Jamal, 2011; Wilcox-Ugurlu, 2011). First, the social media enables dialogue and community building (Guo and Saxton 2014; Lovejoy and Saxton 2012). Second, the social media is used for advocacy purposes (Bortree and Seltzer 2009; Briones et al. 2011). Third, social media is used for financial mobilization 
by expanding the network of individual donors (Greenberg and MacAulay, 2009; Waters, 2009). These three uses are further explored below.

\section{Social Media and Community Engagement}

Social media technologies like Twitter, Facebook, LinkedIn, and YouTube have introduced new mechanisms for organizations to facilitate community engagement, relationship building and stakeholder engagement (Auger, 2013; Brionesa, et. al., 2011; Curtis, , et. al., 2010; Lord, 2009; Miller, 2011). Social media assists organizations to engage current and potential stakeholders, clients and donors through sharing of information in real-time (Kanter and Fine, 2010; Kaplan and Haenlein, 2010; LaCasse, et. al., 2010). Several studies also show that social media is used for public relations purposes (Coston, 1998; Gazley and Brudney, 2007; Greenberg and MacAulay, 2009; Knox, 2006). Social media is dynamic, interactive and decentralized but also less costly to implement with limited knowledge compared to other technologies (Mansfield, 2011; Quinn and Berry, 2010; Safko, 2010; Young, 2010). More importantly, social media offers a relatively low-cost method by which organizations can foster interactive dialogue and mobilize supporters within the shortest possible time (Cho, et. al., 2014; GálvezRodriguez, et. al., 2014). Social media attributes, including its low cost, ease of learning, and minimal infrastructure need (e.g., Internet connected device) make social media one

of the most attractive information dissemination tool as compared to the traditional media (Guo and Saxton, 2014; Smitko, 2012; Waters, et. al., 2011).

Nonprofit organizations incorporate different social media platforms into organizational activities to improve overall stakeholder communication and build a 
network of peers and followers. Large nonprofit organizations use social media like Facebook and Twitter more often than traditional websites to engage with stakeholders (Lovejoy and Saxton, 2012). An analysis of "likes" indicated on 1,000 Facebook posts of the 100 largest nonprofit organizations in the United States show that individuals respond to dialogic and mobilizational messages; at the same time, the individuals expand the organizational network by re-posting the messages on their own networks (Saxton and Waters, 2014).

Extant research is, however, inconclusive on how and why nonprofits use social media. On one hand, according to Auger (2013), Facebook is used for two-way communication to connect with stakeholders and engage communities in dialogic discussions. Briones et al. (2011) also found that American Red Cross used Twitter and Facebook to build community relationships, with two-way dialogues that engaged diverse stakeholders like younger constituents, the local media, and the community leaders (McNutt and Boland, 1999, 2007).

On the other hand, Waters et al.'s (2009) content analysis of Facebook posts by 275 nonprofit organizations found that although nonprofits are transparent with their Facebook profile, they do not use social media to enhance their public relations. Similarly, Waters, et al. (2011) found that Facebook is used as a one-way communication tool to disseminate information. Analysis of Facebook and Twitter use following the Haiti earthquake showed that social media was active used for one-way information dissemination and not for two-way communication as expected (Muralidharan at al., 2011). In their analysis of Twitter updates by Philanthropy 200 nonprofits, Waters and Jamal (2011) found that social media acts as one-way communication tool instead of two- 
way communication. Lovejoy, Waters, and Saxton's (2012) study of Twitter use among the large nonprofits in the United States also showed that the medium was hardly used for stakeholder engagement. Only a small percentage of the tweets generated some form of conversations and engagement with stakeholders. Twitter was used as a one-way communication tool to enable organizational networking and to inform the stakeholders about their activities. (Lovejoy, Waters, and Saxton, 2012). Overall, most studies show that social media is used for one-way communication, except a few cases where social media is used for two-way communication in order to generate stakeholder engagement.

\section{Social media and Nonprofit Advocacy}

Advocacy is one of the activities that drive the adoption and use of social media by nonprofit organizations. Nonprofit organizations use social media to further the cause of their groups, to raise awareness about issues that are important to their stakeholder community, and to create a network of support on issues of both national and local concerns. In their study of social media use by 50 environmental advocacy groups, Bortree, and Seltzer (2009) found that Facebook was used to champion the cause of environmental issues and also to garner support from other nonprofits and advocacy groups that are not necessarily oriented toward environmental causes (Hart, 2002). Canadian environmental nonprofit organizations also use websites and various social media platforms like Facebook, Twitter, and blogs to disseminate information on environmental issues (Greenberg and MacAulay, 2009). In Australia, aboriginal advocacy groups use social media platforms like blogs to present issues on the struggle for rights to a global audience (Petray, 2011). 
Recent studies exploring why and how nonprofit organizations use social media show interesting results. Auger (2013) assessed the use of Facebook, Twitter, and YouTube by nonprofits for advocacy purposes. He investigated issues with polar opposite choices, such as pro vs anti gun control and pro-choice vs pro-life. He found that nonprofits use social media to make ethical arguments to lure a loyal group and maintain that following. Whereas Facebook was used for two-way communication to generate dialogs, Twitter was used to show appreciation and loyalty in followership, and YouTube was used for communicating powerful videos that generate empathy toward the viewpoint (Auger, 2013, Westcott, 2007).

Nonprofit organizations across the spectrum use social media as an instrument for building coalitions in the advocacy of their causes. In their study of 53 advocacy groups in the United States, Obar, Zube, and Lampe (2012) found that the organizations used social media platforms to enhance civic participation. Nonprofit organizations have used social media platforms to undertake advocacy on grassroots lobbying, public events, and direct action on voter registration and education (Guo and Saxton, 2014). Environmental nonprofit organizations have relied on social media to build coalitions, educate and inform members on policy issues, inform followers on advocacy and volunteer related opportunities (Miller, 2011). Schmid et al.'s (2008) study of 1,253 nonprofit human service organizations in Israel shows that the larger the number of volunteers in the organization, the greater the political activities as well as the use of social media to achieve organizational goals. 


\section{Social media and Nonprofit Fundraising}

Nonprofits rely on charitable donations as their principal source of income to fund various activities, including administrative and programs that go to fulfill their missions (Child and Gronbjerg, 2007; Guo, 2007; Mosley, 2011; Suárez and Hwang, 2008). Several studies have acknowledged fundraising as one of the primary mechanisms by which nonprofits receive charitable contributions (Parsons, 2003; Waters, 2007; Zhou, 2008). The financial viability of the organizations matters for maintaining the quality of programs and services (Luther, 2005). Pfeffer and Salancik (1978) argue that the ability to acquire and maintain resources is a key driver to the survival of every organization. Fundraising is the critical factor for success of nonprofits to achieve their mission (Cummings et al., 2010; Gordon et al., 2009). Fundraising is a vital activity for nonprofits because it affects the operations and stability of the organization (López-Rodríguez, 2010). For many nonprofits, fundraising is the major challenge for the leaders and management team (Tinkelman and Neely, 2011; Weisbrod and Dominguez, 1986).

Nonprofits that rely on a single type of funding sources like government grants or foundation grants face many challenges in recent times (López-Rodríguez, 2010). Reliance on a government grant or foundation grant can dry up, making reliance on one single type of funding perilous (Brionesa et. al., 2011). One of the greatest challenges facing many nonprofits is to raise funds to support the charitable cause (Chin, 2011; Cho and Gillespie, 2006; Cho, Schweickartb and Haasec, 2014; Corder, 2001). The strength of nonprofits lies in the diversity of their funding sources (Krestalude, 2011) and the various strategies they use to raise funding (Cho and Gillespie, 2006; Edwards, 1997; Galaskiewicz, 1997; Hughes and Palen, 2009). Edwards (1997) argued that the nonprofit 
funding could range from government to private sources, including individual, foundation, and corporate support (Sargeant, Ford, J. and Hudson, 2008).

The advent of information technology has created new opportunities for nonprofits to conduct fundraising (Ingenhoff and Koelling, 2009). IT is increasingly used for fundraising and financial management in recent times because it helps in enhancing public awareness and facilitates better customer relationship management (Auger, 2013; Cho, Schweickartb and Haasec, 2014). In his examination of the use of information systems for fundraising among nonprofits, Luther (2005) found that fundraising could be more effective with the successful use of IT for networking, relationship building, and partnership building. The use of technology systems can facilitate communication and strengthen the relationship between nonprofits, donors, and stakeholder communities (DiStasio, 2011; Gormley and Cymrot, 2006; Guo and Brown, 2006; LeRoux and Goerdel, 2009).

Krestalude (2011) argues that the use of social media and related technology has a profound impact on effective fundraising among nonprofit organizations. Nonprofit organizations that use technology for marketing and fundraising activities were more successful in fundraising than nonprofit organizations than those that were either unable to make use of technology or relied less on technology for fundraising related activities (Krestalude, 2011). Efficient use of technology improves the chances of getting access to funding avenues in the future and also helps in identifying prospective donors (Sheridan, 2004). For example, various studies show that the use of email has a profound impact on nonprofits' ability to raise funds for athletic programs (Gazley, 2008; Guo and Musso, 
2007; Nah, 2010; Saxton et al., 2007). Saxton's (2003) study showed that over $60 \%$ of the nonprofits used email to raise funding for their programs.

Goecks et al. (2008) argue that social media platforms have both indirect and direct roles in fundraising. Indirectly, social media helps people to know what the organization does, how it operates, and why it is important to contribute to the cause of the organization. In this regard, technology provides a learning opportunity for clients and donors to understand the mission of the nonprofit better and to review the range of activities that the organization undertakes (Goecks et al., 2008). Additionally, social media improves communication of information on various events to the stakeholders. Social media also educates current and potential donors on the activities of the organization and motivates donors to support the organization. Goecks et al. (2008) posit that through the use of technology, potential donors will become aware of the nonprofit organization and will understand the need to support or donate towards the cause of the organization.

In terms of the direct role of social media in fundraising, these platforms make it more convenient for donors to give to nonprofits through simple and accessible tools. For example, "Donate Now" buttons embedded on the web page of the nonprofit organization makes the task of charitable donations more facile (Goecks et al., 2008). Social media tools also allow easy access to the organization's information and they make donations convenient such that the contributions can be made at any time from any place. Nonprofits use social media as a fundraising tool because of their "perceived donor use of social media, the organizational use of social media, fundraisers' ages and size of the fundraising department" (Lord, 2009, p. 37). 


\subsection{Theories of Social Media Diffusion}

It is evident from the foregoing discussion that nonprofits could have different uses of a new technology like the social media. The literature review shows that large nonprofits use social media for enhancing community engagement, advocacy, or fundraising purposes. Yet, these studies had mainly focused on large nonprofits. There is a wide gap in the literature on how social media diffusion happens among locally focused community-based nonprofit organizations. In the absence of a compelling alternative explanation, we can reasonably hypothesize that the same forces of social media diffusion that occur in large nonprofits could be the same for the community-based nonprofits. More broadly, the theoretical forces of information technology diffusion among organizations should provide an explanatory background for how social media diffusion happens among community-based nonprofit organizations.

There are three central theories of how information technology diffusion cocurs. These are: diffusion of innovation theory (Rogers, 2003); resource dependence theory (RDT) (Pfeffer and Salancik, 1978); and institutional theory (DiMaggio and Powell, 1983). Whereas the diffusion of innovation theory focuses on the technological characteristics for how diffusion occurs, the resource dependence theory focuses on the external environment of the organizations, and the institutional theory focuses on the internal organizational features of the organizations. The three theoretical approaches are reviewed below. 


\section{Diffusion of Innovation Theory}

Diffusion of innovation (DOI) explains the adoption of information technology based on the technological characteristics of the innovation. It has been widely used to explain diffusion of any innovation across several disciplines, including communication, political science, anthropology, geography, sociology, marketing, public health, and economics (Jordan, 2015). Rogers (2003, p. 12) defined innovation as "an idea, practice, or object that is perceived as new by an individual or another unit of adoption" (emphasis added). Diffusion of innovation theory describes the mechanism through which new ideas, practices, or technologies spread into a social system (Rogers, 2003). Everett M. Rogers' seminal book, Diffusion of Innovations, which originated the theory of diffusion, was first published in 1962; the latest fifth edition was published in 2003. The theory helps explain the process of adoption of innovation.

Rogers (2003, p.5) defined diffusion as "the process by which an innovation is communicated through certain channels over time among the members of a social system." Thus, diffusion results in adoption, implementation, and institutionalization of the innovation (Rogers, 2003). Individuals or organizations could adopt an innovation by reaching a decision to acquire the innovation and would implement the innovation depending on specific attributes that make the innovation appealing to the individual or

the organization. The innovation adopted is institutionalized by using the innovation into the organization's mainstream routines (Dusenbury and Hansen, 2004).

According to Rogers (2003), the diffusion process consists of the innovation, the communication channels, time, and the social system. The characteristics of the innovation refer to the inherent technological attributes of the innovation. There are five 
such core technological attributes, which are also relevant to this study. They are: relative advantage, ease of use, compatibility, observability, and trialability. The innovation attributes are explored in further detail in the next section as they are central to this dissertation study. The second concept of communication channels refer to the "means by which messages travel from one individual to another" (Rogers, 2003, p. 18). The channels serve as the medium through which the innovation is transferred from one person to another or from one group to another group. Mass media is one of the traditional means by which innovation is passed between individuals and groups through the creation of awareness. In the digital world of today, social media has hastened the awareness process in which it is faster to spread information about an innovation than it was previously possible with the traditional mass media.

The third element of time refers to the amount of time it takes for an individual to adopt an innovation. Rogers (2003) identified five types of adopters, based on the time: innovators, early adopters, early majority, the later majority, and laggards. The rate of adoption of innovation also varies, and the percentage of adopters changes over time (Rogers, 2003). The fourth element, social system, is defined as "a set of interrelated units that are engaged in joint problem-solving to accomplish a common goal" (Rogers 2003, p. 23). The social system comprises of individuals, groups, and organizations. The social system can either impede or facilitate the diffusion of the innovation process. Norms and established behavior patterns of the social system, change agents, and opinion leaders also play an influential role in the diffusion of innovation process. 


\section{The Innovation Attributes}

The core element of Rogers' (2003) diffusion of innovation theory is the set of innovation's technological attributes that lend themselves to diffusion. These features affect the rate and likelihood of innovation adoption. Many studies have examined the diffusion of innovation using the lenses of these innovation attributes (Arnaout, 2015; Duchak, 2015; Etim, 2010; Jordan, 2015). Several scholars have used the lens to study diffusion of information technology in nonprofit organizations (Eyrich, Padman and Sweetser, 2008; Kilpelainen, Paykkonen and Sankala, 2011; LaCasse, Quinn and Bernard, 2010). The rate of innovation adoption depends on the adopter's view of these attributes (Ash, 1997; Au, 2005; Kim, 2004). While some elements are central to the adoption of the innovation, others are central to the use of the innovation. In this study, I examine the adoption and diffusion of social media in nonprofit organizations. Social media is the technological innovation, which came into being only over the last two decades.

Rogers had originally identified five sets of core technological attributes of the innovation: relative advantage, ease of use, compatibility, observability, and trialability. Several scholars have expanded on the attributes in subsequent years. The meta-analysis of Tomatzky and Klein (1982) on the diffusion of innovation found ten such innovation characteristics considered by subsequent authors: complexity, cost, communicability, compatibility, relative advantage, divisibility, profitability, observability, trialability, and social approval. The meta-analysis showed that compatibility, relative advantage, and profitability were the strongest predictors of innovation diffusion. Most of the other innovation attributes were inconclusive or nonsignificant. The attribute that is least 
examined in the 75 studies was user behavior (Tomatzky and Klein, 1982). In the context of social media, this study focused on four of the innovation attributes: relative advantage, ease of use, compatibility, and observability. Trialability is not considered as a crucial element since the social media platforms are freely available and incur no costs for traialbility. Nonprofits can experiment with social media easily as it is accessible over the Internet (at least within the confines of the scope of the study of nonprofits in Florida).

Relative advantage is one of the widely examined characteristics of diffusion of technological innovation in several studies (Duchak, 2015; Etim, 2010; Thompson, 2010). Tomatzky and Klein (1982, p. 34) define relative advantage as "the degree to which an innovation is perceived as being better than the idea it supersedes." Potential adopters evaluate an innovation based on its relative advantage (Arnaout, 2015; Ash, 1997; Au, 2005). An innovation is likely to be adopted if it is perceived to be more efficient than the current technology used by the organization (Hailu, 2012; Holcombe, 2007; Jordan, 2015).

According to Young (2012), the relative advantage of an innovation should be observed with respect to "the speed of delivery of the innovation, the accomplishment, quality improvement, ease of performing tasks, the net benefit of innovation, and degree to which the innovation improves job performance, job effectiveness improvement, control over work, and increase productivity" (p. 63). Measuring the relative advantage in the diffusion of innovation studies is quite arduous. It should generally encompass social benefits of the innovation, time saved due to the innovation, and profitability or productivity achieved due to the innovation (Tomatzky and Klein 1982; Young, 2012). 
In the context of the adoption of social media in nonprofit organizations, benefits such as immediacy, convenience, and affordability to organizations have been reported as some of the features that enable the widespread of social media in nonprofit organizations than previous technologies (Moore and Benbasat, 1991; Jordan, 2015). With over a billion monthly active users, social media remains the most widely used communication platform for nonprofit organizations (Hailu, 2012; Holcombe, 2007; Jordan, 2015). The use of social media to engage communities in dialogic discussion and connect with stakeholders arose from the relative advantage of social media over other technologies (Lovejoy and Saxton, 2012). Thus, social media arguably has positive relative advantage over other technologies used by the organization, which, in turn, would have a positive relationship with the adoption and use of social media in nonprofit organizations.

Ease of use is the extent to which an idea or innovation is perceived as easy to understand and use (Au, 2005; Duchak, 2015; Jordan, 2015). Ease of use is also positively related to the rate of adoption (Tomatzky and Klein 1982, p. 35). Innovations that are simpler to understand are more likely to be adopted than innovations that require the development of new skills and understanding. A vast body of studies suggest the perceived ease of use could have substantial impact on adoption and use of new technology (Jordan, 2015). The users' intention to adopt a technology is enhanced by the perceived ease of use of the innovation (Duchak, 2015).

In the context of social media applications, social media platforms have userfriendly interfaces and do not require much additional infrastructure. The main requirement for social media is an Internet connected device, which could be any mobile device (e.g. smartphone, laptop, etc.). Social media does not require hardware or software 
in addition to what is already available in the mobile and desktop devices (Pearce, 2011; Philpot, 2013; Repack, 2006; Walfall, 2014). The ease of access at any time and from any place has this resulted in the development of positive attitudes towards the adoption and use of social media (Nguyen, 2009). Social media requires less effort than traditional information technology applications, has friendly interfaces, and is easy to navigate. These technological features have facilitated the widespread adoption of social media across different generational groups (Klug, 2014). The ease of use of social media has facilitated its adoption across organizations, including the nonprofit organizations (Holcombe, 2007; Jordan, 2015). Thus, social media will arguably have greater degree of ease of use, leading to a positive relationship with the adoption and use of social media among nonprofit organizations.

Compatibility is the most widely recognized innovation attribute important for the diffusion of innovation (Young, 2012). Tomatzky and Klein (1982) define compatibility as "the degree to which an innovation is perceived as being consistent with the existing values, past experiences, and needs of the receivers" (p. 33). There are two distinct types of compatibility: cognitive compatibility and operational compatibility (Young, 2012). Cognitive compatibility is related to what people think or feel about innovation; operational compatibility is related to the degree of compatibility with the kind of tasks people perform (Tomatzky and Klein 1982; Young, 2012).

Studies show technology is adopted when it is compatible with the pre-existing system (Jordan, 2015; Kim, 2010; Kim, 2004; Pearce, 2011; Philpot, 2013; Repack, 2006). Rogers (2003) indicates that organizations adopt innovations based on how compatible the technology is with the needs of the organization and how the technology 
fulfills organizational goals and mission (Fryer and Granger, 2008; Guthrie, Preston and Sbarbaro, 2004). Innovations can be best assimilated when the innovation is aligned with top management goals and fits the mission of the organization (Young, 2012). Innovation that is compatible with all aspects of work, the work environment, and fits the work style is likely to be successful (Young, 2012). Compatibility enhances conformance to organizational culture and would thus increase the rate of adoption (Rogers, 2003). Research has shown that compatibility is one of the most important factors in determining leadership's attitude towards the adoption of various technologies in nonprofit organizations (Klug, 2014).

In the context of social media, compatibility has a significant influence on the adoption of social media in nonprofit organizations because of the leanness of the technological requirements. Social media requires minimal hardware and software to adopt, and several organizations already have the structures in place, including internet connection, desktop, and mobile devices as well as internet connectivity (Mao, 2001; McConnell, 2009). Moreover, with the mission and goals to engage communities, connect with donors and create a pool of followers, social media fits into the public relations activities of nonprofit organizations (Bortree, and Seltzer, 2009; Brainard and Siplon, 2004). Thus, compatibility should have a positive influence on the adoption and use of social media in nonprofit organizations. At the same time, using social media requires Internet savvy employees, who are comfortable with posting information on the fly. If the organization does not have such technologically savvy employees, it may not adopt or use social media. Such organizations may not have an organizational culture that would be open to adopting social media. 
Observability is the degree to which the benefits of the technology innovation is visible to the members of a social system. Observability improves the innovation process, in that, the chances of adoption become higher if organizations can easily observe the benefits of the technology from the previous adopters. Innovation with observable benefits to users who are considering to adopt the innovation will enhance the chances of new users to adopt the innovation faster. However, an innovation with severe drawbacks will deter new users and will result in many users going for alternative innovation.

In the context of the adoption and use of social media in nonprofit organizations, observability characteristics will influence social media adoption when the usefulness of social media is visible to organizations that are being newly introduced to the technology. Early adopters are pacesetters for later adopters, and later adopters become convinced after seeing the benefits of the innovation for the organization. Social media has several benefits: it enhances organizational communications, improves peer to peer networking without limitations on time and geographic location. If organizations palpably experience these benefits of social media, the rate of social media adoption and use could become faster. Social media arguably has such observable benefits that would have a positive influence on its adoption and use among nonprofit organizations. However, organizations may not adopt social media if they consider it to be disruptive and with little to no benefits to the organization.

\section{Resource Dependency Theory}

Resource dependency theory focuses on the external environment of the organizations in the adoption of innovation. It explains the interdependence and 
uncertainty relationship between organizations and their environments (Hillman et. al., 2009). Resource dependency theory is a very influential theory in explaining the behavior of organizations with external constraints. An organization is perceived as an open system that relies on the external environment (Pfeffer and Salancik, 1978; O'Connor and Netting, 2009). The success of any organization is dependent on the relationship with its environment. Organizations compete for scarce resources offered by the external environment, which could have a direct impact on the survival of these organizations (Pfeffer and Salancik, 1978). As Pfeffer and Salancik (1978, p.1) note, "to understand the behavior of organizations you must understand the context of that behavior - that is, the ecology of the organization."

Since external factors influence the survival of organizations, managers have the responsibility to reduce the environmental uncertainty and dependence for the survival of the organization (Doolin and Lawrence, 1998; Francis and Perlin, 2006). As Ulrich and Barney (1984) argue, organizations need to have the power to control or gain the necessary resources that are needed for the survival of organizations. At the heart of the resource dependency theory is the set of valuable resources crucial to the organization's survival. These resources include, among other things, information and capital (Tillquist, King, and Woo, 2002). The struggle for resources leads to dependency which results in some form of control and power over resources. Pfeffer and Salancik (1978, p. 2) indicate that "the key to organizational survival is the ability to acquire and maintain resources." To avoid excessive external control, organizations must manage the resources judicially. Budgetary allocation to information technology infrastructure is crucial in technology acquisition (Hackler and Saxton, 2007). Organizations that allocate resources 
purposely for the development and promotion of information technology are more likely to adopt sophisticated technologies to enhance the activities of the organization. Lack of resources are likely to affect IT adoption adversely (Schneider, 2003). Hackler and Saxton (2007) found budgetary constraints to be a significant deterrent in nonprofits' ability to develop their websites.

The interconnectedness of organizations and their environment can be witnessed in the formation of associations, customer-supplier relationships, and federations (Pfeffer and Salancik, 1978). In the nonprofit sector, the organizations need to establish relationships with other organizations for funding purposes (Lamothe and Lamothe, 2006). Nonprofits develop a relationship with donors like public sector agencies and departments as well as other major private donors to commandeer the resources required for the survival of the organization (Young, 2012). Nonprofits develop a relationship with federal agencies through grants and other forms of sustained financial support (Brainard and Siplon, 2004; Provan et. al., 1980).

Nonprofit organizations operate in an environment characterized by strict donor requirements. The donors' grants come with various forms of stipulations. Nonprofits need to follow the stipulations strictly to obtain these grants. Technological limitations often inhibit small nonprofits from accessing funds from well established donors who have elaborate reporting requirements. In some instances, donors support nonprofits to acquire technologies that enhance the nonprofits' capacity to seek funding. Donors could help in the form of equipment, infrastructure, and expertise in order to improve the management of nonprofit organizations. 
With the increasing competition for scarce resources, social media adoption among nonprofits can increase their chances of discovering new donors, improve their relationship with the existing donors as well as create an alliance with volunteers and other nonprofits. For example, Kanter and Fine (2010) found that nonprofits successfully tapped on the experts outside the nonprofit organizations using social media. These experts helped the organization to engage communities, connect with stakeholders and conduct fundraising for the nonprofit organizations. Typically, nonprofits depend on the charitable donations from individuals and private foundations; they also seek grant funding from public agencies to provide specific services. Nonprofits would use social media to the extent that the medium helps the nonprofits in raising such funding in order to achieve their organizational mission.

\section{Institutional Theory}

Institutional theory focuses on the internal organizational factors that enable or inhibit in adopting and using an innovation. According to Flood and Scott (1987), "institutional theory emphasizes that organizations are open systems - strongly influenced by their structure and are the result of social and cultural pressures to conform to conventional beliefs rather than rational pressures for more efficient performance" ( $p$. 115). Institutional theory is useful in exploring how nonprofit organizations adopt information technology to survive in a competitive environment characterized by fierce competition from other nonprofits (Haveman, 1993; Zorn, Flanagin, and Shoham, 2011). It focuses on the internal organizational culture and management practices (DiMaggio and Powell, 1983; Scott, 1995; Scott and Christensen, 1995; Scott and Meyer, 1994). 
Organizations adopt changes that reflect the environment in which they operate.

Organizations conform to the norms and standards established within their environment (Scott and Christensen, 1995; Scott and Meyer, 1994). Changes in organizations occur as a result of "spillover of innovation" caused by policy diffusion, institutional norms and institutional efficiencies (Kogut, Bruce, and Macpherson, 2011, p. 23).

The institutional theory posits three mechanisms of internal organizational change: coercive, mimetic, and normative (DiMaggio and Powell, 1983). According to Kim, Hyun, and Heejin (2009), the three pillars are "viewed as independent and alternative sources of organizational structuring” (p. 43). Shipan and Volden (2008) also identified four mechanisms of policy diffusions: learning from earlier adopters, economic competition, imitation, and coercion.

Coercive isomorphism is a response to direct and indirect pressures from other peer organizations that the organization is dependent on (Nelson and Gopalan, 2003). Society's cultural expectations could also mold the organization's structure (Jones, 2001). Coercive isomorphism is thus induced externally, but are reflected internally in the organizational structure and operations. For example, governmental mandates, contractual obligations, financial and performance reporting requirements could arguably result in homogeneous organizations designed to conform with wider institutions. Structures of the large nonprofits can be duplicated on their subsidiaries, especially in federated organizations like United Way. When managers need to respond to powerful constituents, they may adopt strategies that are consistent with the expectations of the powerful actors and how peer organizations like themselves are structured. The dependencies are asymmetrical in a highly institutionalized network, where powerful 
constituents can pressure smaller organizations to conform and adopt strategic behaviors that are similar. In the context of social media, the smaller community-based nonprofits could be pressured to adopt the social media through the networks that they are part of.

Mimetic isomorphism refers to the art of copying systems and practices of other organizations. Shipan and Volden (2008) argue that imitation or emulation is a mechanism of policy diffusion which may influence organizations to adopt policies and innovations from one another. Organizations copy the actions of other organizations to look like their own organization (Meseguer, 2005; Shipan and Volden, 2008). The imitation usually occurs when inferior organizations copy superior organizations. The mimetic isomorphism can result from peer imitation that is intended to alleviate organizational uncertainty within an organization (Haunschild and Miner, 1997). Competitor scanning also influences organizations to imitate one another (Grover and Goslar, 1993). For example, Doolin and Lawrence (1998) found nonprofit organizations mirror the practices or the business models of private sector entities in marketing and organizational branding. Organizations that are seen as leaders in the field or in the industry may perceive themselves as pacesetters and may become prone to mimetic pressure from other organizations (Flanagin, 2000). Flanagin (2000) notes that website use proliferated among nonprofit organizations as a result of other organizations that adopting websites. Organizational uncertainty, poorly understood technologies, and ambiguous goals could influence one organization to copy from other another organization's practices (DiMaggio and Powell, 1983). Through mimetic isomorphism, social media has become fundraising tool for nonprofit organizations even in small nonprofit organizations operating in remote communities. 
Normative pressure, according to DiMaggio and Powell (1983) is a source of institutional "isomorphic organizational change" that comes from professionalization where members of an occupation strive to improve the methods of their operation to enhance efficiency. The "normative mechanism is motivated by norms that are prevalent and observed in the domain of which the organizations exist" (Kim, Hyun, and Heejin 2009, p. 43). DiMaggio and Powell (1983) posit that organizations achieve normative mechanism through education and "filtering of personnel" (p. 152). In the context of social media adoption and use, employees may be formally induced to normative practices of using social media through training, learning of organizational protocols, education, professional associations, and conferences. The normative forces are especially evident in the use of social media for public relations purposes across nonprofit, public and private sector organizations. The use of social media for customer services and fundraising started in the private sector as a way to boost newly created venture capital businesses. Professionals working for the nonprofits also realized the potential of social media use for raising additional funding, increasing awareness, and connecting with other donors.

Using institutional theory to investigate the forces that influence the adoption and use of IT in nonprofits, Zorn, Flanagin and Shoham (2011) found that leadership support and professional IT staff engagement were significant factors. In a similar study, Jaskyte (2011) also found that transformational leadership contributed significantly to technological innovation in nonprofit organizations. Hikmet et. al (2008) found that organizational characteristics such as the size of the organization, leadership, and IT staff were significant for the use of information technology in hospitals in Florida. Finn, 
Maher, and Forster (2006) argue that technology training of the staff is crucial for the use of information technology. Thus, leadership support and professional IT staff availability play an important role in the adoption and use of information technology in nonprofit organizations (Jaskyte, 2011; Zorn, Flanagin, and Shoham, 2011).

\section{$\underline{2.5 \text { Conceptual Model }}$}

The conceptual model proposed for the study brings together the above three powerful theoretical approaches - diffusion of innovation, resource dependence, and institutional theories - to examine the diffusion of social media among nonprofits. The three theories respectively emphasize the technological, external environment, and internal organizational dimensions in shaping the adoption and use of social media. The factors affecting the diffusion of social media within each dimension (i.e. the explanatory variables) are drawn based on the three theories. The full conceptual model is illustrated below in Figure 2.

The conceptual model is consistent with other studies on information technology diffusion among organizations. Broader literature on the adoption and use of information and communication technology (ICT) in the nonprofit organizations have emphasized organizational characteristics, environmental characteristics, and external pressures (Hackler and Saxton 2007; Zorn, Flanagin, and Shoham, 2011). Wilcocks and Lester (1999) argue that ICT investment depends on the ICT's strategic advantage for the organization, resource mobilization, and internal productivity improvements from the investment. 


\section{Figure 2 Full Conceptual Model}

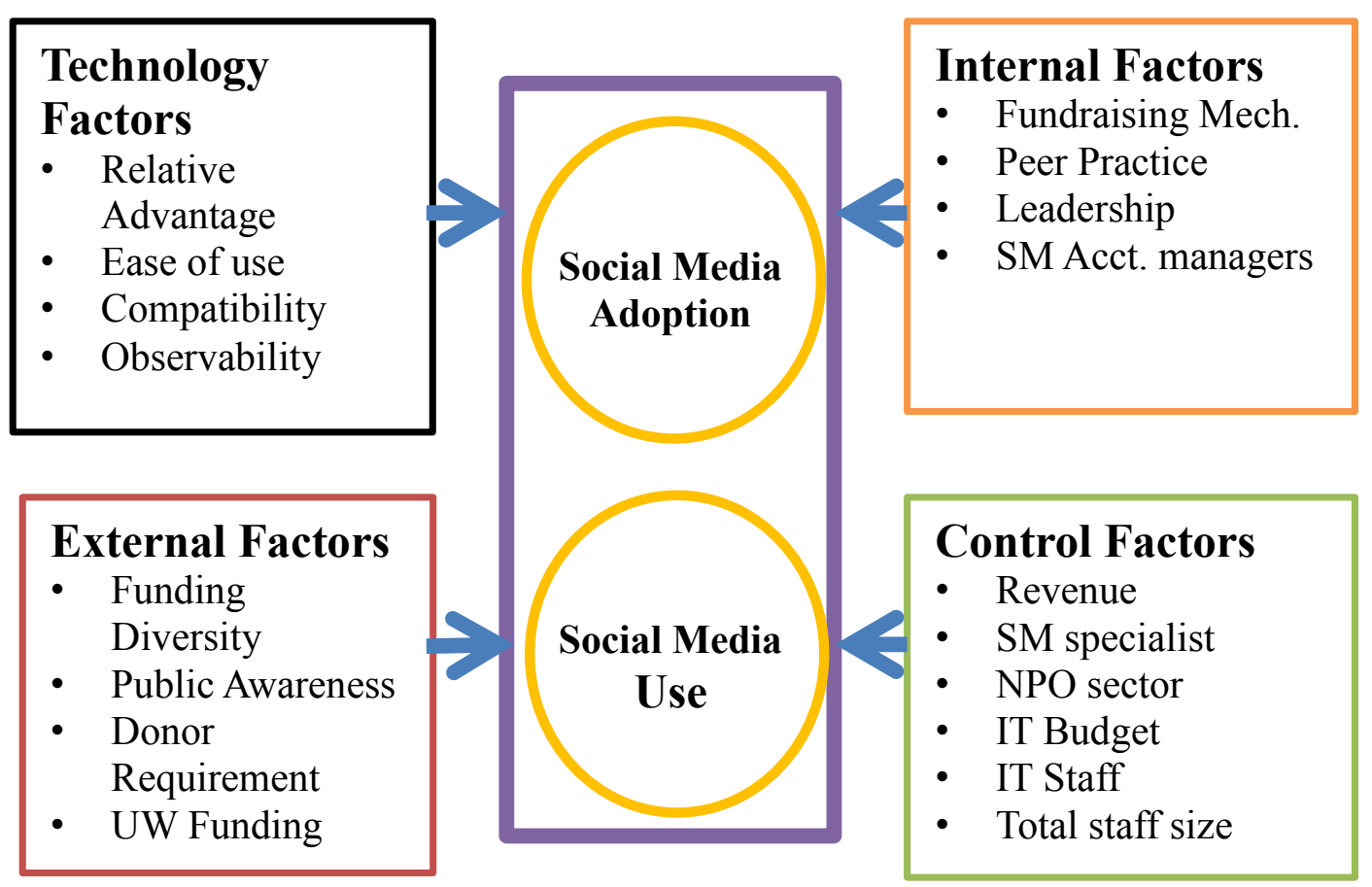

Drawing on the diffusion of innovation theory, the technological characteristics considered for social media diffusion are: relative advantage, ease of use, compatibility, and observability. These four features are expected to positively influence the adoption and use of social media. Based on the resource dependence theory, the external environmental factors for consideration are adoption and use of social media for funding diversity and public awareness. Also included among the external factors are the coercive aspects of external requirements drawing on the institutional theory; these factors include the donor requirements and share of United Way funding. The donor requirements and United Way funding could arguably result in coercive isomorphism, enhancing the adoption and use of social media. 
The internal organizational factors for consideration are drawn upon the institutional theory. Two such factors are mimetic, whereby nonprofits mimic other similar organizations; these include the use of social media for fundraising and peer practice of using social media. Nonprofits could use social media because peer organizations use the platforms for fundraising purposes. Two other factors are normative, drawing on the professionalization of the nonprofits; these include the leadership support for nonprofits and the number of staff handling the social media accounts. Leadership support is indeed a consistent theme in the adoption and use of information technology; the availability of professional social media savvy staff could also be critical.

The control factors for the conceptual model are also drawn from the extant literature on ICT adoption and use (Nah and Saxton, 2012; Waters et al., 2007). There are six organizational factors considered as control variables: type of service sector the nonprofit is involved in; overall revenue resources; IT budget; IT staff size; social media specialists; and overall staff size. The type of service sector is important to consider since social media may not be equally useful across different sectors. The overall revenues and IT budget give the broader resource constraints within which the organizations operate. The IT staff size and social media specialists give the degree of professionalization of the nonprofit. Lastly, the overall staff size is an indicator of the slack resources available in the organization. 


\subsection{The Empirical Context: United Way}

The empirical context of the study is the United Way of America, particularly those organizations affiliated with United Way in the State of Florida. Hence, a brief review of the United Way is required in order to understand the context of the study. Founded in 1887 in Denver Colorado in the United States, the United Way originally started as a collaboration between ten health and welfare agencies with the aim to raise funds through donations for local philanthropies. The United Way has since become one of the largest private philanthropic organizations in the country. It had mobilized $\$ 4.7$ billion in 2015, with over 9.8 million individual donors and 70,000 corporate partners. It harnessed over 2.8 million volunteers. Its total revenue was $\$ 99$ million in 2015 . It is engaged in nearly 1,800 communities across more than 40 countries and territories worldwide. It impacts over 50 million lives annually. According to Nonprofit Times 100, United Way is the third largest 501(c)(3) organization in the United States.

United Way's mission is to improve lives by mobilizing the caring power of communities around the world to advance the common good. It has three main focus areas: education, income and health. The United Way undertakes a number of activities that go toward fulfilling its mission. The activities are centered around childhood success, youth success, economic mobility, and access to health. United Way plays a direct role in the development of communities through educational activities, financial support to the needy and provides health related support (Cords et al., 1999). One of its signature programs is the $2-1-1$, which is a confidential health and human services hotline that can be accessed by anyone from any computer or phone in times of need or crisis. 


\section{The Structure of the United Way}

The key aspect of United Way is that it is a federated organization, which is quite unlike other nonprofits like Planned Parenthood and American Red Cross. The headquarter is located in Alexandria, Virginia. The National chapter provides marketing and branding support to the regional and local chapters. The chapter conducts training, human resource development, national fundraising events fall under the auspices of the national chapter. The National Chapter invests in the "development of a national reputation, the creation of administrative procedures and systems" for the regional and local chapters (Oster 1996, p.87). Figure 3 presents a schematic diagram of the structure of the United Way.

There is one statewide regional chapter in each state (Gilbelman and Gelman, 2001). There are nearly 1,300 local chapters distributed across the 50 states in the United States (Barman, 2008; Benjamin, 2008). In Florida, the United Way has 31 local chapters covering the 67 counties in the state. While some chapters are single county focused, most chapters' jurisdiction span across two or more counties. The regional chapters organize statewide events. They conduct similar activities as the national chapter at the state level for local chapters including training, fundraising events, collaborating with local chapters to undertake various programs and events in alignment with the mission of the organization. The local chapters partner with a range of community-based, locally focused nonprofit organizations address the community's educational, financial and health-related challenges. The United Way funds the local nonprofits to undertake activities in the areas of its mission focus. The local chapters undertake fundraising for their local activities, collaborate with leaders within the county and city, and provide 
training and technical support to local nonprofits (Abramson and McCarthy, 2002;

Hendricks, Plantz, and Pritchard, 2008). As Oster (1996) noted, the local chapters conduct the operational activities of the United Way of America.

Figure 3 Organizational Chart of United Way

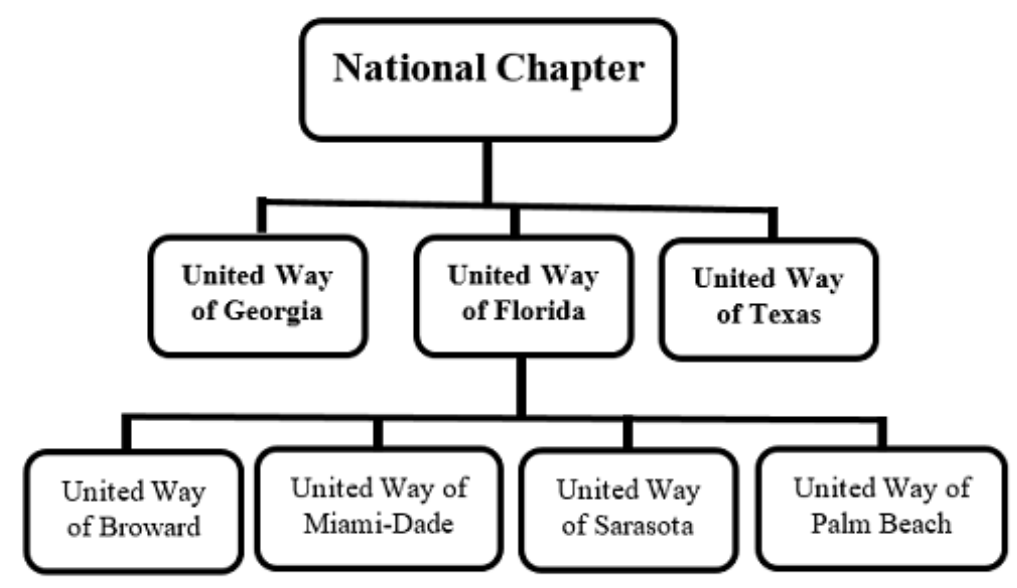

As a federated organization, the regional and local chapters are independent of the national office. The national, regional, and local chapters are independently registered as 501(c)(3) organizations and are administrated separately by an independent board of governors. The regional chapters file separate Form 990 to IRS and are responsible for donations and fundraising activities outside the control of the national chapter. The local chapters are also registered 501(c)(3) entities with their own board of governors and management, independent of the regional and national chapters. The day-to-day administration of the local chapter is outside the management of the regional and national chapters. Local chapters file their own tax returns, organize their fundraising activities at the local communities and have their own volunteer networks and donor agencies in the local communities (Oster, 1996). The local chapters are mostly located in the cities 
within a county. Although independent, the local chapters are called United Way and use the national logo (Oster, 1996). The local chapter pays a small fee to the national chapter as dues for being a part of the United Way federation (Oster, 1996).

The community-based nonprofits affiliated with United Way's local chapters are independent nonprofits, registered with IRS as a tax-exempt organization with a 501(c)(3) status. They can raise funding from other sources as well. The United Way funds the community-based nonprofits to undertake work in the United Way's mission areas. As independent nonprofit organizations, the relationship between the local chapters and the affiliated nonprofit organizations can best be described as "loose" network relationship where the collaboration and the partnership are not enforced.

\section{United Way Fundraising and Nonprofit's Funding}

Fundraising activities at the United Way are organized at various levels of the organization. The national chapter organizes fundraising activities at the national level. Regional and local chapters oversee similar events at the state and local levels. There are donors and corporate partners that are affiliated at all levels of the organization. The national chapter has its corporate partners, different from the corporate partners at the regional and local levels. The national chapter engages in more fundraising activities than the regional and local chapters, with regional chapters hosting more fundraising events than the local chapters. According to Werner, Konopaske, and Gemeinhardt (2000), the local chapters are committed to three goals: fundraising, allocation of funds, and coordination and planning for community needs. The affiliated nonprofit at the community levels may undertake fundraising activities beyond the amounts obtained 
from United Way local chapters. The local nonprofits are not mandated or restricted to focus on issues that are only related to United Way mission.

As a federated organization, the United Way national and regional chapters coordinate fundraising and allocation to local chapters and affiliated nonprofits. Funds received from donors at the national chapter is distributed across to the regional and local chapters depending on the needs (Young, 2001). The United Way's coordination provides a measure of trust for donors. The United Way also acts as an umbrella for fundraising on behalf of the local nonprofits. The United Way local chapter audits and monitors the local nonprofits that receive United Way funding (Werner, Konopaske, and Gemeinhardt, 2000). The donors have an assurance that their donation to United Way will be used for good cause in the organization's mission areas. They do not have to worry about undertaking background checks on individual and local nonprofits that they would otherwise have funded (Young, 2001). Ackerman (1980) argues that "the fund relieves donors of the arduous task of dividing up their gifts among charities and performs auditing and monitoring functions that assure donors that their money is supporting reputable organizations" (p. 324). Cordes, Henig, and Twombly (1999) note that United Way funding is a stable and reliable source of financing for local nonprofits, even though funding from the United Way only constitute a small share of their total operating budgets.

The funding relationship between different United Way local chapters and the affiliated nonprofit agencies is quite complex, taking on many forms. The criteria for distribution of funds vary from chapter to chapter and the financing is competitive. Each local chapter has its own priorities in funding the local nonprofits or partner agencies. 
Generally, local nonprofits need to register with the local chapter to receive the funding, although the registration does not guarantee that the nonprofit will receive funding from the local chapter. Werner, Konopaske, and Gemeinhardt (2000) found that United Way affiliated nonprofits have better financial performance than non-affiliated nonprofits. Often, an affiliated local nonprofit can also pro-actively identify local issues of importance pertaining to the three mission areas of education, income, and health. The local nonprofit can then apply for a grant to address the issues. The United Way local chapter would then evaluate the application and take a decision on whether or not to financially support the local nonprofit to address the issue. The United Way local chapter typically monitors the activities to ensure that they are successfully conducted.

Although United Way acts as an umbrella for fundraising on behalf of local nonprofits, donor advised funding has also been used since 1990. Under this mechanism, donors are allowed to direct their resources to a particular local chapter or specific local nonprofits to undertake activities in the United Way's focus areas of education, health, or financial stability (Barnes, 2008; Young, 2001). Individuals who want to donate to United Way may direct their donations to a particular cause or a specific nonprofit. As donors were allowed to earmark their donations to a particular organization, many organizations that were not regular affiliates of the United Way network have also benefited from this donor advised funding policies (Cordes, Henig, and Twombly, 1999). The prominent nonprofits that benefited from such donor designated funding include American Heart Association and the American Cancer Association. The donations were earmarked towards addressing health-related issues (Cordes, Henig, and Twombly, 1999). 
The donor advised funding programs became quickly popular, which changed the United Way's funding mechanism for local nonprofits. In 1993, 35\% of local United Way donations were designated gifts (Cordes, Henig, and Twombly, 1999); the share was $20 \%$ in 1998 (Blum, 1999). The underlying reason was that the donors preferred to give to specific causes and organizations. United Way became an intermediary in the process that would not only route the funding, but also to conduct the required oversight activities to ensure that the funding is used properly. However, the donor advised funding also implied that it decreased the general funds that the United Way could otherwise flexibly provide to affiliated nonprofits (Werner, Konopaske, and Gemeinhardt, 2000). Hence, many United Way local chapters try to balance between the donor advised funds and the general funds that they receive, based on local community needs.

\section{United Way's Challenges}

United Way has experienced its own set of leadership and management challenges over the last two decades. During the 1990s, it faced one of the biggest nonprofit corruption scandals in the history of nonprofits in the United States, which led to the organization's identity crises (Gilbelman, Gelman, and Pollack, 1997). The corruption scandal hovered around the longtime national president, William Aramony. At the time of the scandal, United Way received over $\$ 3.1$ billion in gifts. The scandal led to an independent investigation into the remuneration and activities of the president (Gilbelman, Gelman, and Pollack, 1997; LeRoux and Wright, 2010; Gilbelman and Gelman, 2001). Mr. William Aramony was indicted for having misappropriated funds meant for the organization (Barman, 2008; Vanderwarren, 2001; Young, 2001). He had 
inappropriately used the funds for buying an expensive condominium, using a limousine, and taking expensive trips on the Concorde jet (LeRoux and Wright, 2010). Mr. Aramony was found guilty of 25 felony charges and was sentenced to seven years in jail.

A former Peace Corps Director, Elaine Chao, replaced Mr. Aramony as the President. She faced another scandal after four years, which further deteriorated the image of United Way. Parallel scandals from other notable national nonprofits (e.g., National Association for the Advancement of Colored People (NAACP) in 1993) further led to public outcry over inadequate accountability measures in nonprofit organizations. These corruption scandals were challenging for United Way's reputation. Many local chapters were faced with the dilemma of whether or not to continue partnership and collaboration with United Way at all (Greiling, 2007). The crises resulted in sharp decline in donations from both corporate and individual donors. The scandals led to a 4.1 percent reduction in donations to United Way across the United States and up to 30 percent in some local chapters in the late 1990s and early 2000s (Barman, 2008; Gilbelman and Gelman, 2001; Vanderwarren, 2001; Young, 2001). According to Gilbelman and Gelman (2001), "nonprofits across the United States experienced cutback in charitable giving due to the United Way scandals" (p. 53). Major corporate donors called for greater autonomy and independence of regional and local chapters from the national chapter as well as a more stringent accountability measures for nonprofits in general (Barman, 2008; Gilbelman and Gelman, 2001; Hall, 2006; Vanderwarren, 2001).

As a response to the national and local outcry for increased accountability in nonprofits following the corruption scandals, the United Way introduced changes to make leadership more accountable and local chapters more independent of the national 
chapter. One of the changes introduced was the Program Accountability Quality Scale (PAQS), an outcome based evaluation of funds distributed to both affiliates and nonaffiliates of United Way (Poole et al., 2000). The PAQS introduced an element of accountability and oversight with the local United Way chapters.

Under the PAQS, local nonprofits acquiring funds from the United Way are required to submit their funding applications, indicators, and evaluation plans that are then used to measure their program outcomes (Campbell, 20028). The purpose of the outcome measurement is to ensure that donors get value for their money and also show the effectiveness of United Way programs and the impacts on the communities (Campbell, 2002; Poole et al., 2000). The national chapter started reforms that were adopted in all local chapters (Plantz, Greenway, and Hendricks (1997).

As a part of the PAQS, capacity building was encouraged for grant seekers and local chapter officials. Trainer of trainer's program was a major component of the reform. Experts train United Way staff in the field of performance measurement and outcome measurement using a manual developed by experts from the Urban Institute on nonprofit management (Benjamin, 2008; Campbell, 2002). To complement the trainer of trainers program, the national chapter engaged the services of external consultants in performance and outcome measurement and program evaluation across all United Way offices to address challenges that may arise in the post-training assessment (Benjamin, 2008; Campbell, 2002).

The reforms resulted in the introduction of the 211 information and referral services to help locate nonprofits for various forms of assistance (Walden, 2006; Wenocur, 1976; Werner, Konopaske and Gemeinhardt, 2000). United Way increased the 
leadership development programs and child and parent education services in several communities (Kearns, 2007; Miller, 2002; Paarlberg and Meinhold, 2012). On the whole, the reforms began to mend the dented image of United Way. The reforms showed results as the United Way's funding began to increase with more donor engagement and fundraising for various activities.

\section{$\underline{2.7 \text { Conclusion }}$}

Information and communication technology has played an important role in the functioning and management of nonprofit organizations (Gandía, 2011; Greenberg and MacAulay, 2009; Melendez, 2001; Saxton, and Benson, 2005). Historically, nonprofit organizations have been very slow in the adoption and use of information technology, in part, due to the cost of investment and the expertise that are required to effectively use these technologies (Zorn, Flanagin, and Shoham, 2011). The trend has changed since the dot-com bubble and the emergence of social media platforms (Takahashi, Tandoc, and Carmichael, 2015). Social media platforms have been influential in shaping the way nonprofits communicate with communities, donors, and also engage other stakeholders including other nonprofit organizations (Hackler and Saxton, 2007). Facebook and Twitter are the two platforms that have become popular over the last decade.

Studies on the use of information and communication technology in nonprofits have focused on the large and well-organized nonprofits that have good organizational structure, often with an exclusive information technology department (Waters, Burnett, Lamm, and Lucas, 2009). Traditionally, research has focused on nonprofit organizations 
that are listed in the Nonprofit Times 100 with little understanding of how smaller nonprofits adopt and use social media like Facebook, Twitter, and YouTube.

Although studies have examined the use of social media in nonprofit organizations, only few empirical studies investigate the adoption and use of various social media platforms in community-based nonprofit organizations. Community-based nonprofit organizations are of particular importance due to various underlying constraints these nonprofits face, including limited revenue and human resources. This research study aims to fill the wide gap in social media diffusion among community-based nonprofits. The empirical context of the study is the set of nonprofits affiliated with United Way. The United Way affiliated nonprofits are appropriate to study since they are independent community-based organizations, which receive funding from the United Way in its mission related focus areas of education, income, and health. 


\section{RESEARCH METHODS}

\subsection{Introduction}

This chapter describes the research methods used to examine the diffusion of social media in nonprofit organizations. There are two questions guiding this study. The first question is, what are the principal determinants of social media adoption and use among nonprofit organizations? The second question is, how do nonprofits that have adopted social media use it? The study uses quantitative and qualitative methods respectively to answer these questions. The empirical focus of the study is the set of local, community-based nonprofits associated with the United Way in Florida. The United Way is the largest federated organization of nonprofits and the local offices are semi- autonomous. In Florida, there are 31 United Way local chapters with over 1,400 affiliated nonprofit organizations. Previous studies on the adoption and use of social media by nonprofit organizations largely focus on large and well-structured nonprofit organizations. This study fills a literature gap on how local, community-based nonprofits have adopted and use social media.

The rest of the chapter explains the research design and methodology to answer the above questions. The next section reiterates the background of the study to set up the context for the research design. The subsequent section describes the quantitative techniques used to answer the first research question. The section after that deals with the qualitative techniques used to answer the second research question. The last section highlights the limitations of the data collection and the research design. The final section concludes with a summary of the research methods. 


\section{$\underline{3.2 \text { Background }}$}

The main goal of this dissertation is to examine the principal determinants of adoption and use of social media platforms in nonprofit organizations in the United States. This study explores the role of the technological, environmental, and organizational factors in this diffusion of social media among nonprofit organizations. The research questions and hypotheses are as follows:

The research questions and hypotheses are as follows:

Q1: What are the principal determinants of adoption and use of social media in nonprofit organizations?

H1: This is an explanatory research question, aimed to identify the determinant factors of adoption and use of social media. Drawing on the conceptual framework, the hypothesis is that social media adoption and use is influenced by technological, environmental, and internal institutional factors. Quantitative research methods are used to identify the determinant factors. An online survey instrument was administered to the community-based nonprofit organizations affiliated with the United Way in Florida. The social media platforms considered for this question are Facebook and Twitter, which are two of the most common platforms. A multivariate regression model is used to analyze the survey data in order to identify the determinants of adoption and use.

Q2: How do nonprofits that have adopted social media use social media to connect with stakeholders?

$\mathrm{H} 2$ : This research question is an exploratory one, where the focus is on how organizations use Facebook, one of the most prominent social media platforms. The guiding hypothesis is that organizations use Facebook for disseminating information, 
organizing events, and raising public interest. Qualitative methods are used to answer the question. Towards this end, the Facebook posts of the United Way local chapters were scraped. Then, content analysis of selected United Way's chapters in Florida and interviews with key officials of the chapters were carried out to explore the use of the Facebook.

\subsection{Quantitative Research Methodology}

The first research question of the study is analyzed using quantitative research methods. The primary goal is to examine the principal determinants of the adoption and use of social media among community-based nonprofit organizations. Consistent with the conceptual framework explained in the previous chapter, the hypothesis is that technological, environmental, and internal institutional factors are significant for the adoption and use of social media. The overall model is as follows:

Social media (adoption/use) $[Y]=f$ (technology, environment, organizational, control factors)

More specifically, the model is as follows:

Social media (adoption/use) $[Y]=a+\sum b_{i} T_{i}+\sum c_{i} E_{i}+\sum d_{i} O_{i}+\sum e_{i} C V_{i}+\varepsilon$, Where $\mathrm{a}=$ constant, $\varepsilon=$ error term,

$\mathrm{T}_{\mathrm{i}}=$ vector of Technological factors

$E_{i}=$ vector of External environmental factors

$\mathrm{O}_{\mathrm{i}}=$ vector of Internal organizational factors

$\mathrm{CV}_{\mathrm{i}}=$ set of control variables, and

$b_{i}, c_{i}, d_{i}$, and $e_{i}$ are the coefficients to be estimated for each $i$ factor. 


\section{Dependent Variables}

The study has two dependent variables: the adoption of social media and the use of social media. Two social media platforms are considered for the study: Facebook and Twitter. These two platforms are the most popular, which have increased their active user base over the last decade. Several studies also show that these two social media platforms are the two most widely used social media in large nonprofit organizations to engage citizens in diologic communication, connet with donors for fundraising, and undertake advocacy to seek the welfare of deprived communities (Briones et al., 2011; Curtis et al., 2010; Gálvez-Rodriguez et. al., 2014; Guo and Saxton, 2014; Lovejoy and Saxton, 2012).

The first dependent variable, the adoption of social media, is measured by the number of years since the social media platform was adopted. The second dependent variable, the use of social media, is measured by how often the social media platform is used to post comments and respond to other posts and comments. The frequency could be hourly, daily, weekly, monthly, or yearly posts. Both the adoption and use of Facebook and Twitter are considered separately in the models.

\section{Independent Variables}

Based on the conceptual framework, there are three sets of independent variables: technological factors, external environmental factors, and internal organizational factors. The technological factors include four variables, drawing from the diffusion of innovation theory. The variables are: the relative advantage of social media over other existing technologies (relative advantage), the compatibility of social media with existing 
technologies (compatibility), the ease of use of social in relation to other technologies (ease of use), and the tangible benefits of social media over existing technologies (observability).

The external environmental factors include four variables. Based on the resource dependence theory, the external environmental factors are funding diversity (i.e. social media is used diversify the funding sources) and public awareness (i.e. social media is used to generate public awareness). The coercive isomorphism could also have an external influence on adoption and use of social media. Towards this end, there are two variables from the coercive aspects of external environment. These factors include the donor requirements (i.e. donors required the nonprofits to adopt social media) and share of United Way funding (i.e. affiliation with United Way had an influence on social media adoption).

The internal organizational factors for consideration are drawn from the institutional theory. Two such factors are related to mimetic isomorphism, whereby nonprofits mimic other similar organizations. These include the use of social media for fundraising (which is a common reason for adopting social media) and peer practice (i.e. social media is adopted because other nonprofits have also done so). Two other factors are normative, drawing on the professionalization of the nonprofits. These include the leadership support for social media (i.e. leadership championed the adoption and use of social media) and the number of staff handling the social media accounts (social media account managers helping with social media). Leadership support is a consistent theme in the adoption and use of information technology; the availability of professional social media savvy staff could also be critical. 


\section{Control Variables}

The control factors for the conceptual model are drawn from the extant literature on IT adoption and use. There are six organizational factors considered as control variables. The first is the type of service sector the nonprofit is involved in. The type of service sector is important to since social media may not be equally useful across different sectors. The second is the overall revenue resources. The overall revenue could circumscribe the extent to which the nonprofit could utilize social media. The third control variable is the IT budget. The IT budget could specifically expand or constrain the adoption and use of social media. The fourth control variable is the IT staff size. The IT staff size gives the broader professional technology specialists available within the organization. The fifth control variable is the social media specialist, who are specifically oriented toward social media. The sixth control variable is the overall staff size. The overall staff size is an indicator of the slack resources available in the organization. Table 1 presents the description of the variables and their measurements.

\section{Data collection method}

The population for the study includes all nonprofit organizations affiliated with the United Way in Florida. They are typically 501(c)(3) tax-exempt status organizations as per the Internal Revenue Service (IRS) tax code. They are also community-based, locally oriented nonprofits. The United Way funds the nonprofits for conducting activities with respect to three areas - education, income, and health. In Florida, the United Way has 31 local chapters and there are over 1,300 local nonprofit organizations 
that are affiliated with these chapters. Of the 31 local chapters, the jurisdiction of 12 local chapters span across two or more counties; the other 19 chapters focus on single counties.

Table 1 Description of Variables

\begin{tabular}{|c|c|c|c|}
\hline \multicolumn{2}{|c|}{ Variable Name } & Description of Variable & Measurement \\
\hline \multicolumn{4}{|c|}{ Dependent variables } \\
\hline \multicolumn{2}{|c|}{$\begin{array}{l}\text { Adoption of social } \\
\text { media }\end{array}$} & $\begin{array}{l}\text { Number of years social media was } \\
\text { adopted }\end{array}$ & Ratio (number) \\
\hline \multicolumn{2}{|c|}{ Use of Social Media } & $\begin{array}{l}\text { Frequency of social media use to } \\
\text { post and reply posts }\end{array}$ & Likert scale (1=yearly, 4=daily) \\
\hline \multicolumn{4}{|c|}{ Independent variables } \\
\hline \multirow{4}{*}{ 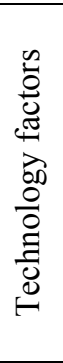 } & $\begin{array}{l}\text { Relative } \\
\text { Advantage }\end{array}$ & $\begin{array}{l}\text { Social media has relative advantage } \\
\text { over other existing technologies }\end{array}$ & $\begin{array}{l}\text { Likert scale }(1=\text { not important, } \\
5=\text { very important })\end{array}$ \\
\hline & Compatibility & $\begin{array}{l}\text { Social media is compatible with } \\
\text { existing technologies }\end{array}$ & $\begin{array}{l}\text { Likert scale }(1=\text { not important, } \\
5=\text { very important })\end{array}$ \\
\hline & Ease of use & $\begin{array}{l}\text { Social media is easy to use compared } \\
\text { to other technologies }\end{array}$ & $\begin{array}{l}\text { Likert scale }(1=\text { not important, } \\
5=\text { very important })\end{array}$ \\
\hline & Observability & $\begin{array}{l}\text { Social media has tangible } \\
\text { organizational benefits }\end{array}$ & $\begin{array}{l}\text { Likert scale }(1=\text { not important, } \\
5=\text { very important })\end{array}$ \\
\hline \multirow{4}{*}{ 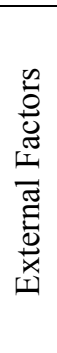 } & $\begin{array}{l}\text { Funding } \\
\text { Diversity }\end{array}$ & $\begin{array}{l}\text { Social media facilitates funding from } \\
\text { other sources }\end{array}$ & $\begin{array}{l}\text { Likert scale }(1=\text { not important, } \\
5=\text { very important })\end{array}$ \\
\hline & $\begin{array}{l}\text { Public } \\
\text { Awareness }\end{array}$ & $\begin{array}{l}\text { Social media is used to generate } \\
\text { public awareness }\end{array}$ & $\begin{array}{l}\text { Likert scale }(1=\text { not important, } \\
5=\text { very important })\end{array}$ \\
\hline & $\begin{array}{l}\text { Donor } \\
\text { Requirements }\end{array}$ & Donors require social media use & $\begin{array}{l}\text { Likert scale }(1=\text { not important, } \\
5=\text { very important })\end{array}$ \\
\hline & $\begin{array}{l}\text { United Way } \\
\text { Funding }\end{array}$ & Share of United Way funding & Ratio (percent) \\
\hline \multirow{4}{*}{ 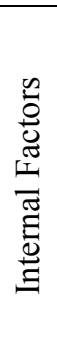 } & $\begin{array}{l}\text { Fundraising } \\
\text { Mechanism }\end{array}$ & $\begin{array}{l}\text { Social media is used as fundraising } \\
\text { mechanism }\end{array}$ & $\begin{array}{l}\text { Likert scale }(1=\text { not important, } \\
5=\text { very important })\end{array}$ \\
\hline & Peer Practice & $\begin{array}{l}\text { Social media is used by peer } \\
\text { organizations }\end{array}$ & $\begin{array}{l}\text { Likert scale }(1=\text { not important, } \\
5=\text { very important })\end{array}$ \\
\hline & Leadership & Leadership interest in social media & $\begin{array}{l}\text { Likert scale }(1=\text { not important, } \\
5=\text { very important })\end{array}$ \\
\hline & $\begin{array}{l}\text { Social media } \\
\text { Managers }\end{array}$ & $\begin{array}{l}\text { Number of staffs who manage social } \\
\text { media account }\end{array}$ & Ratio (number) \\
\hline \multirow{6}{*}{ 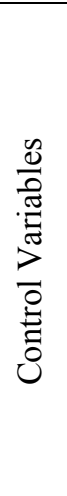 } & Revenue & $\begin{array}{l}\text { Total revenue generated by the } \\
\text { organization in } 2015\end{array}$ & Ratio (number) \\
\hline & IT Staff & $\begin{array}{l}\text { Total IT staff (full time, part time } \\
\text { and volunteers) }\end{array}$ & Ratio (number) \\
\hline & $\begin{array}{l}\text { External } \\
\text { Consultant }\end{array}$ & $\begin{array}{l}\text { Social media specialists outside the } \\
\text { organization }\end{array}$ & $\begin{array}{l}\text { Dummy variable }(1=\text { external } \\
\text { consultant, } 0=\text { otherwise })\end{array}$ \\
\hline & NPO Sector & Sector of the nonprofit organization & $\begin{array}{l}\text { Dummy variable }(1=\text { Human } \\
\text { service, } 0=\text { otherwise })\end{array}$ \\
\hline & IT Budget & $\begin{array}{l}\text { Money allocated to Information } \\
\text { Technology development }\end{array}$ & Ratio (number) \\
\hline & Staff & Total staff in the organization & Ratio (number) \\
\hline
\end{tabular}


The nonprofit organizations were invited to participate in an online questionnaire to collect the data on the dependent, independent, and control variables. Florida International University's online survey tool, Qualtrics, was used for the data collection. The participating organizations for the study were enlisted in collaboration with the regional Florida chapter and all the local chapters of United Way. All the 31 United Way offices agreed to assist in the distribution of the survey to the affiliated nonprofit agencies. Information about the purpose of the study was sent to the regional chapter and all the local chapters of United Way. An email providing the link to the online survey was distributed to the United Way chapters. The United Way local chapters then forwarded the survey link to the affiliated nonprofit organizations. Series of reminders emails were sent to the local nonprofits through the local chapters.

The questionnaire was first pilot tested with three experts in the field of nonprofit leadership and management. The experts gave significant feedback. They asked to reduce the total number of questions and limit the number of open-ended questions. Dillman, Tortora, and Bowker (1998) also note that the response rates of online surveys depend on the total number of questions and the time taken for the survey. Online surveys with fewer questions have higher response rate than web surveys with many questions. The experts also asked to sharpen the wording on a few questions (e.g. in the classification of nonprofits based on annual income). The survey questionnaire was then finalized by considering the recommendations from the experts. The survey was designed in such a manner that it would be accessible across both computers and handheld smartphones. The survey's compatibility with mobile device was considered important for increasing the response rate. The study's survey consisted of 21 questions in total, of which 20 were 
close-ended questions and one was open ended questions. Only one open-ended question was used. The final survey questionnaire is given in the Appendix.

The survey was structured as follows. It started with an outline of the purpose of the survey. Then, a skip logic question asked if the nonprofit used any of the social media platforms. If the answer was yes, the survey jumped to questions related to social media adoption and use; if the answer was no, the survey skipped to questions related to nonadoption. The first section for those respondents answering "yes" dealt with obtaining information about the dependent variables. In this, the first question asked how long (number of years) the nonprofit organization had a social media account (Facebook, Twitter, or other). The second question asked how frequently (hourly, daily, weekly, monthly, yearly) the organizations used social media platforms. The subsequent sections dealt with obtaining information about the independent variables. The second section asked questions related to social media adoption, and the third section asked questions related to the use of social media. These questions were drawn from the conceptual framework covering the three dimensions of technology, external environment, and organizational characteristics. The fourth section asked questions related to the broader organizational demographics, which are pertinent to the control variables. The survey responses were analyzed using multivariate regression to test the hypotheses on adoption and use of social media. Multivariate regression is one of the most widely used statistical models to determine the strength of relationship between one dependent variable and several independent variables. 


\subsection{Qualitative Research Methodology}

The qualitative research methods were used to explore the second research question: How do nonprofits that have adopted social media use it? The qualitative research methods are appropriate since the research question is an exploratory one (Marshall and Rossman, 2011). For this question, the focus is on how organizations use Facebook, one of the most prominent social media platforms. It was also clear from the quantitative analysis that nonprofit organizations overwhelmingly use Facebook; hence, the study focused on Facebook use for the second question. Based on extant literature, the guiding hypothesis is that organizations use Facebook for disseminating information, organizing events, and raising public awareness.

The analysis of Facebook use focused on United Way local chapters in Florida. The rationale for focusing on United Way local chapters is that it provided an expedient way to capture the affiliated nonprofit organizations' Facebook use. The local chapters generally carry posts related to affiliated nonprofit organizations' posts. Two strategies were used for analyzing how the United Way local chapters use Facebook. The first step was to conduct a content analysis of the organizations' Facebook pages. The second step

was to interview some of the key officials from the organizations to validate the results of the content analysis.

In order to conduct the content analysis, at first, all the Facebook accounts of the local chapters needed to be identified. All the 31 local chapters have a website as well as Facebook account. Interestingly, the Facebook account discovery is rather straightforward for most of the local chapters - the Facebook accounts are directly 
accessible through the website for 26 of the 31 chapters. The rest five did not have a direct link, but were easily discoverable through the Google search engine.

The second step was to retrieve the usernames of all 31 United Way local chapters' accounts. The usernames are important to document since they are unique identifiers of Facebook accounts. The usernames are handy for scraping the accounts. Scraping is method by which we can automatically obtain information about each post (e.g. date of post) in a Facebook account. Scraping provides additional information such as the number of posts, pictures, videos, comments, the dates, and so on. As Facebook is an open platform, third party users can easily scrape the Facebook accounts with simple programs called Application Programming Interface (API). For the purposes of this study, Facepager 3.8 was used to download the summary of data on total number of likes, comments, posts, reactions, likes and shares. Facepager is a free open source software available through Github, which is an online resource for such free software.

The third step in the analysis was to examine the Facebook use. The Facepager software allowed downloading the data about United Way local chapters' posts for the year 2016. The usage statistics of all the local chapters (e.g. total number of posts) was analyzed to identify the extent to which the chapters were frequently using Facebook. The usage statistics revealed that the local chapters' Facebook use fell along a continuum, from organizations with a high volume of posts to some with very low volume of posts. Consequently, the organizations were classified into three categories of Facebook use: high intensity users (which had 120 or more posts during the six months period, equating to one daily Facebook post on average during weekdays), moderate intensity users (above 60 posts, equating to a Facebook post every other day on average) and low intensity users 
(below 60 posts). Table 2 summarizes the Facebook posts of all the 31 chapters in

Florida.

Table 2 Summary of United Way Facebook posts, July 2016- December 2016

\begin{tabular}{|c|c|c|c|}
\hline & No. & Name of Organization & Posts \\
\hline \multirow{14}{*}{ 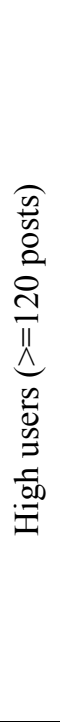 } & 1 & United Way of Central Florida & 324 \\
\hline & 2 & United Way Suncoast & 306 \\
\hline & 3 & Heart of Florida United Way & 192 \\
\hline & 4 & United Way of Miami-Dade & 169 \\
\hline & 5 & United Way of Escambia County & 160 \\
\hline & 6 & United Way of Manatee County & 153 \\
\hline & 7 & United Way of Volusia-Flagler Counties & 151 \\
\hline & 8 & United Way of Broward County & 142 \\
\hline & 9 & United Way of North Central Florida & 141 \\
\hline & 10 & United Way of Lee, Hendry and Okeechobee Counties & 139 \\
\hline & 11 & United Way of Martin County & 135 \\
\hline & 12 & United Way of Palm Beach County & 133 \\
\hline & 13 & United Way of Pasco County & 131 \\
\hline & 14 & United Way of Hernando County & 129 \\
\hline \multirow{12}{*}{ 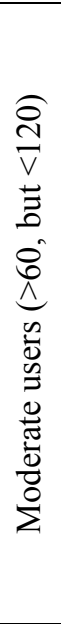 } & 15 & United Way of Northeast Florida & 118 \\
\hline & 16 & United Way of the Big Bend & 93 \\
\hline & 17 & United Way Of Lake \& Sumter Counties & 81 \\
\hline & 18 & United Way of Marion County & 80 \\
\hline & 19 & The United Way of Charlotte County & 74 \\
\hline & 20 & United Way of Citrus County & 73 \\
\hline & 21 & United Way of Collier County & 71 \\
\hline & 22 & United Way of Indian River County & 68 \\
\hline & 23 & St. Johns County United Way & 66 \\
\hline & 24 & United Way of Brevard & 66 \\
\hline & 25 & United Way of Santa Rosa County & 64 \\
\hline & 26 & United Way of Okaloosa \& Walton Counties & 63 \\
\hline \multirow{5}{*}{$\begin{array}{l}\text { ô } \\
\text { v } \\
3 \\
0 \\
0\end{array}$} & 27 & United Way of the Florida Keys & 60 \\
\hline & 28 & United Way of Northwest Florida & 47 \\
\hline & 29 & United Way of St. Lucie County & 40 \\
\hline & 30 & United Way of Suwannee Valley & 36 \\
\hline & 31 & United Way of Putnam County & 22 \\
\hline
\end{tabular}


In the fourth step, four local chapters were identified from each of the above three categories of high, moderate, and low intensity Facebook use. The motivation for selecting chapters from across the spectrum of use is to ensure representation of organizations across the usage spectrum. Prior studies (e.g. Lovejoy and Saxton, 2012; Kang \& Norton, 2004), had also used a similar procedure to examine Facebook use across high, medium, and low intensity users. Care was also taken to ensure that the chapters are distributed evenly across Florida geographically and are representative of both urban and rural counties (Figure 4). The twelve organizations finally selected for content analysis are listed below in Table 3.

Table 3 Selected United Way Chapters

\begin{tabular}{clc}
\hline No. & \multicolumn{1}{c}{ Name of Organization } & Status \\
\hline 1 & United Way of Central Florida & High \\
\hline 2 & United Way Suncoast & High \\
\hline 3 & Heart of Florida United Way & High \\
\hline 4 & United Way of Miami-Dade & High \\
\hline 5 & United Way of Hernando County & Medium \\
\hline 6 & United Way of Northeast Florida & Medium \\
\hline 7 & United Way of the Big Bend & Medium \\
\hline 8 & United Way Of Lake \& Sumter Counties & Medium \\
\hline 9 & United Way of Northwest Florida & Low \\
\hline 10 & United Way of St. Lucie County & Low \\
\hline 11 & United Way of Suwannee Valley & Low \\
\hline 12 & United Way of Putnam County & Low \\
\hline
\end{tabular}


Figure 4 Distribution of Selected United Way Chapters

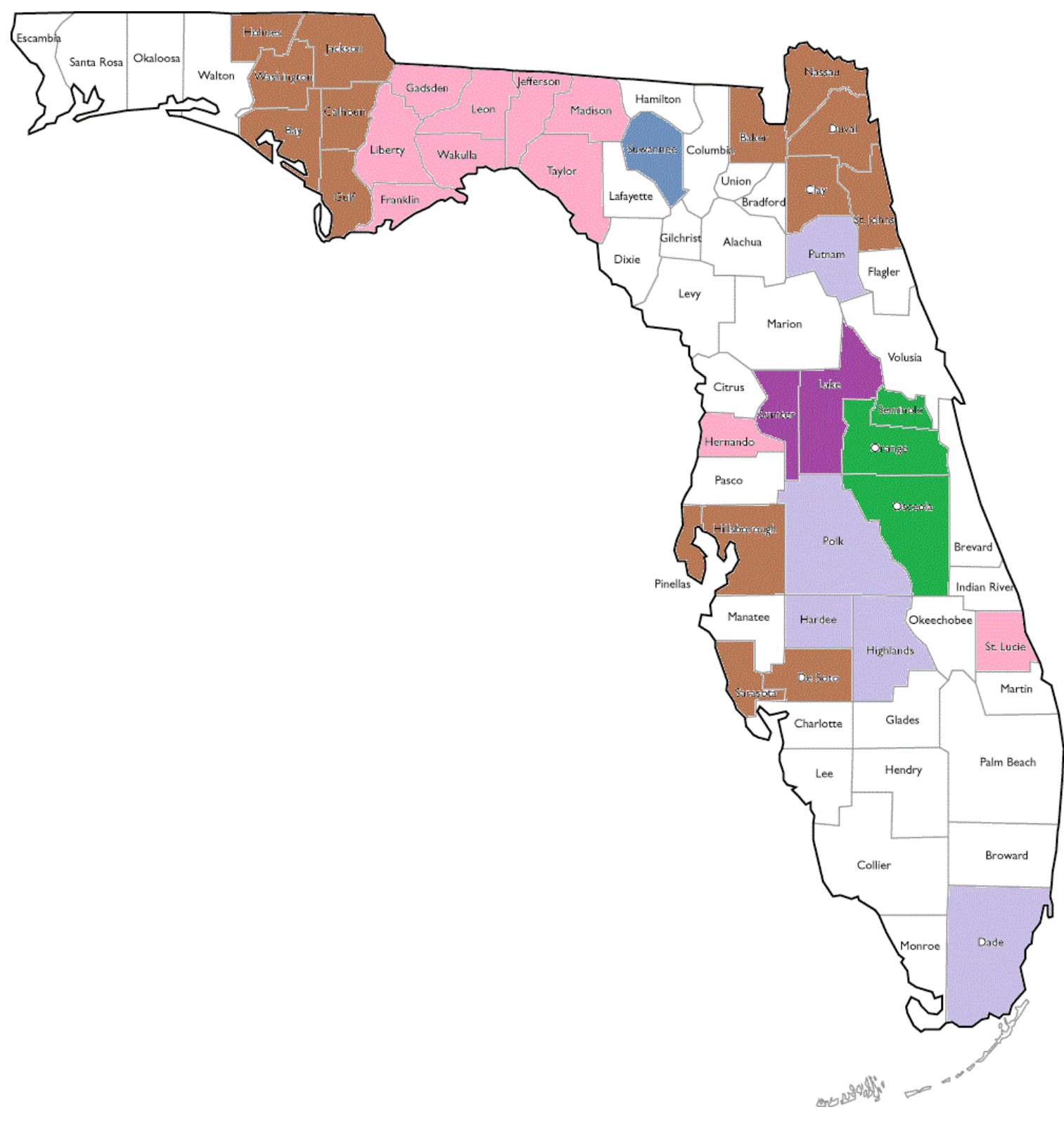

Content Analysis: Data collection and Procedure

The content analysis required Facebook posts from the 12 selected United Way local chapters. Facebook's Graph API explorer for data analytics enabled collection of these posts. The API is available through the Facebook developer portal, a site for software programmers and advanced users who develop various applications to integrate 
with Facebook. The Facebook content download required several steps. First, an access token was generated using Facebook Graph API explorer. Second, the Graph API helped in retrieving the Facebook page ID of the nonprofit. Third, the Facebook ID was used to extract data from the Facebook page. The following data were retrieved from the Facebook account of each local chapter:

- All Facebook status updates including the status messages and links

- Permalinks for the nonprofit's Facebook posts

- Number of shares, reactions, likes and comments for each post

- Time each post was created.

The above-extracted data are in JSON file format, which are not human readable for analytical purposes. Hence, the data were converted into a spreadsheet, which could be used for analytical purposes.

The second phase of data collection involved compiling a comprehensive set of Facebook posts for content analysis. Each United Way local chapter's Facebook page contents (posts and comments) were downloaded using google chrome for a period of six months (July 2016 to December 2016). The posts were downloaded between January 5, 2017 and January 15, 2017. The data scraped consisted of 1,838 pages of Facebook posts. The time period is the latest in terms of a half year period to collect Facebook posts. The period was also fortuitious for two reasons. First, Hurricane Matthew made its landfall in the southeastern coast of Florida in October. During this period, several nonprofits were busy directing disaster victims on where to seek shelter and get assistance. Social media use by nonprofit organizations surged in Florida. Second, the last week of November is regularly considered as the beginning of the festive season for Christmas, particularly 
after the celebration of Thanksgiving. This period also saw an uptake in the social media use.

The content analysis required coding (i.e. identifying similar themes) all the Facebook posts scraped from the twelve organizations. The coding is critical for identifying the main themes of how nonprofit organizations use Facebook. NVivo, a qualitative analysis software, enabled the coding process. Each theme is called a node in NVivo; a node can have multiple sub-nodes (i.e. sub-themes). At first, I coded about 100 Facebook posts of three United Way chapters that were not a part of the twelve organizations selected for study. These codes provided a guide to identify nodes in the Facebook posts of the organizations under study. The pilot coding also helped in ensuring that the nodes of the Facebook posts of the selected organizations is representative of other organizations. The Facebook posts of all of the selected local chapters were then coded using NVivo.

At first, each post was assigned a single node. When a post appeared to serve dual purposes, a node was assigned based on the primary objective of the post. When a post had two or more purposes, it was assigned a sub-node to denote the other purposes. For example, the collaboration node has three sub-nodes—collaboration with public, nonprofit, and private sector organization. In instances where the posts contain all the three aspects of collaboration, the posts are assigned all three sub-nodes. The author conducted all of the coding. To ensure reliability, the dissertation advisor examined a sample of the codes and posts to ensure that the nodes matched the intended purpose of the node. 


\section{Interviews}

The interviews were a follow up to the content analysis to ensure that the findings from the content analysis matched the intentions of the users. The interviews provide an excellent method to investigate the motivation and the challenges of why the United Way local chapter adopted and used social media. Previous studies on the adoption and use of social media in nonprofit organizations have not resorted to interviews to ascertain the motivations. The interviews supplemented the content analysis. The interviews examined specific factors, including, how the organization adopted social media platforms, the main reasons for the preference of Facebook over other social media platforms, the organization's perceived advantages and disadvantages of using Facebook, and how they overcome the challenges of using Facebook. The interviews provided insights into social media adoption and use that could not be gleaned through the survey or content analysis.

The twelve selected United Way chapters were the subjects of the interview. An email request was sent to the organizations' chief officers (CEO or the President), requesting an appointment for interview. All the officers accepted to be interviewed, after several email reminders and personal calls to their offices. However, only four officers actually could take part in the interview. The others could not take part due to their busy schedule and various other commitments during the time period. Two officers agreed to respond in writing via email due to their time constraints. Hence, I have had responses from six officers in all. The average working experience of these respondents was 18 years.

With respect to interviews, I interviewed one representative from each of the four organizations. If the president was not available, I spoke to a senior staff member in the 
management who had first hand knowledge of the social media adoption and use within the organization. In all, I interviewed one president and three senior managers who were in charge of social media in the organization. I conducted telephone interview as per the Institutional Review Board (IRB) protocol. Two interviewees permitted recording, which were indeed recorded and transcribed. Two did not permit the recording, but I had ample time to take notes during the conversation. The interviews were semi-structured, wherein I asked questions about the adoption and use of social media. The length of the interviews ranged from 10 minutes to 45 minutes. With respect to the email responses, I emailed questions to the officers. They provided detailed responses to the questions. The list of guiding questions are provided in the Appendix. None of the subjects were compensated, as per the university's Institutional Review Board approved protocol. All respondents provided verbal consent via telephone or written consent via a link sent to the email for the interview, as per the protocol.

For analyzing the interviews, I used the NVivo 11 software. NVivo is a qualitative analysis software used to analyze interviews and secondary data. NVivo has tools that provide search, query and visualization of secondary data. I imported all the transcripts of the interviews into NVivo and coded the transcripts to determine the broad themes, relationships among the themes, and finer nuances of the interviews. Six major themes were identified from the transcripts, including motivation for the adoption of Facebook, motivation for the use of Facebook, how the organizations use Facebook, challenges in using Facebook, and the future of social media. 


\section{$\underline{3.5 \text { Conclusion }}$}

This study uses both quantitative and qualitative methods for examining the two questions. Quantitative research methods were used to answer the question on social media adoption and use. A survey questionnaire was administered to all the community based local nonprofits affiliated with the United Way local chapters in Florida. The survey provided data on the social media adoption and use (dependent variables). It also provided data on the technological, external environment, and internal organizational dimensions (independent variables). Regression models analyzed the principal determinants of the adoption and use of social media in nonprofit organizations. Specifically, the regression analysis examined if the adoption and use of social media in nonprofit organizations is influenced by technological factors, external environmental factors, and internal organizational factors.

Qualitative methods are used to answer the second question on how the organizations use social media. The qualitative methods comprised of content analysis and a limited set of interviews to verify the findings from the content analysis. Content analysis comprised of examining the Facebook posts of twelve United Way local chapters during the latest six month period (July to December, 2016). The qualitative analysis software, NVivo 11, helped in identifying the major themes of the Facebook posts. The themes are central to gaining insights on how the United Way chapters use social media platforms. I obtained additional insights into why organizations adopt and use social media by interviewing senior officials or by reaching out to them through email. 


\section{DETERMINANTS OF ADOPTION \& USE OF SOCIAL MEDIA}

\section{$\underline{4.1 \text { Introduction }}$}

This chapter deals with the first question of the study: What are the principal determinants of adoption and use of social media in nonprofit organizations? The hypothesis is that technological, environmental, and organizational factors influence the adoption and use of social media. These three dimensions are drawn from the conceptual framework, which is built on three theoretical perspectives: Rogers' (2003) diffusion of innovation theory; Pfeffer and Salancik's (1978) resource dependence theory; and DiMaggio and Powell's (1983) institutional theory. These three theoretical frameworks have been powerful in explaining organizations' adoption (or non-adoption) of information technology. This chapter tests the relevance of these factors in the adoption of newly emerging information technologies like social media.

Quantitative analysis is used for examining the determinants of social media adoption and use. The data for the analysis are drawn from an online survey of all the nonprofits affiliated with the United Way chapters in Florida. The nonprofits organizations are typically locally focused and community based. United Way funds the nonprofits for their activities in the United Way's focus areas of education, income, and health. The United Way chapters helped in distributing the online survey to their affiliated nonprofits. Although 546 organizations responded to the survey, 506 were valid survey responses that had answers for all the key questions required for measuring the variables. As the total affiliated nonprofits are 1300, the survey response rate was about $38.9 \%$. The survey response rate is considered to be good for analytical purposes because 
out of the 14 variables used in the study, only two variables (revenue and Staff) were negatively skewed. The variables were normalized using the natural log.

\subsection{The Analytical Model and Variables}

The primary goal of the analysis is to identify the principal determinants of the adoption and use of social media. Extant literature on the diffusion of information technology draws upon three theoretical frameworks, which are the basis for the conceptual framework for this study. Rogers' (2003) diffusion of innovation theory emphasizes the technological characteristics in the adoption of an innovation. Pfeffer and Salancik's (1978) resource dependence theory emphasizes that external environmental forces shape the adoption of a technological innovation in the process of the organization's survival. DiMaggio and Powell's (1983) institutional theory highlights the internal organizational factors in the adoption of the technological innovation. Drawing on the conceptual framework, the hypothesis is that the technological, environmental, and internal organizational factors are significant for the adoption and use of social media. The overall model is as follows:

Social media (adoption/use) $[Y]=f$ (technology, environment, organizational factors)

More specifically, the model is as follows:

Social media (adoption/use) $[Y]=a+\sum b_{i} T_{i}+\sum c_{i} E_{i}+\sum d_{i} O_{i}+\sum e_{i} C V_{i}+\varepsilon$, Where $\mathrm{a}=$ constant, $\varepsilon=$ error term, $\mathrm{T}_{\mathrm{i}}=$ vector of Technological factors $E_{i}=$ vector of External environmental factors 
$\mathrm{O}_{\mathrm{i}}=$ vector of Internal organizational factors

$\mathrm{CV}_{\mathrm{i}}=$ set of control variables, and

$b_{i}, c_{i}, d_{i}$, and $e_{i}$ are the coefficients to be estimated for each $i$ factor.

\section{Dependent Variables}

The study has two dependent variables: the adoption of social media and the use of social media. The first dependent variable, the adoption of social media, is measured by the number of years since the social media platform was initially adopted. The length of social media adoption is important to identify the factors that influence when organizations decide to adopt social media. Since the length is a continuous variable, the social media adoption is modeled as a multivariate linear regression model. The second dependent variable, the use of social media, is measured by how often the social media platform is used to post comments and respond to other posts and comments. The variable is ordinal, measured as yearly (1), monthly (2), weekly (3), or daily (4) use. The frequency of use shows the extent to which the nonprofit organizations consider the importance of social media for organizational purposes. Since the social media use is an ordinal variable, ordered logistic regression is used to model the analysis.

Two social media platforms are central to the analysis: Facebook and Twitter. These two platforms are the most popular, which have increased their active user base over the last decade. Several studies also show that these two social media platforms are the two most widely used social media in large nonprofit organizations to engage citizens in diologic communication, connet with donors for fundraising, and undertake advocacy to seek the welfare of deprived communities (Briones et al., 2011; Curtis et al., 2010; 
Gálvez-Rodriguez et. al., 2014; Guo and Saxton, 2014; Lovejoy and Saxton, 2012). Both the adoption and use of Facebook and Twitter are considered separately in the models.

\section{Independent Variables}

Based on the conceptual framework, there are three sets of independent variables: technological factors, external environmental factors, and internal organizational factors. Drawing from the diffusion of innovation theory, the technological factors include four variables. The variables are: the relative advantage of social media over other existing technologies (relative advantage), the compatibility of social media with existing technologies (compatibility), the ease of use of social in relation to other technologies (ease of use), and the tangible benefits of social media over existing technologies (observability).

The external environmental factors include four variables. Based on the resource dependence theory, the external environmental factors are funding diversity (i.e. social media is used to diversify the funding sources) and public awareness (i.e. social media is used to generate public awareness). The coercive isomorphism could also have an external influence on adoption and use of social media. Towards this end, there are two variables from the coercive aspects of external environment. These factors include the donor requirements (i.e. donors required the nonprofits to adopt social media) and share of United Way funding (i.e. affiliation with United Way had an influence on social media adoption).

The internal organizational factors for consideration are drawn from the institutional theory. Two such factors are related to mimetic isomorphism, whereby 
nonprofits mimic other similar organizations. These include the use of social media for fundraising (which is one of the common reasons for adopting social media) and peer practice (i.e. social media is adopted because other nonprofits have also done so). Two other factors are normative, drawing on the professionalization of the nonprofits. These include the leadership support for social media (i.e. leadership championed the adoption and use of social media) and the number of staff handling the social media accounts (social media account managers helping with social media). Leadership support is a consistent theme in the adoption and use of information technology; the availability of professional social media savvy staff could also be critical.

\section{Control Variables}

The control factors for the conceptual model are drawn from the extant literature on IT adoption and use. There are six organizational factors considered as control variables. The first is the type of service sector the nonprofit is involved in. The type of service sector is important to since social media may not be equally useful across different sectors. It is measured as a dummy variable, differentiating between human service organizations and all others. The second is the overall revenue resources. The overall revenue could circumscribe the extent to which the nonprofit could utilize social media. The third control variable is the IT budget. The IT budget could specifically expand or constrain the adoption and use of social media. The fourth control variable is the IT staff size. The IT staff size gives the broader professional technology specialists available within the organization. The fifth control variable is the social media specialists, who are specifically oriented toward social media. The sixth control variable is the 
overall staff size. The overall staff size is an indicator of the slack resources available in the organization. Table 4 below presents a summary of the independent, dependent, and control variables and their measurements. The Appendix provides the correlation matrix between the variables.

Table 4 Summary of Variables

\begin{tabular}{|c|c|c|}
\hline \multirow{4}{*}{$\begin{array}{l}\text { Dependent } \\
\text { Variables }\end{array}$} & Adoption of Facebook & Number of years since adoption in 2016 \\
\hline & Adoption of Twitter & Number of years since adoption in 2016 \\
\hline & Use of Facebook & Ordinal (1=yearly; $4=$ daily $)$ \\
\hline & Use of Twitter & Ordinal (1=yearly; $4=$ daily) \\
\hline \multirow{4}{*}{$\begin{array}{l}\text { Technology } \\
\text { factors }\end{array}$} & Relative Advantage & Likert ( $1=$ not important, $5=$ very important $)$ \\
\hline & Compatibility & Likert ( $1=$ not important, $5=$ very important) \\
\hline & Ease of use & Likert ( $1=$ not important, $5=$ very important $)$ \\
\hline & Observability & Likert ( $1=$ not important, $5=$ very important $)$ \\
\hline \multirow{4}{*}{$\begin{array}{l}\text { External } \\
\text { Factors }\end{array}$} & Funding Diversity & Likert ( $1=$ not important, $5=$ very important $)$ \\
\hline & Public Awareness & Likert ( $1=$ not important, $5=$ very important $)$ \\
\hline & Donor Requirements & Likert ( $1=$ not important, $5=$ very important $)$ \\
\hline & United Way Funding & Ratio (percent) \\
\hline \multirow{4}{*}{$\begin{array}{l}\text { Organizational } \\
\text { Factors }\end{array}$} & $\begin{array}{l}\text { Fundraising } \\
\text { Mechanism }\end{array}$ & Likert ( $1=$ not important, $5=$ very important) \\
\hline & Peer Practice & Likert ( $1=$ not important, $5=$ very important $)$ \\
\hline & Leadership & Likert ( $1=$ not important, $5=$ very important $)$ \\
\hline & $\begin{array}{l}\text { Social Media } \\
\text { Managers }\end{array}$ & Ratio (number) \\
\hline \multirow{6}{*}{$\begin{array}{l}\text { Control } \\
\text { Factors }\end{array}$} & Revenue & Likert ( $1=$ not important, $5=$ very important $)$ \\
\hline & IT Staff & Ratio (number) \\
\hline & External Consultant & Dummy $(1=$ Yes, $0=$ No $)$ \\
\hline & NPO Sector & Dummy ( $1=$ Human service, $0=$ all others) \\
\hline & IT Budget & Ratio (number) \\
\hline & Staff & Ratio (number) \\
\hline
\end{tabular}




\subsection{Social Media Adoption}

Social media adoption relates to when the nonprofit organization decided to have a presence in the social media platform. The focus of this study is on two social media platforms, Facebook and Twitter. Facebook was founded in 2004 and Twitter was founded in 2006. Hence, the maximum length of time for adoption of these two platfoms could be 12 or 10 years by 2016, when the online survey was administered. Table 5 provides the descriptive statistics of the variables. As the table shows, Facebook's adoption ranges between 0 and 10 years, with an average of 4.5 years; Twitter's adoption ranges from 0 to 9 years, with an average of 2.9 years. In the context of the digital age, Facebook and Twitter adoption is thus rather late, wherein community based nonprofit organizations have adopted Facebook only in the last five years on average, and they have adopted Twitter only in the last three years on average.

Overall, $88.5 \%$ of the survey respondents indicated having adopted some form of social media. Facebook is, by far, more popular than the other social media platforms. Analysis of the survey data shows that the Facebook adoption is in the late majority stage, wherein nearly $90.5 \%$ of the respondents indicated that they have adopted Facebook platform. Twitter adoption is in the early majority stage with about $73.3 \%$ indicating that they have adopted the platform. The correlation between Facebook and Twitter adoption is 0.67 , showing that there is reasonably strong relationship between the two platforms' adoption. Other social media platforms are still in the early adoption stage, with about $37.5 \%$ of the respondents indicating that they have adopted other platforms. The other platforms include: Instagram, a photosharing site that is now owned 
by Facebook (indicated by $24 \%$ of the respondents), Youtube, a multimedia sharing platform (7\%) and LinkedIn, a professional networking platform (3\%).

Table 5 Descriptive Statistics for Social Media Adoption

\begin{tabular}{|c|c|c|c|c|c|c|}
\hline Var & Item & $\mathrm{N}$ & Minimum & Maximum & Mean & Std. Deviation \\
\hline \multirow{2}{*}{ 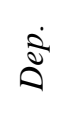 } & Facebook & 506 & 0 & 10 & 4.514 & 2.607 \\
\hline & Twitter & 506 & 0 & 9 & 2.897 & 2.589 \\
\hline \multirow{4}{*}{ 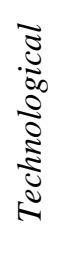 } & Relative Adv. & 506 & 1 & 5 & 3.751 & 1.052 \\
\hline & Compatibility & 506 & 1 & 5 & 3.281 & 1.220 \\
\hline & Ease of Use & 506 & 1 & 5 & 4.154 & 0.942 \\
\hline & Observability & 506 & 1 & 5 & 3.166 & 1.345 \\
\hline \multirow{4}{*}{ 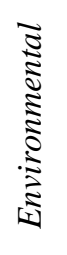 } & Funding Diversity & 506 & 1 & 5 & 3.178 & 1.342 \\
\hline & Public Awareness & 506 & 1 & 5 & 4.103 & 1.154 \\
\hline & Donor Requirement & 506 & 1 & 5 & 2.812 & 1.450 \\
\hline & UW Funding & 506 & 0 & 100 & 42.184 & 32.676 \\
\hline \multirow{4}{*}{ 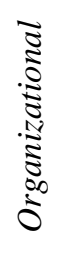 } & Fundraising Mech. & 506 & 1 & 5 & 3.542 & 1.143 \\
\hline & Peer Practice & 506 & 1 & 5 & 2.731 & 1.394 \\
\hline & Leadership & 506 & 1 & 5 & 3.660 & 1.141 \\
\hline & SM. Managers & 506 & 0 & 4 & 2.166 & 1.171 \\
\hline \multirow{6}{*}{$\begin{array}{l}\overrightarrow{0} \\
\stackrel{0}{0}\end{array}$} & Revenue & 506 & 0 & $\$ 126,000,000$ & $\$ 6,854,478$ & $\$ 17,500,000$ \\
\hline & IT Staff & 506 & 0 & 8 & 1.663 & 1.969 \\
\hline & External Consultant & 486 & 0 & 1 & 0.140 & 0.347 \\
\hline & NPO Sector & 506 & 0 & 1 & 0.488 & 0.500 \\
\hline & IT Budget & 501 & 0 & 10 & 1.229 & 1.242 \\
\hline & Staff & 506 & 3 & 975 & 144.158 & 185.245 \\
\hline
\end{tabular}

Table 6 below provides the results of respondents indicating why they adopted social media. As the table indicates, a significant motivation for adopting social media is to achieve the organizational mission (about $91.7 \%$ indicated this to be "very important" or "important"). Two technological factors stand out as important motivations: about 
$91.7 \%$ of the respondents indicated relative advantage to be "very important" or "important", and $91.7 \%$ indicated the social media's compatibility with the needs of the organizational activities characteristics to be "very important" or "important." Nearly $85 \%$ of the respondents indicated fundraising as a motivation to adopt social media. About $83.3 \%$ of the respondents indicated that the donor requirements were important motivations for adopting social media. Interestingly, peer practice (i.e. adoption of social media by peer nonprofits) and leadership (i.e. champion for adopting social media) were not regarded as being important motivations. In fact, $70.8 \%$ and $75 \%$ of the respondents indicated that peer practice and leadership respectively were "slightly important" or "not important."

Table 6 Motivations for Adopting Social Media

\begin{tabular}{|l|r|r|r|r|r|}
\hline Motivation & $\begin{array}{r}\text { Very } \\
\text { important }\end{array}$ & Important & $\begin{array}{c}\text { Mod- } \\
\text { rerately } \\
\text { important }\end{array}$ & $\begin{array}{c}\text { Slightly } \\
\text { Important }\end{array}$ & $\begin{array}{c}\text { Not } \\
\text { important }\end{array}$ \\
\hline To accomplish our mission & $83.33 \%$ & $8.33 \%$ & $4.17 \%$ & $4.17 \%$ & $0.00 \%$ \\
\hline $\begin{array}{l}\text { Social media offers relative advantage } \\
\text { over existing technologies }\end{array}$ & $8.33 \%$ & $83.33 \%$ & $8.33 \%$ & $0.00 \%$ & $0.00 \%$ \\
\hline $\begin{array}{l}\text { Social media fulfils the needs of our } \\
\text { organizational activities }\end{array}$ & $20.83 \%$ & $66.67 \%$ & $12.50 \%$ & $0.00 \%$ & $0.00 \%$ \\
\hline $\begin{array}{l}\text { Social media is easy to adopt in our } \\
\text { organization }\end{array}$ & $8.33 \%$ & $12.50 \%$ & $75.00 \%$ & $4.17 \%$ & $0.00 \%$ \\
\hline $\begin{array}{l}\text { Social media adoption has resulted in } \\
\text { tangible organizational benefits }\end{array}$ & $8.33 \%$ & $16.67 \%$ & $75.00 \%$ & $0.00 \%$ & $0.00 \%$ \\
\hline $\begin{array}{l}\text { Our organization adopted social media } \\
\text { for fundraising purposes }\end{array}$ & $12.50 \%$ & $62.50 \%$ & $20.83 \%$ & $4.17 \%$ & $0.00 \%$ \\
\hline $\begin{array}{l}\text { Our organization adopted social media to } \\
\text { diversify our funding sources }\end{array}$ & $0.00 \%$ & $16.67 \%$ & $79.17 \%$ & $4.17 \%$ & $0.00 \%$ \\
\hline $\begin{array}{l}\text { Our organization adopted social media to } \\
\text { generate public awareness }\end{array}$ & $12.50 \%$ & $12.50 \%$ & $66.67 \%$ & $8.33 \%$ & $0.00 \%$ \\
\hline $\begin{array}{l}\text { Our donors required us to adopt social } \\
\text { media }\end{array}$ & $8.33 \%$ & $75.00 \%$ & $8.33 \%$ & $4.17 \%$ & $4.17 \%$ \\
\hline $\begin{array}{l}\text { Our organization adopted social media } \\
\text { because other nonprofits have adopted it }\end{array}$ & $8.33 \%$ & $4.17 \%$ & $16.67 \%$ & $62.50 \%$ & $8.33 \%$ \\
\hline $\begin{array}{l}\text { Our leadership championed the adoption } \\
\text { of social media }\end{array}$ & $4.17 \%$ & $12.50 \%$ & $8.33 \%$ & $66.67 \%$ & $8.33 \%$ \\
\hline
\end{tabular}


To further understand the motivations for adopting social media, regression analysis is used to explore the adoption of two social media platforms: Facebook and Twitter. These two platforms are the most widely adopted among the nonprofits. Multivariate regression model is used for analyzing the factors influencing the adoption of each of the above platforms. As explained earlier, the independent variables are technological, environmental, and organizational factors.

\section{Adoption of Facebook}

Table 7 shows the results of regression model (Model 1a) for the adoption of Facebook. As shown in Table 7, the overall R-square is low (0.20), indicating that the theorized variables account for only about $20 \%$ of the Facebook adoption. The low Rsquare is interesting because theorized factors do not account for Facebook adoption very well. The forces of Facebook adoption could be distinctive from the factors that explained the information technology adoption.

The model shows that five of the twelve independent variables are statistically significant. Three of these are technological factors-relative advantage, compatibility and ease of use. Relative advantage is statistically significant at 5\% level while compatibility and ease of use are significant at $1 \%$ level. Relative advantage and ease of use have positive coefficients, i.e. organizations adopt Facebook earlier if they perceive the platform has relative advantage over other technologies and is easy to use. Compatibility is negatively correlated with length of Facebook adoption, which implies that compatibility with the organization's activities could be more important for the late adopters than early adopters. 
Table 7 Summary of Regression Analysis of Adoption of Facebook (Model 1a)

\begin{tabular}{|c|c|c|c|c|}
\hline & Variable & $B$ & SE & $\operatorname{Sig}(p)$ \\
\hline \multirow{4}{*}{$\begin{array}{l}\text { Technological } \\
\text { factors }\end{array}$} & Relative Advantage & 0.282 & 0.135 & $0.037^{*}$ \\
\hline & Compatibility & -0.381 & 0.141 & $0.007 * *$ \\
\hline & Ease of Use & 0.447 & 0.128 & $0.001 * *$ \\
\hline & Observability & 0.078 & 0.095 & 0.414 \\
\hline \multirow{4}{*}{$\begin{array}{l}\text { Environmental } \\
\text { factors }\end{array}$} & Fund Diversity & -0.117 & 0.132 & 0.376 \\
\hline & Public Awareness & 0.260 & 0.113 & $0.022^{*}$ \\
\hline & Donor Requirement & -0.171 & 0.104 & 0.102 \\
\hline & UW Funding & -0.001 & 0.003 & 0.659 \\
\hline \multirow{4}{*}{$\begin{array}{l}\text { Organizational } \\
\text { factors }\end{array}$} & Fundraising Mechanism & -0.417 & 0.143 & $0.004 * *$ \\
\hline & Peer Practice & 0.002 & 0.090 & 0.978 \\
\hline & Leadership & 0.145 & 0.112 & 0.196 \\
\hline & SM. Managers & -0.430 & 0.097 & $0.000 * *$ \\
\hline \multirow[t]{9}{*}{ Control variables } & Revenue & 0.000 & 0.000 & 0.248 \\
\hline & IT Staff & -0.073 & 0.053 & 0.174 \\
\hline & External Consultant & 1.093 & 0.318 & $0.001 * *$ \\
\hline & NPO Sector & 0.555 & 0.211 & $0.009^{* *}$ \\
\hline & IT Budget & -0.122 & 0.084 & 0.148 \\
\hline & Staff & 0.001 & 0.001 & 0.175 \\
\hline & Constant & 4.350 & 0.733 & $0.000 * *$ \\
\hline & $\mathrm{N}$ & 482 & & \\
\hline & $\mathrm{R} 2$ & 0.20 & & \\
\hline
\end{tabular}

Note: ${ }^{* *} \mathrm{p}<.01,{ }^{*} \mathrm{p}<.05$

With respect to the external environmental factors, only public awareness is statistically significant at $5 \%$ levels with positive relationship. That is, the greater the organizations perceive they can use Facebook for generating public awareness, the earlier they will adopt the platform. With respect to the internal organizational factors, the motivation to adopt social media as a fundraising mechanism and the number of people who manage the social media accounts are statistically significant at $1 \%$ levels. Both internal institutional factors are negatively related with the adoption of Facebook. The negative relationship with adoption of social media as fundraising mechanism indicates 
that this motivation is important for those organizations that adopted Facebook later. The negative relationship with dedicated social media managers indicates that the later adopters realized the need for such dedicated managers. Interestingly, other independent variables were not significant statistically.

Two of the six control variables are also statistically significant. The use of external consultant or social media specialists and the sector of the nonprofit organization are statistically significant at $1 \%$ levels. The signs are also positive. The results imply that an external consultant could lead to earlier adoption of Facebook; human service organizations are also likely to adopt social media earlier. Interestingly, the financial capacity of the nonprofit (revenue) and organizational size, which are purportedly significant for information technology adoption, are not statistically significant for Facebook adoption. The rationale could be that Facebook does not require upfront financial investments; the platform is available for free and has flat learning curve. The main issue is to have Internet savvy staff who are capable to use the medium effectively. In most organizations, the frontline employees (secretary or receptionist) or the communications team handle the social media accounts.

\section{The Adoption of Twitter}

Table 8 presents the results of regression analysis of Twitter adoption by the nonprofit organizations (Model 1b). As Table 8 shows, the overall R-square is low (0.19), indicating that only 19 percent of the changes in the adoption of Twitter is explained by the model. Similar to Facebook, the theorized variables in the model do not fully account 
for the motivations to adopt Twitter. The factors affecting Twitter adoption could thus be distinctive from those affecting information technology adoption.

Table 8 Summary of Regression Analysis of Adoption of Twitter (Model 1b)

\begin{tabular}{llccl}
\hline & Variable & $\mathrm{B}$ & $\mathrm{SE}$ & Sig $(\mathrm{p})$ \\
\hline Technological & Relative Advantage & 0.453 & 0.140 & $0.001^{* *}$ \\
& Compatibility & -0.479 & 0.147 & $0.001^{* *}$ \\
& Ease of Use & 0.686 & 0.133 & $0.000^{* *}$ \\
& Observability & 0.050 & 0.099 & 0.616 \\
\hline Environmental & Fund Diversity & -0.203 & 0.137 & 0.140 \\
factors & Public Awareness & 0.424 & 0.118 & $0.000^{* *}$ \\
& Donor Requirement & -0.112 & 0.109 & 0.302 \\
& UW Funding & -0.001 & 0.003 & 0.711 \\
\hline Organizational & Fundraising Mechanism & -0.400 & 0.149 & $0.007^{* *}$ \\
& Peer Practice & 0.025 & 0.093 & 0.787 \\
& Leadership & -0.057 & 0.116 & 0.622 \\
& SM. Managers & 0.089 & 0.100 & 0.377 \\
\hline Control variables & Revenue & 0.000 & 0.000 & 0.152 \\
& IT Staff & -0.068 & 0.055 & 0.222 \\
& External Consultant & 0.764 & 0.331 & $0.021^{*}$ \\
& NPO Sector & 0.481 & 0.220 & $0.029^{*}$ \\
& IT Budget & -0.113 & 0.088 & 0.196 \\
& Staff & 0.001 & 0.001 & 0.401 \\
\hline & Constant & 0.427 & 0.762 & 0.576 \\
& & & & \\
& N & 482 & & \\
& R2 & 0.19 & & \\
\hline
\end{tabular}

Note: ${ }^{* *} \mathrm{p}<.01,{ }^{*} \mathrm{p}<.05$

With respect to the independent variables, five variables are statistically significant. Similar to Facebook, three technological factors are significant for Twitter adoption: relative advantage, compatibility and ease of use (they are statistically significant at $5 \%$ level). Relative advantage and ease of use have a positive coefficient. Compatibility is negatively related with length of Twitter adoption, which implies that 
compatibility with the organization's activities could be more important for the late adopters than early adopters.

With respect to external environmental factors, only public awareness is statistically significant at $1 \%$ levels with a positive relationship. Twitter adoption is thus motivated by using it for public awareness about the organization's activities. With respect to internal organizational factors, only fundraising mechanism is statistically significant at $1 \%$ level but negatively related to adoption of Twitter. The negative relationship implies that the fundraising was not necessarily a motivation for early adopters, but was so for the later adopters.

Two of the six control variables are statistically significant at 5\% levels and positively related to Twitter adoption. The use of external consultant in managing the social media account and the sector of the nonprofit organization are both statistically significant at $1 \%$ levels. An external consultant could thus motivate earlier adoption of Twitter, and human services organizations are more likely to adopt Twitter earlier.

\subsection{The Use of Social Media}

Social media use relates to nonprofit organization's utilization of the platform in the context of their organizational activities. The usage would imply that the nonprofit organization's officials will undertake Facebook postings or provide Twitter feeds. The frequency by which the nonprofits use the social media platform is a good indication of the organizations' ability and commitment to use the platform. The frequency is measured on an ordinal scale, in terms of yearly (1), monthly (2), weekly (3), and daily (4) use. As the descriptive statistics show (Table 9), the average is 3.5 for Facebook and 
3.3 for Twitter. On average thus organizations use the social media platforms on a weekly basis.

Table 9 Descriptive Statistics of Social Media Use

\begin{tabular}{|c|c|c|c|c|c|c|}
\hline Var & Item & $\mathrm{N}$ & Minimum & Maximum & Mean & Std. Deviation \\
\hline \multirow{2}{*}{$\dot{\Xi}$} & Facebook & 506 & 1 & 4 & 3.595 & 0.573 \\
\hline & Twitter & 506 & 1 & 4 & 3.310 & 0.748 \\
\hline \multirow{4}{*}{ 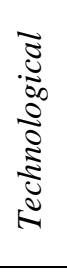 } & Relative Adv. & 506 & 1 & 5 & 3.613 & 1.122 \\
\hline & Compatibility & 506 & 1 & 5 & 3.374 & 1.270 \\
\hline & Ease of Use & 506 & 1 & 5 & 3.407 & 1.251 \\
\hline & Observability & 506 & 1 & 5 & 3.686 & 1.067 \\
\hline \multirow{4}{*}{ 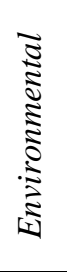 } & Funding Diversity & 506 & 1 & 5 & 3.486 & 1.191 \\
\hline & Public Awareness & 506 & 1 & 5 & 4.109 & 1.168 \\
\hline & Donor Requirement & 506 & 1 & 5 & 3.516 & 1.549 \\
\hline & UW Funding & 506 & 0 & 100 & 42.184 & 32.676 \\
\hline \multirow{4}{*}{ 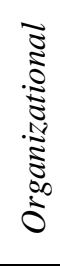 } & Fundraising Mech. & 506 & 1 & 5 & 3.391 & 1.270 \\
\hline & Peer Practice & 506 & 1 & 5 & 2.733 & 1.324 \\
\hline & Leadership & 506 & 1 & 5 & 3.800 & 1.125 \\
\hline & SM. Managers & 506 & 0 & 4 & 2.166 & 1.171 \\
\hline \multirow{6}{*}{$\begin{array}{l}\overrightarrow{0} \\
\overrightarrow{0}\end{array}$} & Revenue & 506 & 0 & $\$ 126,000,000$ & $\$ 6,854,478$ & $\$ 17,500,000$ \\
\hline & IT Staff & 506 & 0 & 8 & 1.663 & 1.969 \\
\hline & External Consultant & 486 & 0 & 1 & 0.140 & 0.347 \\
\hline & NPO Sector & 506 & 0 & 1 & 0.488 & 0.500 \\
\hline & IT Budget & 501 & 0 & 10 & 1.229 & 1.242 \\
\hline & Staff & 506 & 3 & 975 & 144.158 & 185.245 \\
\hline
\end{tabular}

Table 10 provides a summary of the nonprofit organizations' motives to use social media platforms. As the table show, all (100\%) agree that social media is used to enhance their mission. All of the technological characteristics are important for why social media is used. The share of respondents indicating "very important" or "important" for the 
technology characteristics is quite high: nearly $95 \%$ for relative advantage, $83.3 \%$ for compatibility with the organization's activities, $87 \%$ for ease of use, and $70.8 \%$ for observability. With respect to environmental factors, social media is used for diversifying funding sources (75\%). With respect to organizational factors, the leadership has a key role to play in using social media (69.5\%). Interestingly, emulating peer practice of using social media was not an important factor according to $75 \%$ of the respondents.

Furthermore, very few (20\%) use social media for generating public awareness.

Table 10 Motivations for Using Social Media

\begin{tabular}{|l|r|r|r|r|r|}
\hline Statement & $\begin{array}{r}\text { Very } \\
\text { important }\end{array}$ & Important & $\begin{array}{r}\text { Mod- } \\
\text { erately } \\
\text { important }\end{array}$ & $\begin{array}{r}\text { Slightly } \\
\text { Important }\end{array}$ & $\begin{array}{c}\text { Not } \\
\text { important }\end{array}$ \\
\hline $\begin{array}{l}\text { Our organization uses social media to } \\
\text { accomplish our mission }\end{array}$ & $33.33 \%$ & $66.67 \%$ & $0.00 \%$ & $0.00 \%$ & $0.00 \%$ \\
\hline $\begin{array}{l}\text { Social media is better than existing } \\
\text { technologies used in our organization }\end{array}$ & $4.17 \%$ & $91.67 \%$ & $4.17 \%$ & $0.00 \%$ & $0.00 \%$ \\
\hline $\begin{array}{l}\text { Our organization uses social media to } \\
\text { conduct our activities }\end{array}$ & $70.83 \%$ & $12.50 \%$ & $8.33 \%$ & $8.33 \%$ & $0.00 \%$ \\
\hline $\begin{array}{l}\text { Social media has been easy to use in } \\
\text { our organization }\end{array}$ & $66.67 \%$ & $20.83 \%$ & $12.50 \%$ & $0.00 \%$ & $0.00 \%$ \\
\hline $\begin{array}{l}\text { Social media use has resulted in } \\
\text { tangible organizational benefits }\end{array}$ & $8.33 \%$ & $62.50 \%$ & $20.83 \%$ & $4.17 \%$ & $4.17 \%$ \\
\hline $\begin{array}{l}\text { Our organization has been using } \\
\text { social media for fundraising purposes }\end{array}$ & $0.00 \%$ & $16.67 \%$ & $70.83 \%$ & $12.50 \%$ & $0.00 \%$ \\
\hline $\begin{array}{l}\text { Our organization has been using } \\
\text { social media to diversify our funding } \\
\text { sources }\end{array}$ & $62.50 \%$ & $12.50 \%$ & $8.33 \%$ & $8.33 \%$ & $8.33 \%$ \\
\hline $\begin{array}{l}\text { Our organization has been using } \\
\text { social media to generate public } \\
\text { awareness }\end{array}$ & $8.33 \%$ & $12.50 \%$ & $66.67 \%$ & $8.33 \%$ & $4.17 \%$ \\
\hline $\begin{array}{l}\text { Our donors required us to use social } \\
\text { media }\end{array}$ & $8.33 \%$ & $8.33 \%$ & $62.50 \%$ & $8.33 \%$ & $12.50 \%$ \\
\hline $\begin{array}{l}\text { Our organization has been using } \\
\text { social media since other nonprofits } \\
\text { have been using it }\end{array}$ & $4.17 \%$ & $8.33 \%$ & $12.50 \%$ & $66.67 \%$ & $8.33 \%$ \\
\hline $\begin{array}{l}\text { Our leadership has championed the } \\
\text { use of social media }\end{array}$ & $4.35 \%$ & $65.22 \%$ & $17.39 \%$ & $4.35 \%$ & $8.70 \%$ \\
\hline
\end{tabular}


Regression analysis is carried out to further test the significance of the technological, environmental, and organizational factors in the adoption of social media. Since the adoption of social media is on an ordinal scale, an ordered logistic regression is employed. The analysis is carried out for both Facebook and Twitter.

\section{The Use of Facebook}

Table 11 summarizes the results of the logistic regression (Model 2a) of Facebook use. The pseudo-R2 is only 0.08 , which indicates that the model is not a good fit to explain the Facebook use. Of the twelve independent variables, only two variables, observability and social media account managers are statistically significant at $5 \%$ levels. Both variables are positively related to the use of Facebook. Frequency of Facebook use increases if the nonprofit organizations experience tangible benefits from the use of the platform. Similarly, social media account managers result in significant increase in the frequency of use of Facebook. The results in Table 11 also shows that a unit increase in observability increases the odds of using Facebook by 1.03 and a unit increase in social media account managers increases the odds of using Facebook by 1.4.

Three control variables are statistically significant at $1 \%$ levels but are negatively associated with the use of Facebook. They are: external consultant, NPO sector and IT budget. The external consultant could reduce the frequency of the use of Facebook. The human service organizations are not as frequent Facebook users as the other nonprofits. The increase in IT budget has reduces the frequency of Facebook use, possibly because social media is not handled by the IT department. In most organizations, the frontline 
workers (secretary/ receptionist) handle the social media accounts. Often, social media is housed with the communications or public relations department.

Table 11 Summary of Logistic Regression, Facebook Use (Model 2a)

\begin{tabular}{|c|c|c|c|c|c|}
\hline & Variable & $B$ & SE & $P$ & Odds ratio \\
\hline \multirow{4}{*}{$\begin{array}{l}\text { Technological } \\
\text { factors }\end{array}$} & Relative Advantage & -0.123 & 0.125 & 0.403 & 0.885 \\
\hline & Compatibility & 0.127 & 0.114 & 0.302 & 1.135 \\
\hline & Ease of use & -0.1 & 0.11 & 0.336 & 0.905 \\
\hline & Observability & 0.264 & 0.127 & 0.038 & 1.302 \\
\hline \multirow{4}{*}{$\begin{array}{l}\text { Environmental } \\
\text { factors }\end{array}$} & Funding Diversity & 0.047 & 0.138 & 0.761 & 1.048 \\
\hline & Public Awareness & -0.076 & 0.113 & 0.575 & 0.927 \\
\hline & Donor Requirement & -0.129 & 0.083 & 0.135 & 0.879 \\
\hline & UW Funding & 0.003 & 0.003 & 0.381 & 1.003 \\
\hline \multirow{4}{*}{$\begin{array}{l}\text { Organizational } \\
\text { factors }\end{array}$} & Fundraising Mechanism & 0.091 & 0.132 & 0.494 & 1.095 \\
\hline & Peer Practice & -0.082 & 0.09 & 0.3 & 0.921 \\
\hline & Leadership & -0.173 & 0.1 & 0.088 & 0.841 \\
\hline & SM Managers & 0.327 & 0.095 & 0.001 & 1.387 \\
\hline \multirow{6}{*}{$\begin{array}{c}\text { Control } \\
\text { variables }\end{array}$} & Revenue (log) & -0.028 & 0.072 & 0.183 & 0.972 \\
\hline & IT Staff & 0.01 & 0.051 & 0.823 & 1.01 \\
\hline & External Consultant & -1.009 & 0.286 & 0 & 0.365 \\
\hline & NPO Sector & -0.819 & 0.203 & 0 & 0.441 \\
\hline & IT Budget & -0.275 & 0.076 & 0 & 0.759 \\
\hline & Staff $(\log )$ & 0.143 & 0.126 & 0.14 & 1.154 \\
\hline & $\mathrm{N}$ & \multicolumn{4}{|c|}{470} \\
\hline & Pseudo R2 & \multicolumn{4}{|c|}{0.08} \\
\hline & Log Likelihood & \multicolumn{4}{|c|}{-349.13} \\
\hline
\end{tabular}




\section{The Use of Twitter}

Table 12 shows the results of logistic regression for Twitter (Model 2b). As the table shows, four of the twelve independent variables are statistically significant for the use of Twitter. One technological variable (observability) is statistically significant at $1 \%$ levels and is positively related to Twitter use. In other words, Twitter use increases with the tangible benefits that the organization experiences. Two external environment variables (public awareness and donor requirement) are statistically significant at $1 \%$ levels. Both variables are negatively associated with the use of Twitter. In other words, increasing Twitter use is less frequent for increasing public awareness, and donor requirements reduce the frequency of Twitter. The results in Table 12 demonstrate that a unit increase in observability increases the odds of using Twitter by 1.9; and a unit increase in public awareness increases the odds of using Twitter by 0.7 . Similarly, a unit increase in donor requirement increases the odds of using Twitter by 0.7 ; and a unit increase in social media account managers increases the odds of using Twitter by 0.8

Two of the six control variables are statistically significant but negatively related to Twitter use. The use of social media specialist and the sector of the nonprofit organization are statistically significant at $1 \%$ levels. The social media specialist could reduce the frequency of the use of Twitter. The human service organizations are not as frequent Twitter users as the other nonprofits. 
Table 12 Summary of Logistic Regression, Twitter Use (Model 2b)

\begin{tabular}{llrrrr}
\hline & Variable & \multicolumn{1}{c}{$B$} & $\mathrm{SE}$ & $P$ & Odds ratio \\
\hline Technological & Relative Advantage & 0.065 & 0.113 & 0.60 & 1.067 \\
factors & Compatibility & 0.077 & 0.105 & 0.47 & 1.08 \\
& Ease of use & -0.1 & 0.099 & 0.35 & 0.905 \\
& Observability & 0.636 & 0.119 & 0.00 & 1.89 \\
\hline Environmental & Funding Diversity & -0.167 & 0.124 & 0.18 & 0.846 \\
factors & Public Awareness & -0.347 & 0.102 & 0.00 & 0.707 \\
& Donor Requirement & -0.305 & 0.077 & 0.00 & 0.737 \\
& UW Funding & -0.003 & 0.003 & 0.29 & 0.997 \\
\hline Organizational & Fundraising Mech. & 0.142 & 0.12 & 0.19 & 1.153 \\
factors & Peer Practice & -0.116 & 0.082 & 0.22 & 0.891 \\
& Leadership & -0.149 & 0.089 & 0.11 & 0.862 \\
& SM Managers & -0.216 & 0.084 & 0.01 & 0.806 \\
\hline Control & Revenue (log) & -0.117 & 0.066 & 0.81 & 0.89 \\
variables & IT Staff & -0.019 & 0.046 & 0.53 & 0.981 \\
& External Consultant & -0.739 & 0.271 & 0.01 & 0.478 \\
& NPO Sector & -0.429 & 0.183 & 0.01 & 0.651 \\
& IT Budget & -0.052 & 0.072 & 0.38 & 0.949 \\
& Staff (log) & -0.048 & 0.118 & 0.52 & 0.954 \\
\hline & & & & & \\
& N & 470 & & & \\
& Pseudo R2 & 0.06 & & & \\
& Log Likelihood & -464.94 & & &
\end{tabular}

\subsection{Summary Analysis of Social Media Adoption and Use}

The regression analysis of social media adoption and use of both Facebook and Twitter yield interesting results. The conceptual framework of diffusion of innovation, resource dependence, and institutional theory highlighted the role of technological characteristics, external environment, and internal organizational factors. However, the regression models for adoption and use of Facebook and Twitter are weak-the R2 and pseudo-R2 values for the multivariate regression and the logistic regression are moderately low. Factors for social media adoption and use could be distinctive from other 
information technology platforms. Unlike other information technology applications, social media does not require significant upfront investment in the technology infrastructure. The acquisition costs are low. However, social media does require Internet savvy personnel.

The regression results are also interesting in terms of the variables that are significant, and those that are not significant. The factors for Facebook and Twitter adoption are similar. Three technological characteristics, namely relative advantage, compatibility and ease of use are statistically significant for adoption of both. Relative advantage and ease of use are positively correlated and compatibility is negatively related with Facebook and Twitter adoption. Interestingly, none of these factors are significant for the social media use. Observability, which is not significant for social media adoption, is significant for social media use. The findings highlight the difference between factors influencing ex-ante decision to adopt social media platform vs ex-post use of social media platforms. Relative advantage, compatibility, and ease of use are important for social media adoption, but once adopted, social media needs to bear tangible results for the nonprofit organizations. Else, nonprofits are unlikely to use the social media platform. With respect to external environmental factors, public awareness is statistically significant with a positive relationship with both Facebook and Twitter adoption. Donor requirement is also significant for social media adoption. Public awareness is not significant for Facebook use, but is so for Twitter use (negatively related). Increasing public awareness is thus a significant factor for social media adoption. Indeed, social media provides a facile mechanism for reaching out to the community, especially among the youth. Nonprofits could also adopt social media as a result of donor requirements. 
Many of the responses to the survey's open-ended question to comment on adoption and use of social media attest to how social media is important tool for information dissemination. The following comments show how the nonprofit organizations view the social media adoption and use. The following comments show that nonprofits use the social media to spread word about their mission, about critical needs of their community, and for education.

- Social media allows for us to reach far more people.

- Despite the hype, it appears that Facebook for advocacy and public awareness has made a greater impact than any other anticipated Social Media benefit.

- Social media is somewhat helpful in developing long term relationships and communication channels about status, events, and fundraising needs, but it is highly dependent upon market awareness to make a bigger difference.

- As our volunteer base becomes younger, social media plays a greater role. It brings awareness to our mission.

The following two quotes highlight how significant social media is in espousing the local needs and increase public awareness of critical community needs.

- It [social media] has been a wonderful way to educate the community about epilepsy. It also helps us connect with those with epilepsy whose mobility is limited since, by law, they need to be seizure free for 6 months before they can drive. Many patients with epilepsy cannot drive and are also socially isolated due to their condition. Social media allows everyone to participate and learn. 
- $\quad$ There are no USO Facilities here in Vero Beach Fl. The local United Way funds $\$ 5000$ here as residents from this area and their families are serving in the Armed Forces worldwide and utilize USO services where they are stationed.

Many respondents also noted the importance of social media for attracting donors and the importance of donor requirements to adopt and use social media.

- Social media is an important tool within our organization that allows us to form relationships with our donors and supporters, and allow them to be a part of our mission in an additional, interactive way. We believe it is the perfect way to be a digital storyteller, and engage both aspiring donors and supporters with our current demographic of donors and supporters.

- We utilize social media as a tool to spread awareness and increase the number of donors to our organization.

- We still continue to have the most amount of interaction and positive feedback from Facebook, since the majority of our followers are donors/volunteers over the age of 30 .

- It is an expectation of funders that you use social media to recognize them and share the outcomes of their investments in your organization.

- We find the use of social medial to be a very easy and effective way of staying current with our marketing and fund development activities.

- Promote Fundraising Events. 
With respect to the internal organizational variables, the number of social media managers within the organization is a consistent factor for both social media adoption and use. The variable signifies the professionalization of social media specialists within the organization. The importance of the professionalization cannot be under-emphasized. Indeed some of the large public, private, and non-profit organizations have an explicit position as a "Social Media Manager" to handle the social media activities. It requires a person who is specialized in communications. External consultants could facilitate the social media adoption and provide the required support, but the regression results show that they could have a negative impact on the use of social media. The significance of the social media managers is also recognized to a limited extent by the nonprofit organizations. Community-based nonprofits may not have the resources for enploying a full time social media specialist. An overwhelming majority of the organizations indicated that the frontline employees (secretary or receptionist) also handles the social media account. Some of them hire interns or make social media a partial responsibility of a full-time employee. Such arrangements could be short term solutions, but are not adequate for a sustained use of social media. As some of them commented in the survey:

- We have a full time person that was hired to run our social media. But that is half her job.

- We had very little social media until this past summer where we won a grant that pays for a social media summer intern. This was the launch of much of our social media efforts.

- There are plans in place to hire a part time social media staff person. 
Moreover, the social media specialists are communications specialists, who are not the same as information technology specialists. They may not be housed within the IT department. As one respondent noted:

- IT doesn't handle our social media - communication does. We are very happy with our continued growth in using social media as a public awareness vehicle.

\section{$\underline{4.6 \text { Conclusion }}$}

The chapter dealt with the adoption and use of social media, specifically Facebook and Twitter platforms, among the United Way affiliated community-based, local nonprofits. Multivariate regression analysis was used for the social media adoption and logistic regression analysis was used for the social media use. The findings yield important insights. The theorized set of technology, environmental, and organizational variables do not explain the adoption and use of social media very well. The forces of social media adoption and use could be distinctive from that of other information technology platforms. Social media does not require upfront hardware and software costs, but do require personnel who are savvy to use the communications platforms.

The innate technological characteristics of relative advantage, compatibility and ease of use are important factors for social media adoption, but not so for use. Observability of tangible gains to the organization is a significant factor for social media use. Among the external factors, social media is an important mechanism for increasing public awareness. Public awareness is a significant factor for nonprofits to adopt and use social media. Within the organization, social media managers are significant for the 
adoption and use. Although external consultants could assist in the adoption process, they may not be as helpful in the social media use. Nonprofit organizations typically have frontline personnel dealing with social media. However, they will benefit more from appointing professional social media managers who can use the platforms for effective communications, including public awareness. 


\section{THE USE OF FACEBOOK}

\section{$\underline{5.1 \text { Introduction }}$}

This chapter deals with the second question of the study: how do nonprofit organizations that have adopted social media use it? The chapter examines the social media use by empirically focusing on how United Way local chapters in Florida actually use Facebook. Whereas Chapter 4 was based on perceptions of survey respondents, this ascertains the reality of how social media is used in reality. The focus is on Facebook use since it is the most common social network platform used by nonprofits. The United Way local chapters provide an expedient way to capture the affiliated nonprofit organizations' Facebook use in Florida. The local chapters generally carry posts related to affiliated nonprofit organizations' posts. These chapters have broader scope of activities than the affiliated nonprofits as well. Hence, examining the United Way local nonprofits provides broader insights into how the community-based nonprofits use social media in Florida.

Qualitative research design is employed to analyze the use of Facebook. There are two steps in this design: content analysis and interviews. For the content analysis, the Facebook pages of the United Way chapters were scraped and then the pages were analyzed for the major themes of use. The volume of Facebook posts of all the chapters were first analyzed for the latest six months period of last year (January 1, 2016 to December 1, 2016). The volume of posts is a good indicator of the extent to which the chapters and their affiliated nonprofits use Facebook. The chapters were then ranked according to high, medium, and low volume of posts. Four chapters from each group (i.e. a total of 12 chapters) were then selected for undertaking the content analysis of the 
posts. The stratified selection process ensured that the chapters selected for the content analysis are representative across all the United Way chapters in terms of intensity of use. Care was also taken to ensure that the chapters are geographically representative (e.g. rural and urban counties, coastal vs inland counties, and counties from the north, south, east, west, and central regions). Content analysis was conducted on the Facebook posts of the twelve selected United Way chapters. The scraping of the twelve chapters gave 1,838 pages of Facebook posts.

NVivo, a qualitative analysis software, was used to conduct the content analysis. In this, the major themes of the posts were identified for how the nonprofit organizations utilize Facebook. The findings of the content analysis was also checked for their credibility, confirmability, and dependability through interviews with officials from the United Way chapters. Four officials were interviewed and two officials gave responses through email. These six officials were from among the selected United Way nonprofits.

\subsection{Types of Facebook Posts}

Posts are central to Facebook platform as a social media platform. A post is an item (text, picture, video, share from another organization, etc.) that an organization puts online on the Facebook platform. The text could be an information update, news, or an announcement; the picture and videos are the visual media. Posting on Facebook is quite simple from any Internet connected device. Consequently, people generally post on the spur moments with status updates. A unique aspect of Facebook as a social media platform is the "Like" feature. The "Like" feature allows one user to indicate his or her liking the organization's Facebook page or the organization's post. Other users can also 
comment on the posts and provide reactions on the posts. The number of likes and

reactions are generally good indicators of the organizations' outreach and engagement

with the stakeholder community.

Table 13. Summary of United Way Facebook posts, July-December 2016

\begin{tabular}{|c|c|c|c|c|c|}
\hline & No. & Name of Organization & Posts & Likes & $\begin{array}{c}\text { Comment } \\
\mathrm{s}\end{array}$ \\
\hline \multirow{14}{*}{ 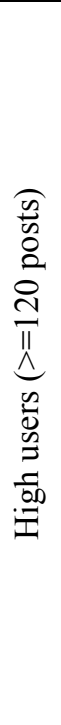 } & 1 & United Way of Central Florida & 324 & 2055 & 2148 \\
\hline & 2 & United Way Suncoast & 306 & 5791 & 6153 \\
\hline & 3 & Heart of Florida United Way & 192 & 885 & 951 \\
\hline & 4 & United Way of Miami-Dade & 169 & 869 & 910 \\
\hline & 5 & United Way of Escambia County & 160 & 1074 & 648 \\
\hline & 6 & United Way of Manatee County & 153 & 1175 & 707 \\
\hline & 7 & United Way of Volusia-Flagler Counties & 151 & 432 & 599 \\
\hline & 8 & United Way of Broward County & 142 & 696 & 925 \\
\hline & 9 & United Way of North Central Florida & 141 & 1603 & 389 \\
\hline & 10 & United Way of Lee, Hendry and Okeechobee Counties & 139 & 740 & 719 \\
\hline & 11 & United Way of Martin County & 135 & 808 & 940 \\
\hline & 12 & United Way of Palm Beach County & 133 & 684 & 609 \\
\hline & 13 & United Way of Pasco County & 131 & 1057 & 1403 \\
\hline & 14 & United Way of Hernando County & 129 & 2264 & 2402 \\
\hline \multirow{12}{*}{ 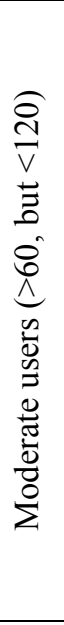 } & 15 & United Way of Northeast Florida & 118 & 2813 & 2983 \\
\hline & 16 & United Way of the Big Bend & 93 & 632 & 649 \\
\hline & 17 & United Way Of Lake \& Sumter Counties & 81 & 640 & 683 \\
\hline & 18 & United Way of Marion County & 80 & 444 & 683 \\
\hline & 19 & The United Way of Charlotte County & 74 & 1825 & 393 \\
\hline & 20 & United Way of Citrus County & 73 & 364 & 643 \\
\hline & 21 & United Way of Collier County & 71 & 251 & 349 \\
\hline & 22 & United Way of Indian River County & 68 & 891 & 1186 \\
\hline & 23 & St. Johns County United Way & 66 & 780 & 249 \\
\hline & 24 & United Way of Brevard & 66 & 449 & 525 \\
\hline & 25 & United Way of Santa Rosa County & 64 & 735 & 291 \\
\hline & 26 & United Way of Okaloosa \& Walton Counties & 63 & 399 & 328 \\
\hline \multirow{5}{*}{ 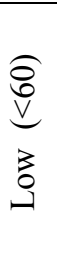 } & 27 & United Way of the Florida Keys & 60 & 1356 & 321 \\
\hline & 28 & United Way of Northwest Florida & 47 & 631 & 662 \\
\hline & 29 & United Way of St. Lucie County & 40 & 135 & 146 \\
\hline & 30 & United Way of Suwannee Valley & 36 & 128 & 128 \\
\hline & 31 & United Way of Putnam County & 22 & 66 & 66 \\
\hline
\end{tabular}


Table 13 presents the volume of Facebook posts, likes, and comments by the 31 United Way chapters over the six month period of the study. The high users have at least one Facebook post during workdays; the moderate users post every other day; and the low users have less than 2 posts per week. The likes and comments of the chapters are statistically related to the volume of posts. Regression analysis shows that one additional post could result in over 10 "likes" (Intercept=-123; R-square=0.44) and in over 11 comments (Intercept $=-345.8$; R-square $=0.47$ ). Facebook posts are thus good ways of engaging stakeholders following the organization's activities.

Table 14. Profile of the selected United Way Chapters

\begin{tabular}{|l|l|l|l|c|}
\hline No & \multicolumn{1}{|c|}{ Name } & \multicolumn{1}{|c|}{ Counties served } & $\begin{array}{c}\text { Location } \\
\text { affiliates }\end{array}$ \\
\hline 1 & $\begin{array}{l}\text { United Way of } \\
\text { Northeast Florida }\end{array}$ & Baker, Duval, Nassau & Jacksonville & 56 \\
\hline 2 & $\begin{array}{l}\text { United Way of } \\
\text { Northwest Florida }\end{array}$ & $\begin{array}{l}\text { Bay, Calhoun, Gulf, Holmes, Jackson, } \\
\text { Washington }\end{array}$ & Panama City & 45 \\
\hline 3 & $\begin{array}{l}\text { United Way of } \\
\text { Suwannee Valley }\end{array}$ & Columbia, Clay, Suwannee, Hamilton & Lake City & 24 \\
\hline 4 & $\begin{array}{l}\text { United Way of The } \\
\text { BigBend }\end{array}$ & $\begin{array}{l}\text { Franklin, Gadsden, Jefferson, Lafayette, } \\
\text { Leon, Liberty, Wakulla, Taylor, Madison }\end{array}$ & Tallahassee & 42 \\
\hline 5 & $\begin{array}{l}\text { United Way of } \\
\text { Central Florida }\end{array}$ & Hardee, Polk, Highlands & $\begin{array}{l}\text { Highland } \\
\text { City }\end{array}$ & 81 \\
\hline 6 & $\begin{array}{l}\text { United Way of } \\
\text { Hernando County }\end{array}$ & Hernando & Spring Hill & 30 \\
\hline 7 & $\begin{array}{l}\text { United Way of Lake } \\
\& \text { Sumter Counties }\end{array}$ & Lake, Sumter & Leesburg & 20 \\
\hline 8 & $\begin{array}{l}\text { United Way of } \\
\text { Miami-Dade }\end{array}$ & Miami-Dade & Miami & 163 \\
\hline 9 & $\begin{array}{l}\text { Heart of Florida } \\
\text { United Way }\end{array}$ & Orange, Osceola, Seminole & Orlando & 59 \\
\hline 10 & $\begin{array}{l}\text { United Way of } \\
\text { Putnam County }\end{array}$ & Putnam & Palatka & 23 \\
\hline 11 & $\begin{array}{l}\text { United Way of } \\
\text { Suncoast }\end{array}$ & Sarasosa, DeSoto, Hillsborough, Pinellas & Tampa & 84 \\
\hline 12 & $\begin{array}{l}\text { United Way of St. } \\
\text { Lucie County }\end{array}$ & St. Lucie & Fort Pierce & 31 \\
\hline
\end{tabular}


As mentioned before, twelve United Way Chapters were selected from the 31 for deeper investigation of Facebook use. The twelve organizations are composed of four high, four moderate, and four low intensity users of Facebook. These organizations are geographically distributed through the state. The high, moderate, and low users are also spread across the state, and are not concentrated in urban or rural areas. Their location, the counties served and the number of affiliated nonprofits are provided in Table 14. As the table shows, each chapter could serve one or more counties.

The volume of the posts was further analyzed for the selected twelve United Way chapters. The posts could be announcements of events, links, photos, status updates, and videos. Table 15 below summarizes the types of Facebook posts of the selected United Way chapters during the six month period of study. As the table shows, photos are the most common posts across the spectrum of the United Way chapters. Over half of the posts of most nonprofit organizations are the pictures. The pictures are mainly of various events, activities, people, and other aspects of the chapters. The pictures give a powerful visual medium of what the organization has achieved and is a good promotion and attestation for the organization's mission related activities. Links are the next category of popular posts across the United Way chapters. The links give a visual cue to details of the activities. Events and status updates are common only for those United Way chapters that are high users of the Facebook; these are not as common among the moderate and low users of Facebook. Interestingly, videos do not form a significant share of posts for any of the users. 
Table 15. Summary of Type of Posts (July 2016 to December 2016)

\begin{tabular}{clrrrrrr}
\hline No. & Name of Organization & Events & Links & Photo & Status & Video & Total \\
\hline 1 & United Way of Central Florida & 34 & 113 & 121 & 53 & 3 & 324 \\
\hline 4 & United Way of Miami-Dade & 38 & 116 & 150 & 2 & 306 \\
\hline 3 & Heart of Florida United Way & 0 & 95 & 63 & 34 & 192 \\
\hline 2 & United Way Suncoast & 28 & 17 & 96 & 26 & 2 & 169 \\
\hline 6 & United Way of Northeast Florida & 1 & 50 & 78 & 0 & 129 \\
\hline 8 & United Way Of Lake \& Sumter Counties & 0 & 9 & 108 & 1 & 118 \\
\hline 5 & United Way of Hernando County & 2 & 4 & 83 & 4 & 93 \\
\hline 7 & United Way of the Big Bend & 2 & 18 & 58 & 3 & 81 \\
\hline 10 & United Way of St. Lucie County & 2 & 3 & 42 & 0 & 47 \\
\hline 9 & United Way of Northwest Florida & 9 & 3 & 24 & 3 & 1 \\
\hline 11 & United Way of Suwannee Valley & 0 & 12 & 15 & 9 & 40 \\
\hline 12 & United Way of Putnam County & 2 & 2 & 12 & 6 & 36 \\
\hline
\end{tabular}

\section{$\underline{5.3 \text { Themes of Facebook posts }}$}

Scraping the Facebook pages of the twelve United Way chapters for July to December 2016 period yielded 1,838 pages of posts. Content analysis was then conducted on the posts, in order to identify the major themes of Facebook use. Word frequency provides a basic starting point and general overview of the major thematic emphases in the content analysis. The word cloud depicts the word frequency in a graphical form. Figure 5 gives the word cloud for the 12 United Way chapters' Facebook posts. The major word frequencies such as United, comment, Florida, and Facebook are not quite surprising since they form the context of the textual analysis. Beyond the common names, the important signifier is the community. As we shall see soon with more nuanced content analysis, the Facebook posts indeed emphasize the community in different ways — community building, community support, collaboration, and partnership. The Facebook posts also emphasize the United Way's three core focus area of education, 
income (indirectly indicated as financial), and health. Children, families, and schools are important objects of assistance for United Way. Charity and helping are also reflected in the word cloud.

Figure 5 Word Frequency Query of Facebook Posts

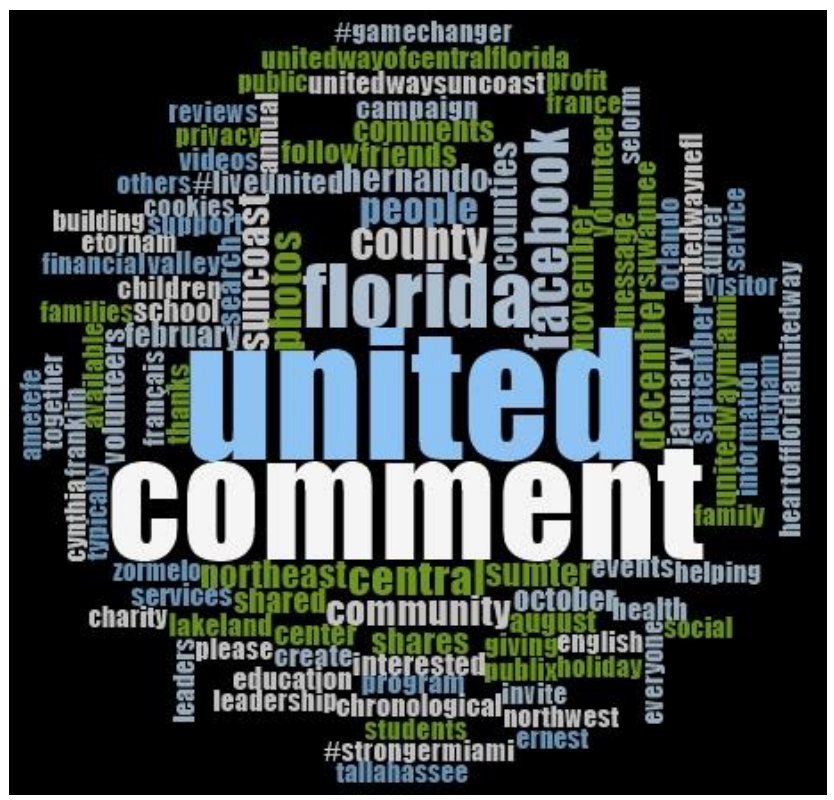

In order to identify the major themes, the Facebook's posts were coded for their major thematic emphasis. In this, the posts were coded using NVivo 11, assigning each post a node. Each post was given one primary code initially. In cases where a post crossed over two or more codes, the posts were also assigned secondary codes. The coding revealed three main categories of Facebook posts. They are: collaboration, dialogue and community engagement, and promotion of events. The first theme, collaboration, refers to partnership between the United Way chapter and other private, public, and nonprofit organizations in the area. The collaboration is mainly to undertake community projects and events jointly. The second category, dialogue, and community 
engagement, highlights Facebook use for community engagement through dialogue and interaction to educate the public on various activities.

Table 16. Themes of Facebook Posts

\begin{tabular}{|c|c|c|c|}
\hline Post Content Type & Description & Frequency & Share \\
\hline Collaborative Activities & $\begin{array}{l}\text { The post shares information about } \\
\text { collaboration with other } \\
\text { organizations }\end{array}$ & 369 & $18.61 \%$ \\
\hline $\begin{array}{l}\text { Collaborations with Public } \\
\text { Organizations }\end{array}$ & $\begin{array}{l}\text { The post shares information about } \\
\text { collaboration with Public Sector } \\
\text { Organization }\end{array}$ & 69 & $3.48 \%$ \\
\hline $\begin{array}{l}\text { Collaborations with Private } \\
\text { Organizations }\end{array}$ & $\begin{array}{l}\text { The post shares information about } \\
\text { collaboration with Private Sector } \\
\text { Organization }\end{array}$ & 223 & $11.25 \%$ \\
\hline $\begin{array}{l}\text { Collaborations with Nonprofit } \\
\text { Organizations }\end{array}$ & $\begin{array}{l}\text { The post shares information about } \\
\text { collaboration with Nonprofit Sector } \\
\text { Organization }\end{array}$ & 77 & $3.88 \%$ \\
\hline $\begin{array}{l}\text { Dialogue and Community } \\
\text { Building }\end{array}$ & $\begin{array}{l}\text { The post shares information or } \\
\text { deliver information to the } \\
\text { community }\end{array}$ & 328 & $16.54 \%$ \\
\hline $\begin{array}{l}\text { Recognizing Community } \\
\text { Supporters }\end{array}$ & $\begin{array}{l}\text { The post acknowledge the recognition } \\
\text { of philanthropists for their support to } \\
\text { the community }\end{array}$ & 321 & $16.19 \%$ \\
\hline Response Solicitation & $\begin{array}{l}\text { The post asks for information and seek } \\
\text { public response }\end{array}$ & 7 & $0.35 \%$ \\
\hline Promote Events & $\begin{array}{l}\text { The posts shares information about a } \\
\text { past, current and future events and } \\
\text { seek community participation }\end{array}$ & 1286 & $64.85 \%$ \\
\hline Campaign Activities & $\begin{array}{l}\text { The post shares information about } \\
\text { campaign for event that jointly } \\
\text { organized by the nonprofit with } \\
\text { collaboration with other organizations }\end{array}$ & 851 & $42.91 \%$ \\
\hline Charitable Activities & $\begin{array}{l}\text { The post shares information on their } \\
\text { support for a cause the calls on the } \\
\text { community to support }\end{array}$ & 47 & $2.37 \%$ \\
\hline Fundraising Activities & $\begin{array}{l}\text { The post seek support in the form of } \\
\text { funding for a special cause that will } \\
\text { help the community }\end{array}$ & 290 & $14.62 \%$ \\
\hline Public Interest & $\begin{array}{l}\text { The post shares information that seeks } \\
\text { to inform the public about a specific } \\
\text { issue on behalf of other organizations }\end{array}$ & 23 & $1.16 \%$ \\
\hline Volunteer recruitment & $\begin{array}{l}\text { The post asks for volunteers support for } \\
\text { a specific program }\end{array}$ & 75 & $3.78 \%$ \\
\hline & Total & 1,983 & $100 \%$ \\
\hline
\end{tabular}


The third category is the promotion of events which involves information on events, including past, present and future events that are useful to the community. These events directly have some community benefits, and followers are encouraged to take part in these events. The posts are meant to encourage active participation of the community in various activities organized by the nonprofit organization as well as other external bodies that will benefit the community. The themes are summarized in Table 16. As the table shows, the promotion of events forms the largest number of themes: of the total 1,983 posts, 1,286 (or about $65 \%$ ) posts were promotion of events. Collaboration is the second category, with about 369 posts (about 19\%). Dialogue and community engagement posts are the third, with 328 posts (about 16\%). Each of the major themes are explored further in the following sections.

\section{$\underline{5.4 \text { Collaborative Activities }}$}

United Way chapters' posts on collaboration share information about how they collaborate with other organizations from the public, private, and the nonprofit sectors. Collaborative messages show how the United Way chapters team up with organizations from other sectors to reach their target of providing essential services to the communities they serve. The United Way chapters typically partner with the local public and private donors to raise funding for the nonprofits. The chapters deliver the services related to their focus areas of education, income, and health through affiliated nonprofit organizations.

Table 17 presents the overall collaborative activities of the twelve selected chapters. Most of the posts about collaboration are with the private sector-223 out of 
369 (about 60\%) are such collaborations. Public and nonprofit collaborations are approximately similar, accounting for about $20 \%$ of the collaborative posts. The pattern persists across all twelve United Way chapters. The high, moderate, and low intensity users of Facebook have similar types of posts that emphasize collaboration with private sector. The three types of collaborations in the posts are further explored below.

Table 17. Collaboration by United Way Chapters

\begin{tabular}{clrrrrr}
\hline No & Name of Organization & $\begin{array}{c}\text { Public } \\
\text { Sector }\end{array}$ & $\begin{array}{c}\text { Private } \\
\text { Sector }\end{array}$ & $\begin{array}{c}\text { Nonprofit } \\
\text { Sector }\end{array}$ & Total & $\%$ \\
\hline 1 & United Way of Central Florida & 12 & 28 & 10 & 50 & 13.55 \\
\hline 2 & United Way of Miami-Dade & 15 & 52 & 11 & 78 & 21.14 \\
\hline 3 & Heart of Florida United Way & 7 & 21 & 6 & 34 & 9.21 \\
\hline 4 & United Way Suncoast & 2 & 16 & 7 & 25 & 6.78 \\
\hline 5 & United Way of Northeast Florida & 1 & 6 & 8 & 15 & 4.07 \\
\hline 6 & United Way Of Lake \& Sumter Counties & 1 & 11 & 6 & 18 & 4.88 \\
\hline 7 & United Way of Hernando County & 3 & 28 & 7 & 38 & 10.30 \\
\hline 8 & United Way of the Big Bend & 6 & 7 & 3 & 16 & 4.34 \\
\hline 9 & United Way of St. Lucie County & 1 & 13 & 5 & 19 & 5.15 \\
\hline 10 & United Way of Northwest Florida & 2 & 3 & 2 & 7 & 1.90 \\
\hline 11 & United Way of Suwannee Valley & 1 & 5 & 3 & 9 & 2.44 \\
\hline 12 & United Way of Putnam County & 69 & 223 & 77 & 369 & 100 \\
\hline & Total & & & & 60 & 16.26 \\
\hline
\end{tabular}

\section{Public Sector Collaboration}

Public sector collaboration covers posts pertaining information about the organization's activities that highlights its relationship with public sector organizations within its jurisdiction. Posts in this subcategory highlight the various levels of partnership with state agencies, public schools (elementary and colleges) and county offices. Among the key public collaborative partners are the county sheriff's office, the mayor's office, and elementary schools. The United Way chapters teamed up with these government 
institutions and agencies to organize programs, including early learning programs for kids, after-school care for parents who cannot afford after-school care for their children, mobilize donations from and for the community, and drive partnership for local schools. Many of the posts demonstrate a high level of collaboration with the county and city governments. The relations extend to employees of these agencies. These posts show the importance attached to the collaborations that the nonprofits have with the public sector agencies. The following post shows the relationship between the nonprofit and the top echelons of public sector agencies and departments.

\author{
Make sure to tune back here tomorrow at 11 am as Orange County Mayor \\ Teresa Jacobs and City of Orlando - Your City Government Commissioner Jim \\ Gray present Robert H. (Bob) Brown with National Philanthropy Day \\ proclamations from Orange County and the City of Orlando.
}

Posts in this category also demonstrate the financial partnership with public sector organizations. The posts cement the financial relationship by publicly recognizing the partnerships and the financial contributions. The post below is an illustration of how county employees support nonprofit activities within their counties.

Orange County, Florida employees proudly contributed $\$ 574,854$ to the Heart of Florida United Way this year through fundraising efforts and donations.

The posts also show the direct involvement of top County and City governments in many of the core activities of nonprofits. For example, the post below shows how both city and county governments have joined hands with the nonprofits to support the nonprofit organization undertake one of its core mission for the community. 
Orange County Government and City of Orlando - Your City Government are partnering with Heart of Florida United Way to manage the Orlando United Assistance Center...

\section{Private Sector Collaboration}

The majority of the collaborative posts are related to the private sector. Private sector partnership covers posts containing information on the organization's activities that highlights its relationship with the private sector entities. Posts in this subcategory highlight the supports nonprofits receive from local privately owned companies and institutions in both cash and kind. The private entities help the United Way chapters in conducting targeted events or raise general funding to support United Way activities. The following posts that recognizes the private donors for their help with supporting efforts for senior citizens.

- What an amazing start to our day! We were able to visit 27 home bound seniors throughout Lake County to bring gifts, caroling, and Christmas Cheer. Thank you, Publix, LovExtension, Boys \& Girls of Lake \& Sumter Counties, and Midway Church for making this happen.

- Dr Alan Holden received a grant for United Way Of Lake \& Sumter Counties from Bank of America to feed our homebound seniors. Thank you Bank of America!

Many of the Facebook posts related to private sector collaboration are oriented toward recognizing the private company's corporate gifts and donations. Large companies that have national or state-wide branches often support the United Way 
activities and donate to the chapters across the state. For example, Publix Super Market, one of the chain grocery stores in Florida, has a good relationship with almost all the twelve United Way chapters. Publix has been one of the major donors for United Way in Florida. Social media provides a way to recognize the contribution of major donors like Publix publicly, as the following Facebook post shows:

UWCF collaborates with businesses, local government, school districts and effective social service programs to provide services for the community. Every Tuesday, we want to thank one of those groups for our new \#Top50Tuesday. Today we are starting at the top of our list with Publix Super Markets. Last year alone, Publix donated \$4,539,258. Thank you for your amazing support! \#PowerOfU \#LiveUnited.

Facebook posts also show how large banks like Bank of America support local United Way chapters with cash donations as well as donations of miscellaneous items for the promotion of reading in elementary schools. The following posts illustrate the funding support from Bank of America.

- Extending gratitude to our partners at Bank of America for their generous corporate gift to our Annual Fundraising Campaign. Representatives from the bank pictured presenting a check to our Director of Communications \& Workplace Giving, Roxanne Wells."

- David Hulse, Bank of America, Market President, Bobby Dick, Senior vice president, Merrill Lynch, and Certified Financial Planner, Brady Squires, present \$15,000 grant check to UWBB President 
The support that private companies give to United Way often go beyond cash donations. The support includes volunteering at events organized by the nonprofits and donation of toys and other accessories to kids as a way to support donation drives organized by the nonprofit organization. For example, the four posts below show the level of support and collaboration between Publix Super Market and the United Way chapters:

- United Way Of Lake \& Sumter Counties caught Publix employees caroling!

- Always great to sit down with Todd Jones, Pres \& CEO of Publix. Very appreciative of his, Publix's and all their associates' continued support of United Way of Central Florida and United Ways throughout southeastern United States. \#PowerOfU \#LiveUnited

- Everyone had a great time at Publix Day of Mentoring with Big Brothers Big Sisters. Kelly Williams Puccio began the day reading "The Giving Tree." There were many activities for the kids and a great time was had by all! Thank you to all the volunteers for making the day a big success! \#PowerOfU \#LiveUnited

Employees of other organizations ranging from the banks to aviation industry also spend their time volunteering to help the cause of the United Way. They may also donate miscellaneous items in the form of toys, books, and clothes to nonprofits as part of special programs organized by the nonprofit organizations. The post below illustrates the partnership with Lockheed Martin, an aviation firm. 
Shout out to Lockheed Martin who had over 1,500 volunteers last weekend for their \#DayofCaring! They worked hard beautifying the Orlando VA Medical Center for Central Florida veterans.

\section{Nonprofit Sector Collaboration}

The Facebook posts with respect to the nonprofit sector collaboration highlight the United Way chapters' relationship with their affiliated nonprofit organizations. The nonprofit affiliates are key partners for the United Way chapters to carry out the local activities. The United Way chapter funds the local nonprofits in the core areas of the United Way's mission area. The Facebook posts highlight how nonprofits reach out to peer organizations to conduct programs and activities with the aim of helping the community to overcome their challenges.

The Facebook posts on the chapters' programs and activities aim to raise public awareness as well as generate revenue through fundraising for the community. For example, the post below shows how several organizations from the three sectors teamed up to assist Lake Alfred community for the provision of educational assistance, financial coaching, health services and safety net services. Six organizations came together to support the program. Over 230 citizens of Lake Alfred benefited from the program.

The Power of CommUNITY: Close up on Lake Alfred, Florida United Way of Central Florida has teamed up with organizations like the Early Learning Coalition of Polk County, Catholic Charities of Central Florida and more to serve members of the Lake Alfred community. Thanks to our community partnerships, we've helped provide educational assistance, financial coaching, 
health services and safety net services that aided 231 Lake Alfred citizens last year. Thank you to everyone who donates to UWCF for helping make Lake Alfred a better place. \#PowerOfU \#LiveUnited United Way of Central Florida @unitedwayofcentralflorida

The Facebook posts show that the United Way chapters tap on nonprofit partnerships to provide such services as support for after school children's activities, health-related interventions, and poverty reduction programs. Social media enables the nonprofit organizations to form virtual networks and collaborate with each other, even if the employees have not had face to face contact. Social media helps United Way chapters to bring forth the critical community issues and seek partnerships to address the critical issues.

\subsection{Dialogue and Community Building}

Extant literature shows how social media can be used for dialogue and community building (Rybalko and Seltzer, 2010). The literature on the use of Facebook and Twitter shows that nonprofit organizations use social media to engage citizens in dialogic communications, advocacy and connect with donors for a financial relationship (Lovejoy and Saxton, 2012; Waters et al., 2009). The use of social media to communicate and engage communities is on the rise, particularly, to garner support for mission-related programs and to engage communities in times of catastrophic events (Lovejoy and Saxton, 2012). Facebook facilitates the creation of online dialogue and builds community forum with followers. Social media enables nonprofits to build stronger ties with communities and donors (Guo and Saxton, 2010; Miller, 2002; Vishwanath and 
Goldhaber, 2003; Obar et al., 2012). The dialogue and community building posts show direct and interactive conversations between organizations, followers and the community as a whole (Kent et al., 2003).

Lovejoy and Saxton (2012) found that social media is used for two types of dialogue and community building. The first type is recognition, and thanksgiving wherein the organization recognizes or appreciates individual or organizational support during previous events. It contributes to the community building function of social media. The second type is response solicitation, wherein the organization seeks public response to a query or an issue. Such social media use contributes to dialogic communication within the online community.

The content analysis of the United Way chapter's Facebook posts also reveal the above two types of dialogue and community building. However, the posts are mainly oriented toward community building through recognition and thanksgiving, rather than dialogic communications. Table 18 provides the breakdown of the two types of dialogue and community building for the twelve nonprofits. As the table shows, 321 out of the 328 (or about $98 \%$ ) posts are related to recognition and thanksgiving. A very small percentage is related to dialogic communications. The social media use for dialogic communication is limited to those United Way chapters that are high users of Facebook.

\section{Recognition and Thanksgiving}

Nonprofits, by law, are prohibited from engaging in profit-making activities. They have to rely on the goodwill of charitable donations from individuals, corporate donors, and government agencies in order to fund their operations, to pay their employees, and to 
pay the overhead administrative costs (Olson, 2000; Schmid et al., 2008; Wang and Graddy, 2008; Yeon, Choi and Kiousis, 2007). Community-based nonprofits need to maintain long term relationships with their community supporters to fulfill their mission and to deliver their services. United Way chapters need to nurture the relationships.

Table 18. Dialogue and Community Building by United Way Chapters

\begin{tabular}{clcccc}
\hline No & Name of Organization & $\begin{array}{c}\text { Recognition \& } \\
\text { Thanksgiving }\end{array}$ & $\begin{array}{c}\text { Response } \\
\text { Solicitation }\end{array}$ & Total & \% \\
\hline 1 & United Way of Central Florida & 58 & 3 & 61 & 18.60 \\
\hline 2 & United Way of Miami-Dade & 67 & 2 & 69 & 21.04 \\
\hline 3 & Heart of Florida United Way & 31 & 1 & 32 & 9.76 \\
\hline 4 & United Way Suncoast & 6 & & 6 & 1.83 \\
\hline 5 & United Way of Northeast Florida & 19 & & 19 & 5.79 \\
\hline 6 & United Way Of Lake \& Sumter Counties & 25 & & 25 & 7.62 \\
\hline 7 & United Way of Hernando County & 16 & & 16 & 4.88 \\
\hline 8 & United Way of the Big Bend & 30 & & 30 & 9.15 \\
\hline 9 & United Way of St. Lucie County & 18 & 18 & 5.49 \\
\hline 10 & United Way of Northwest Florida & 22 & & 23 & 7.01 \\
\hline 11 & United Way of Suwannee Valley & 14 & & 14 & 4.27 \\
\hline 12 & United Way of Putnam County & 15 & & 15 & 4.57 \\
\hline & Total & 321 & 7 & 328 & 100 \\
\hline
\end{tabular}

Acknowledgment, recognition, and show of appreciation are essential ingredients of building stronger ties and motivating people. It is a token of gratitude as well as a reminder of good work. It is important for nonprofits to recognize and render sincere thanks to supporters, community partners, donors, and volunteers during fundraising, volunteering and donation drives. The recognition and the gratitude build long-term relationships. Nonprofits use social media to acknowledge publicly the hard work of followers, partners and volunteers through recognition and thanksgiving. The United Way chapters also use Facebook primarily for this purpose. 
Posts and messages in this category account for $16.19 \%$ of the total dataset. The posts below illustrate how nonprofit organizations use social media to acknowledge and thank the supporters, donors, and volunteers to reinforce the positive commitment from stakeholders. The following United Way of Miami-Dade chapter's post publicly acknowledges the commitment of local agencies towards its \#StrongerMiami campaign.

During peak fundraising campaign season, United Way borrows the best and brightest employees from corporate and public partners for the Loaned Executive Program. These Loaned Executives lend their expertise and energy, working side-by-side and hand-in-hand with United Way employees during the busiest time of year. Building a \#StrongerMiami is impossible without you all. United Way of Miami-Dade @UnitedWayMiami Thank you Miami-Dade County Department of Transportation and Public Works, Miami-Dade Police Department, Miami-Dade County, Fla., Ricardi Properties, Miami-Dade Public Library System, Miami Dade County Animal Services, Publix and FPL Connect.

The following United Way of Central Florida's post provides a general acknowledgement to all voluntary donations and highlights the scale of impact of the donations on human lives.

The Power of CommUNITY: Close up in Avon Park, Florida United Way of Central is committed to improving lives in Polk, Highlands, and Hardee counties. UWCF partners with local agencies to target the specific needs of citizens in EVERY community. In Avon Park alone, UWCF has touched the 
lives of 1,735 individuals, including 970 people who now have the health services they need to live a long life. Thank you to everyone who donates to UWCF for helping make Avon Park a better place. \#LiveUnited.

The following post explicitly expresses gratitude for a large donation from private individuals.

For David and Linda Stein, giving back is more than making a donation; it's being active agents for change in the community they serve and inspiring others to do the same. United Way is privileged to have the opportunity to continue the Steins' philanthropic legacy thanks to their generous $\$ 2$ million dollar legacy gift.

The above Facebook posts reiterate the appreciation and thanksgiving to collaborators across the three sectors (public, private, and nonprofit) in support of the United Way chapter's programs and activities. They mark appreciation of expertise from public agencies and other nonprofit organizations in the provision of services to the communities. They reinforce the value of giving, support and commitment to the communities. Public acknowledgment contributes to long term relationships with organizations and individuals who can contribute beneficially for local development activities.

\section{Response Solicitation}

Response solicitation is one of the ways for the United Way chapters to engage in dialogic communication in order to improve customer relationship. It provides the stakeholders and other community members a voice and promotes cohesion between the 
organization, the community, and followers. Extant literature on the use of social media is inconclusive on whether or not social media is effective for two-way communication (Briones et al., 2011; Ellison et al., 2007; Java et al., 2007; Waters, 2007; Waters et al., 2009).

This study also highlights how social media is used in a limited way for two-way dialogic communication. Only $2 \%$ of the Facebook posts related to such dialogic communications, seeking interaction with the community members. Such Facebook posts could be of two types. First, the Facebook posts could ask the community members for feedback on programs, survey the community residents, or be a part of the visioning process of the nonprofit. In this, the United Way chapter could seek the views, opinions, advice, or any form of feedback from the social media followers. The following post, for example, asked for comments about a specific United Way program.

\section{Comments wanted: Share what you think about the Imagination Library program.}

Such comments could contribute to the larger objective of the United Way's justification to continue (or not) about the program. Critical comments could indeed negatively affect the program. As Facebook is an open platform, the organization (United Way chapter) does not have control over what kinds of comments or responses it will get. Of course, in certain instances, the organization can delete the comments it deems critical or close down obtaining additional comments after a period.

Second, the Facebook posts could be used to mobilize the community around a local topic of interest. Such form of response solicitation enables conversation between 
the United Way and the other social media users, leading to asking direct questions to fans and followers also asking direct questions for an answer. In some instances, the community mobilization could lead to debates about specific programs. More often, however, the community mobilization is a call to action, requesting community members to participate in an event, campaign, or other activity. The following post exemplifies such kind of response solicitation.

This year is the 25th anniversary of Day of Caring, the largest one-day volunteer project in Central Florida. If your non-profit is a partner agency and would like to be a part of it and host a project, please complete this form: https://secure.hfuw.org/epledge/comm/SurveyNE.jsp...

\section{$\underline{5.6 \text { Promotion of Events }}$}

As a freely available medium for reaching out to a potentially large audience asynchronously, social media is a site for free advertisement to attract a large contingency to the events. Promoting events through social media incurs much less costs than advertising through print and electronic media. In the digital age when many of the millennials and the younger generation are attuned to social media, the platforms offer the opportunity for organizations to get their messages to the new generation of clients, followers, and potential customers who are active on social media. Many organizations rely on various social media platforms to promote products and services. Promotion of events serves the purpose of free advertisement as well as mobilizing the community members on social media. As the most commonly used platform, Facebook is one of the 
effective platforms to promote events and advertise activities. Hence, it is not surprising that promotion of events accounts nearly two-thirds of the United Way's Facebook posts.

The United Way's promotion of events can be categorized into five classes. They are promotion of: campaigns, charitable events, fundraising events, public interest events, and volunteer recruitment events. In promotion of campaigns, United Way uses Facebook posts to promote joint campaign activities organized with partner agencies. The majority of these partners operated outside the jurisdiction of the United Way. Charitable events promotion consists of the promotion of programs and activities in which the nonprofit organization supports the community and individuals by donating equipment, money and miscellaneous items as the means to improve conditions of community and individuals. In other words, these are events undertaken by the United Way chapter. Fundraising events are means by which nonprofits appeal to both individuals and organizations for financial support and other forms of special support towards earmarked programs. These events are not campaigns to increase donor contributions, but to get funding for specific program. Facebook posts of public interest events are the promotion of events organized by partner agencies that seek to inform the public on health and other community related issues such as jobs and disaster mitigation. Facebook posts for volunteer recruitment seek to recruit volunteers to donate their time towards accomplishing specific goals that support community events.

The large part of United Way's Facebook posts are related to event promotions. Table 19 summarizes how United Way chapters use Facebook posts in each of the five categories. As the table shows. most Facebook posts were for promoting campaign events (almost two-thirds of the Facebook posts are for such events). The next highest category 
of use is fundraising, which accounts for nearly $22.5 \%$ of the posts. Promotions for charitable, public interest, and voluntary events form a small percentage of the overall Facebook posts. Whereas campaign and fundraising posts are common across all twelve United Way chapters, the other posts on charity, public interest, and volunteer are mostly pronounced among the high intensity users of Facebook.

Table 19. Promotion of Events by United Way Chapters

\begin{tabular}{clcccccc}
\hline No & Name of Organization & $\begin{array}{c}\text { Camp } \\
\text { aign }\end{array}$ & $\begin{array}{c}\text { Cha- } \\
\text { rity }\end{array}$ & $\begin{array}{c}\text { Fund- } \\
\text { raising }\end{array}$ & $\begin{array}{c}\text { Public } \\
\text { Interest }\end{array}$ & $\begin{array}{c}\text { Volu } \\
\text { nteer }\end{array}$ & Total \\
\hline 1 & United Way of Central Florida & 189 & 21 & 40 & 2 & 16 & 268 \\
\hline 2 & United Way of Miami-Dade & 229 & 9 & 66 & 8 & 27 & 339 \\
\hline 3 & Heart of Florida United Way & 76 & 4 & 38 & 3 & 7 & 128 \\
\hline 4 & United Way Suncoast & 83 & 2 & 47 & 1 & 9 & 142 \\
\hline 5 & United Way of Northeast Florida & 44 & 3 & 13 & 2 & 2 & 64 \\
\hline 6 & United Way Of Lake \& Sumter Counties & 29 & 1 & 11 & 0 & 2 & 43 \\
\hline 7 & United Way of Hernando County & 35 & 1 & 22 & 0 & 0 & 58 \\
\hline 8 & United Way of the Big Bend & 55 & 2 & 16 & 5 & 1 & 79 \\
\hline 9 & United Way of St. Lucie County & 32 & 2 & 18 & 0 & 3 & 55 \\
\hline 10 & United Way of Northwest Florida & 28 & 1 & 12 & 2 & 5 & 48 \\
\hline 11 & United Way of Suwannee Valley & 31 & 1 & 2 & 0 & 3 & 37 \\
\hline 12 & United Way of Putnam County & 20 & 0 & 5 & 0 & 0 & 25 \\
\hline & Total & 851 & 47 & 290 & 23 & 75 & 1286 \\
\hline
\end{tabular}

\section{External Campaign Events}

United Way chapters use Facebook for external campaign events extensively. The external events are mostly collaborative activities between the United Way and partner agencies. It takes the form of joint activity to improve conditions of people, address some societal problem or support individuals in need. Activities in this category also include programs and activities organized by external agencies. These agencies are mostly forprofit and public sector organizations that want to undertake some corporate social 
responsibility events. The United Way chapters offer logistical support for the events, wherein they prepare the venue, advertise the programs, and increase participation in the programs. Partner agencies bring their expertise, human resources, and funding to support the program. The benefit for the United Way chapter is that the partner organizations, in the end, make some commitment, donations, and support to the chapter for their active participation in the program. The Facebook posts emphasize the benefits of the joint programs for the community. For example, the following posts promote a program provided by a partner organization:

- On National Child Health Day and every day, the Help Me Grow program is here to help support parents with behavior or development concerns about their children. Dial 2-1-1 to learn more or visit: www.hfuw.org/health/helpme-grow

- Being a baby is stressful, so treat your newborn with one of our infant massage classes. The next class is scheduled for next Thursday with much more planned for next year. Click below to sign up for the \#FREE class! \#LiveUnited.

\section{Fundraising Events}

Fundraising is one of the core activities of nonprofit organizations as they rely on donations and grants from government and private philanthropies to support activities. The United Way chapters use the Facebook posts to host and publicize the fundraising events. The posts and messages in this category directly request followers and the public to make a donation to the nonprofit organization. To encourage potential and new donors, the nonprofits highlight the charity of previous donors to attract more donors. Nonprofits post pictures of past donors who have given to the organization, acknowledging the good 
work of notable individuals and ask others to join former donors to support the cause of the United Way chapter. Some of the messages also highlight the tax benefits of the donations. Messages in this category also include product sales with cash or percentage of sale bonuses. These bonuses incentivize consumers to purchase products with some additional benefits; the United Way gains by getting a portion of the proceeds as donation. The following posts illustrate fundraising drives and incentives to donate.

- Last call! TODAY is the last day to drop off your donations for the Basics for Babies supply drive. Little Eva just brought in her donation! www.hfuw.org/basicsforbabies.

- Become a monthly donor to show your support and you'll be entered for a chance to win a $\$ 100$ Amazon Gift Card. Anyone who confirms a monthly donation is automatically entered to win. Donate today!

- It's that time of year for eggnog, ugly holiday sweaters, and charitable giving! United Way encourages you to carefully decide where you invest your hard earned dollars this \#HolidaySeason. Know the facts! Click the link below for a Guide to Giving - Myths \& Facts.

- This is it everyone! It is the final day of the \#12DaysofGiving and we are in the running for the $\$ 5000$ Grand Prize. Please make a donation today to help create a huge impact for our organization and send us into the new year with a bang! 


\section{Volunteer Recruitment}

Volunteers are an integral part of the nonprofit sector, providing human resources support with minimal effect on payroll. They expand the human capital base of the nonprofit to conduct the mission related activities. School age children, young adults and professionals donate their time to support nonprofit organizations. Active employees also make time to support nonprofits as part of the corporate social responsibility. There are several benefits to using volunteers in nonprofits, including savings on payroll expenses and the ability to gain access to experienced professionals free of charge. Nonprofits also use social media to appeal to the young adults and millennials who use social media intensively. As observed by Waters et al. (2009) and Lovejoy and Saxton (2012), the United Way also use Facebook to list volunteer opportunities and mobilize volunteers for the organization's events. The following post below illustrates how nonprofit organizations use Facebook to recruit volunteers:

Come together to live the dream! Sign up to volunteer with our partners and us on Jan. 16 for Martin Luther King Jr. Day of Service: bit.ly/MLKDayJax \#makeyourmoment \#MLKDayJax

In the above post, the United Way asked Facebook followers to volunteer to the organization and their partner agencies. These partner organizations are mostly other nonprofit organizations either located in the same community or near-by community. Nonprofits seize opportunities on federal holidays like Martin Luther King Jr day to recruit volunteers for the benefits of the community and the organization. Federal holidays are convenient days for employees to volunteer for the community. 


\section{Charitable Events}

United Way chapters act as a channel for mobilizing funds to engage in charitable events related to their mission focused areas of education, income, and health. The charitable events are not fundraising events; rather, they are events oriented toward benefiting targeted population in the community. In this, the United Way chapters serve as intermediaries between donors and beneficiaries. Charitable events mark the United Way's support to the community. Facebook posts are used to showcase the events and their contributions to the community.

Social media gives a direct medium for United Way chapters to demonstrate how the events help the intended community members (e.g. school children, seniors, jobless, low-income, etc.). The Facebook posts include pictures and videos to demonstrate the significance of the events and the organizations' efforts to support the community. Such activities include projects undertaken by the chapter, donations made to communities, school reading programs in deprived areas as well as healthcare and financial initiatives to low-income communities. For example, the following Facebook posts aim to attract community members to the United Way's camps to attend free tax preparation program, credit counseling program and budgeting tips.

- From free tax prep, to credit counseling, to holiday budgeting tips, the United Way Center for Financial Stability will help will you pave a path to financial independence. 
- Our Investing in Results competitive grant process is currently accepting applications. These grants will focus on prevention in the areas of education, financial stability, and health. To learn more or apply.

Although the intent of the Facebook posts of charitable events is to reach out to the constituent beneficiaries, the posts are also expedient for the United Way chapters to solicit further financial assistance. The charitable event becomes a compelling reason for the individuals and corporations to donate to similar events in the future. The following post illustrates how nonprofits use social media to showcase charitable events and use the occasions to raise further funding.

Kim Smith receives \$1,000 from the United Way Fighting Hunger Program. The funds will enable the "Bless A Bulldog" program to increase the number of children served in their weekend meals program next school year. To learn how you can sponsor a child through the "Bless A Bulldog” program, contact Columbus Grove Elementary school at 419-659-2631. To find out more about the Fighting Hunger Program, visit our website."

\section{Public Interests Events}

Nonprofits take active participation different kinds of community development and promotion programs including those organized by local, state, and national agencies. For example, when the Hurricane Matthew hit the southeastern coast of the United States in October 2016, many nonprofits were active on social media, sharing links from local, state, and national media organizations and government agencies on the hurricane. The messages served public interest purposes of warning citizens to take adequate precautions 
and prepare themselves for the event. The United Way chapter's messages also indicated where to seek help, where to go for shelter, which areas would be worse affected, and when to expect the landfall of the storm. All these Facebook posts were aimed toward the public interest of seeking to promote the well-being of the citizens.

Similarly, posts in this category also share information on jobs and health related activities. Facebook posts serve as additional channels to inform the public about job openings. The posts share important health alerts that the public should be aware of and advise on the precautionary measures to take. The following posts illustrate how the United Way chapters share messages that relate to the public interest.

- It's going to be cold Friday night so help us get the word out! There will be a cold night shelter at Parkview Baptist Church.

- From the National Weather Service in Jacksonville: Strong to Severe Thunderstorms with Isolated Tornadoes will be possible tonight and early Tuesday. The best chance for Severe Weather will be across inland Southeast Georgia and the Suwannee River Valley of North Florida Tonight and Tuesday Morning. Stay tuned to the latest forecast and potential watches and warnings with this event. Scattered to widespread showers and scattered storms will develop across the region tonight...

- Have we got a job for you! Position Description Community Investment Director"

- These nine companies are hiring seasonal workers: http://www.thepennyhoarder.com/seasonal-jobs-hiring-now 


\subsection{Leaders' views on Using Facebook: Interview Findings}

I interviewed nonprofit officials in leadership positions from the selected organizations to verify the findings from the content analysis. Whereas four interviews were conducted over the phone, two responded to email questions. The four interviewees were senior executives familiar with the use of social media from the following organizations: the United Way of Central Florida, United Way of Suwanee Valley, United Way of Putnam County, and United Way Of Lake \& Sumter Counties. The six responses were also coded with NVivo to identify the themes of Facebook use. The interviewees broadly attested to the main themes from the content analysis, highlighting how they use Facebook for collaborative engagement with other private, public, and nonprofit organizations, for engagement with community donors, and for promoting their events. The interviews also highlighted two distinctive themes frequently observed in the content analysis. First, interviewees broadly attested to the significance of social media as a communication tool to engage with clients. Second, the interviews highlighted how they used the platform to connect with donors.

\section{Facebook as a Communication Tool to Engage Clients}

The officials I interviewed consistently highlighted how social media in general, and Facebook in particular, is satisfies their communication needs. Facebook acts as a communication tool for disseminating the activities of the United Way chapters. Facebook has changed how the chapters communicate about their programs and activities, engage constituents in the daily operations of the organization and connect with donors who otherwise may not have heard of the activities of the organization. As 
the content analysis revealed as well, Facebook is also used to inform constituents about the United Way's mission-related activities. For example, the United Way of Suwannee official said, "the mission of our organization is better known among the constituents after we engage in the use of Facebook and other social media platforms than previously when these platforms were not in place within our organization" (personal communication, February 18, 2017). The Putnam County United Way executive also said:

Social media can help communicate with a wider audience. Instead of using advertisement, words of mouth to inform people to come to events and programs, Facebook made it much easier to reach out to a wider audience at a relatively no cost to the organization. This is much simpler and cheaper to do than we previously do when social media was not in use within the organization. (Personal communication, February 10, 2017).

The United Way of Central Florida executive similarly averred:

The community does not know much about the activities of the nonprofit organization. Hence, the goal for the adoption and use of Facebook and social media as a whole was to make known to the community what United Way does in the community and how the community can engage United Way in addressing essential problems facing the community. (Personal communication, January 23, 2017).

One key aspect that did not emerge in the content analysis is the use of Facebook as an instantaneous mode of communication. As the administrative director of the United 
Way of Suwannee Valley said, "Information goes out more quickly than the traditional media. One of our motivation for using Facebook was to get information to our constituents and donors as soon as possible, including post photos, news, and share links to all our stakeholders" (Personal communication, February 10, 2017). The social media specialist for United Way of Putnam County, who is also the finance officer and the administrative director said,

When I came onto the United Way two years ago, there was no social media. However, one of the means through which people communicate was through social media like Facebook, Twitter, and Instagram. I thought it would be a good way to reach more people who might be in need as well as more people who might be interested in donating to the organization if they knew we were there on social media" (personal communication, February 10, 2017).

United Way chapters have also been able to elicit responses to participate in many of their collaborative programs through the Facebook post. Social media did not change the nature of programs and activities, but it changed how organizations communicate their programs and activities to the audience. For example, the manner in which the United Way of Putnam County communicated about a baby shower program had an impact on the participation in general. The official explained, "We communicate the program to everyone through Facebook. We got a lot more visitors and participants to our programs than previously when Facebook was not used to organize our events. Facebook has considerably improved attendance to our programs and activities. In the baby shower 
program, we received more than triple the number of people who came to that event than previously" (Personal communication, February 10, 2017).

The interviews confirmed the content analysis findings that social media is used as a free advertisement tool to promote events. Facebook has lessened the burden of advertising and cost of publicizing programs and activities of nonprofit organizations. As the United Way of Central Florida official opined:

We post all our events, meetings, and all our programs into social media and get it out to the people through social media and Facebook in particular. We have not regretted using social media and Facebook in particular for this purpose. Social media is more or less a free source of advertisement, and it has improved our communication with the community. (Personal communication, January 23, 2017).

United Way chapters use Facebook to advertise for jobs. The United Way of Putnam County's official recalled an episode where the job advertisement was more effective than traditional job advertisements. She said:

I had a call from a single parent (father) who was desperately looking for a job. I could have reached out to only my partner agencies for help to see if they can assist or if they have any job openings. But instead of just reaching out to my partner agencies through emails, we sent out the Facebook post about any job openings, and within an hour, we received eight job openings. The donors were out there, they saw the need and responded accordingly. Without Facebook, I would not have had such a response, and the information would 
only be limited to my partner agencies which would not have resulted in the help that we received when the information was posted on Facebook. Facebook was a huge impact on the job search for people in need than the traditional email we usually share with partner agencies." (Personal communication, February 10, 2017).

\section{Facebook as a Tool to Connect with Donors}

The second theme that emerged from the interviews was the use of Facebook to connect with donors. Donors are one of the important stakeholders of nonprofit organizations. Enhancing donor retention can bring substantial benefits to nonprofit organizations. Nonprofit organizations do fundraising through presentations, word-ofmouth, sending out letters and having special dinners. All these activities connect organizations with donors. The traditional methods of fundraising through newspaper and radio advertisements are costly. Raising money through traditional channels incurs two to three times more costs than the social media. Donor relationships are also important. As the United Way of Suwannee Valley official highlighted,

One of the main reasons we adopted Facebook was because of our donors, to connect with donors. We connect with donors through the information on Facebook. We hope to reach our primary population through Facebook, not only the community but donors and volunteers because they form the core of our activities. (Personal communication, February 18, 2017).

When the donor-nonprofit relationship is properly developed, donors can voluntarily give or enhance their contribution, which is not possible through persuasions. 
It takes trust and long years of relationship for a nonprofit donor relationship to sustain. Social media helps in developing these long relationships as it offers a medium for the donors to be engaged with the organization. Koenig's (2015) study found that for every 100 new donors acquired by nonprofit organizations in 2014, 103 existing donors were lost by nonprofit organizations. Retaining existing donors is the most cost effective way to increase fundraising revenue than struggling to acquire new donors because of the cost involved in donor acquisitions. Contributions from existing donors increase the fundraising revenue and make the donation valuable because of the cost involved. Retaining existing donors is one of the main reasons why nonprofit organizations use social media. Informing donors of how their donations were helpful in undertaking activities is one of the main ways by which donors can be retained. The United Way of Suwannee Valley official said, "Donors want to see their dollars at work, and how they are at work, we use pictures and posts to illustrate this to donors and donors are always proud to see nonprofit organizations showing strong community support and appreciation of the donations" (Personal communication, February 18, 2017). Social media enables nonprofit organizations to share what they do using pictures and text messages on social media, which shows the investment of donors at work. The Facebook posts enhance the ambient reputation of the United Way chapters, which are useful to attract donors (United Way of Lake Sumter Counties, personal communication, April 18, 2017).

One aspect that did not emerge in the content analysis, but did so in the interviews is the dualistic view of donors. While many of the United Way chapters did attest to the usefulness of Facebook posts for attracting donors, some of them highlighted that a few donors are also wary of the public exposure. These donors want to maintain their 
anonymity and want to have a one-to-one relationship with the nonprofit organization. Facebook posts make the donations public. Hence, some donors explicitly do not want to mention their contributions over social media. Grant awarding donors are among those who limit how the nonprofit organizations give information to the communities through social media. According to United Way of Suwannee official

Clients cannot learn much about our activities as our grants and some donors prohibit us from putting our activities on social media. We can put some information although but very limited information. You cannot advertise your grants or programs about your grants - strictly prohibited. Because most of our services are grant funded by donors, we are largely restricted from how and what sort of information we put on social media about our activities. (Personal communication, February 18, 2017).

Some of the United Way chapters also downplayed the role of social media for attracting donors. Some of the interviewees did not consider Facebook as a medium for raising additional funds. They argued that the traditional personal touch is required for fundraising purposes. As the United Way of Putnam County official said, I thought there would be a lot more actions on donation on Facebook, but it turns out not to be the case. Fundraising remains word of mouth, presentations, and dinner events. We do not do fundraising or solicit donations on Facebook. (Personal communication, February 10, 2017). 


\section{$\underline{5.8 \text { Conclusion }}$}

This chapter used qualitative methods to analyze how United Way chapters in Florida use Facebook. Content analysis of the Facebook posts show three major themes of Facebook use. First, the United Way chapters use Facebook for enhancing collaboration with private, public, and other nonprofit agencies. They jointly conduct many projects that are directed towards the local community. The Facebook posts highlight how useful and effective these projects are. Facebook is an effective communication tool to showcase these projects.

Second, United Way chapters use Facebook for dialogue and community building purposes. Although dialogues form a small part, Facebook is useful in publicly expressing gratitude about the involvement and support of the community organizations. The support could be in the form of providing funds, voluntary workers, or supporting targeted events.

Third, United Way chapters use Facebook to promote their events. As a free platform, Facebook is an effective medium of advertisement. Organizations can reach out to a wide audience within the community, who are already on Facebook. It is one of the largest social media platforms in the digital age. The chapters use Facebook in promoting five types of events: campaign activities, charitable activities, fundraising activities, public interest activities, and volunteer recruitment activities. Among these, Facebook is prominently used for promoting campaign activities with other external organizations and for help with fundraising.

The interviews reiterated the findings from the content analysis. At the same time, the interviews highlighted two prominent themes. First, Facebook is an effective 
communication tool for reaching out to the organizations' constituents. The program activities are directly relayed through Facebook. The organizations also receive enthusiastic response through the Facebook posts. Second, social media is a good tool for fundraising. The medium helps in enhancing donor relationships as the events get public exposure. A small set of donors who request anonymity may, however, refrain from getting such attention through social media.

Clearly, social media has transformed how nonprofit organizations engage stakeholders for strategic communication. Social media not only facilitates effective communication among stakeholders but the communication occurs in real-time, which improves effective decision making and response to emergencies (Waiters, 2009). Social media is more effective than the traditional website that has been in existence before the emergence of social media platforms like Facebook and Twitter. Unlike a website, the interaction between stakeholders on social media platforms is more efficient, faster, and cost-effective (Bortree and Seltzer, 2009; Sweetser and Lariscy, 2008). Because of the enormous benefits of social media applications, nonprofit organizations, including community agencies have to incorporate social media into their marketing and management decision making. Social media like Facebook and Twitter have been integrated into communication strategies across organizations from different sectors. The use of social media for communication is cheaper than the traditional means of communication. 


\section{CONCLUSION}

\section{$\underline{6.1 \text { Introduction }}$}

Social media has become a pervasive technological force in the last decade, influencing the functioning of public and nonprofit organizations. This study contributes to the emerging research on social media in the nonprofit sector. Extant research has largely focused on the social media use for public relations and information dissemination among large nonprofits (Nah and Saxton, 2012). In contrast, this study examines the enablers of social media adoption and use among locally oriented nonprofit organizations. The empirical focus of the study is on the community-based local organizations affiliated with United Way.

This study fills a gap in the research on nonprofit organizations by focusing on local, community based nonprofits. Community-based nonprofit organizations are important to study because they are essential partners in the development of communities. Hence, understanding the diffusion of social media applications will improve the services of community-based nonprofit organizations. Second, communitybased nonprofits operate in low-income areas with limited governmental support, high unemployment rates, limited nonprofit activities and are inherently ignored by both public and commercial activities due to high crime rates. Social media offers a means to communicate in such difficult settings, which do not get sufficient coverage in newspaper and other traditional media.

There is lack of sufficient human and administrative capacities for communitybased nonprofits to undertake the difficult jobs that prevail in these low-income 
communities. Studies show social media applications offer a wider range of services that improve fundraising and communication activities of nonprofit organizations. Hence, research into social media activities in community-based nonprofits will improve the fortunes of fundraising and communication activities of these local nonprofits. Additionally, community-based nonprofits play unique roles in the deprived communities, ignored by large and well-funded nonprofit organizations. Communitybased nonprofits act as agents of poverty eradication, focusing on education, economic development and revitalization of communities. Social media can aid the several challenges that confront these local nonprofits particularly in the areas of fundraising and communication with constituents and stakeholders.

\subsection{Research Context and Conceptual Framework}

The extant literature highlights how social media has been used by large organizations in specific contexts. Prior studies have shown that the use of social media sites like Facebook and Twitter to create interactive pages and build a network of friends, clients, stakeholders and followers for real-time contact is widespread among nonprofit organizations (Gálvez-Rodriguez et. al., 2014; Kanter and Fine, 2010). Social media is one of the innovative information technology platforms that has the capability to reach a very broad audience (Guo and Saxton, 2014; Lovejoy, Waters \& Saxton, 2012). Nonprofit organizations use social media to facilitate community and stakeholder engagement (Saxton, et. al., 2015). Social media is a low-cost method to engage current and potential stakeholders through sharing of information in real-time (Mansfield, 2011; Young, 2010; Gálvez-Rodriguez, et. al., 2014). 
Nonprofits have used Facebook and Twitter for advocacy and engaging stakeholders (clients as well as donors) (Waters et al. 2009) and for educating and training volunteers (Briones et. al., 2011). Nonprofits have also increasingly used social media for disaster response and recovery. Facebook and Twitter were used as active means of information dissemination and to coordinate response mechanisms following the 2010 Haiti earthquake (Bird, Ling, and Haynes, 2012; Takahashi, Tandoc, and Carmichael, 2015), the 2011 Japanese tsunami and earthquake (Acar and Muraki, 2011), the 2015 California wildfire crisis (Brengarth and Mujkic, 2016), etc. Social media is also an important means of fundraising for nonprofits to support their emergency operations.

The conceptual framework for the study draws upon extant research on information technology diffusion among private and public organizations. The framework emphasizes three dimensions: technological, environmental, and institutional (Hackler and Saxton 2007; Young, 2012; Zorn, Flanagin, and Shoham, 2011). These three dimensions also frame the broader context of IT adoption and use in nonprofit organizations in this study. Three theories formed the theoretical basis for this dissertation: the diffusion of innovation theory (Rogers, 2003), the resource dependence theory (Pfeffer and Salancik, 1978), and the institutional theory by DiMaggio and Powell (1983).

\subsection{Study's Findings and Contributions to Literature}

This dissertation examines two principal research questions: (i) What are the principal determinants of adoption and use of social media in nonprofit organizations? and, (ii) How do nonprofits that have adopted social media use it? With respect to the 
first question, the hypothesis is that social media adoption and use is influenced by technological, environmental, and internal institutional factors. The social media platforms considered for this question are Facebook and Twitter, two of the common ones. An online survey was conducted to examine the principal determinants. With respect to the second question, the guiding hypothesis is that organizations use Facebook for disseminating information, organizing events, and raising public interest. Content analysis of selected United Way's chapters in Florida and interviews with key officials of the chapters are used for exploring the use of the Facebook.

\section{Factors affecting Adoption and Use of Social Media}

The regression analysis of social media adoption and use of both Facebook and Twitter yielded interesting results. The conceptual framework of diffusion of innovation, resource dependence, and institutional theory highlighted the role of technological characteristics, external environment, and internal organizational factors. However, the regression models for adoption and use of Facebook and Twitter are weak. The models highlight that the factors for social media adoption and use could be distinctive from other information technology platforms. Social media has unique characteristics that may set it apart from other information technology applications.

Although the prior insights on the influence of technological, environmental, and organizational variables are useful, they may not sufficiently explain social media adoption and use. Unlike other information technology applications, social media does not require significant upfront investment in the technology infrastructure. The acquisition costs are low. The study's findings could also contradict the findings of 
earlier studies for various reasons. Previous studies had focused on large and wellestablished nonprofit organizations with strong revenue, huge assets, and large staff size. These organizations are managed by professionals with required skills and experience in nonprofit leadership and management. The subjects of this study are community-based nonprofit organizations with various challenges, including limited staff, limited budget, shrinking revenue sources, and are mostly managed by people with no professional background in nonprofit management.

The findings are also interesting with respect to the variables within the broad conceptual framework of the three dimensions. The regression models tested the significance of four technological, environmental, and organizational variables, and also controlled for six other variables. The regression results are interesting in terms of the variables that are significant, and those that are not significant. The factors for Facebook and Twitter adoption are similar. Three technological characteristics, namely relative advantage, compatibility and ease of use are statistically significant for adoption of both. Relative advantage and ease of use are positively correlated and compatibility is negatively related with Facebook and Twitter adoption. Interestingly, none of these factors are significant for the social media use. Observability, which is not significant for social media adoption, is significant for social media use. The findings highlight the difference between factors influencing ex-ante decision to adopt social media platform vs ex-post use of social media platforms. Relative advantage, compatibility, and ease of use are important for social media adoption, but once adopted, social media needs to bear tangible results for the nonprofit organizations. Else, nonprofits are unlikely to use the social media platform. 
With respect to external environmental factors, public awareness is statistically significant with a positive relationship with both Facebook and Twitter adoption. Donor requirement is also significant for social media adoption. Public awareness is not significant for Facebook use, but is so for Twitter use (negatively related). Increasing public awareness is thus a significant factor for social media adoption. Indeed, social media provides a facile mechanism for reaching out to the community, especially among the youth. Nonprofits could also adopt social media as a result of donor requirements.

Among the control variables, the appointment of an external consultant is significant for the adoption and use of social media. Whereas the external consultant is positively related to adoption, it is negatively related to use. This finding is also interesting since it points to the influence of external consultant in earlier adoption of social media, but has a negative impact on frequency of use. External consultant could thus jumpstart adoption, but could slow the use. A social media specialist is required to use the social media platforms effectively.

\section{Use of Facebook}

The second question explores the use of Facebook among United Way chapters. Qualitative methods were used to explore this question. Florida has 31 United Way chapters, with different frequencies of Facebook posts. Four organizations from each category of high frequency use, medium use, and low use were selected for the study. The Facebook posts of these twelve selected United Way chapters over a six-months period of July to December, 2016 were scraped for analysis. Content analysis was performed on the Facebook posts thus scraped from the United Way chapters. Interviews 
were also conducted with officials from six of the chapters. The content analysis and the interview transcripts were coded with NVivo 11 in order to identify the major themes of Facebook use.

Content analysis of the Facebook posts show three major themes of Facebook use. They are: collaboration, dialogue and community engagement, and promotion of events. The first theme, collaboration, refers to partnership between the United Way chapter and other private, public, and nonprofit organizations in the area. The collaboration is mainly to undertake community projects and events jointly. Public sector collaboration covers posts pertaining information about the organization's activities that highlights its relationship with public sector organizations within its jurisdiction. Posts in this subcategory highlight the various levels of partnership with state agencies, public schools (elementary and colleges) and county offices. Private sector partnership covers posts containing information on the chapter's activities that highlights its relationship with the private sector entities. Posts in this subcategory highlight the supports nonprofits receive from local privately owned companies and institutions in both cash and kind. The nonprofit affiliates are key partners for the United Way chapters to carry out the local activities. The United Way chapter funds the local nonprofits in the core areas of the United Way's mission area. About $60 \%$ of the posts about collaboration are with the private sector. Public and nonprofit collaborations are approximately similar, accounting for about $20 \%$ of the collaborative posts.

The second category, dialogue, and community engagement, highlights Facebook use for community engagement through dialogue and interaction to educate the public on various activities. Lovejoy and Saxton (2012) found that social media is used for two 
types of dialogue and community building. The first type is recognition, and thanksgiving wherein the organization recognizes or appreciates individual or organizational support during previous events. It contributes to the community building function of social media. The second type is response solicitation, wherein the organization seeks public response to a query or an issue. Such social media use contributes to dialogic communication within the online community. The content analysis of the United Way chapter's Facebook posts also reveal the above two types of dialogue and community building. However, $98 \%$ of the posts are oriented toward community building through recognition and thanksgiving, rather than dialogic communications. The social media use for dialogic communication is limited to those United Way chapters that are high users of Facebook.

Third, United Way chapters use Facebook to promote their events. As a free platform, Facebook is an effective medium of advertisement. Organizations can reach out to a wide audience within the community, who are already on Facebook. It is one of the largest social media platforms in the digital age. The United Way chapters use Facebook to promote events directly have some community benefits, and followers are encouraged to take part in these events. The posts are meant to encourage active participation of the community in various activities organized by the nonprofit organization as well as other external bodies that will benefit the community.

The United Way's promotion of events can be categorized into five classes. They are promotion of: campaigns, charitable events, fundraising events, public interest events, and volunteer recruitment events. In promotion of campaigns, United Way uses Facebook posts to promote joint campaign activities organized with partner agencies. The majority of these partners operated outside the jurisdiction of the United Way. Charitable events 
promotion consists of the promotion of programs and activities in which the nonprofit organization supports the community and individuals by donating equipment, money and miscellaneous items as the means to improve conditions of community and individuals. In other words, these are events undertaken by the United Way chapter. Fundraising events are means by which nonprofits appeal to both individuals and organizations for financial support and other forms of special support towards earmarked programs. These events are not campaigns to increase donor contributions, but to get funding for specific program. Facebook posts of public interest events are the promotion of events organized by partner agencies that seek to inform the public on health and other community related issues such as jobs and disaster mitigation. Facebook posts for volunteer recruitment seek to recruit volunteers to donate their time towards accomplishing specific goals that support community events. Nearly two-third of the Facebook posts are for promoting campaign events. The next highest category of use is fundraising, which accounts for nearly $22.5 \%$ of the posts. Promotions for charitable, public interest, and voluntary events form a small percentage of the overall Facebook posts.

The interviews reiterated the findings from the content analysis. At the same time, the interviews highlighted two prominent themes. First, Facebook is an effective communication tool for reaching out to the organizations' constituents. The program activities are directly relayed through Facebook. The organizations also receive enthusiastic response through the Facebook posts. Second, social media is a good tool for fundraising. The medium helps in enhancing donor relationships as the events get public exposure. A small set of donors who request anonymity may, however, refrain from getting such attention through social media. Social media did not change the nature of 
programs and activities, but it changed how organizations communicate their programs and activities to the audience.

\subsection{Implications for Policy and Practice}

The findings of this dissertation are useful to provide insights on factors that influence community-based nonprofit organizations to adopt and use social media to engage communities and connect with donors. Social media has an important role to play in an era of expanded role of nonprofits accompanied with cuts in government funding, reduction in donor-funded grants, and fierce competition from other nonprofit organizations. Social media facilitates connection with donors and mobilization of revenues to remain vibrant and relevant to the communities. The study has four implications for policy and practice. They are as follows.

\section{Policy Implication 1: Community-Based Nonprofit Organizations must engage Social Media Specialist or an External Consultant for adoption of Social Media}

The adoption of social media and any other information and communication technology requires expertise with extensive knowledge in the technology. Social media looks very simple to adopt in the first glance. However, for an organization, it requires a systematic examination. Social media carries the image of the organization and has the potential to improve or harm the image of the organization. Whatever information appears on the profiles of the organization, pictures, texts or links shared by the organization reflects the image of the organization. The quantitative results show the use of a social media specialist or an external consultant is positively associated with social 
media adoption. Thus, engaging the services of social media experts improves successful adoption of social media.

Community-based nonprofit organizations must engage the services of experts during the adoption stages of social media to jumpstart with the platform and integrate it into organizational activities. Several large and well-established nonprofit organizations listed in the Nonprofit Times 100 (NT100) have dedicated social media specialists that manage the social media profiles of the organization. The services of a social media specialist require an enormous cost. Although expensive, community-based nonprofits must develop a strategy during the adoption. The external consultant or social media specialist will be engaged and later train internal employees to take over the management of the social media profiles. While most of the NT100 organizations have dedicated ICT department that manages the ICT infrastructure, community-based nonprofits are resource constrained and cannot afford that type of infrastructure. However, to remain vibrant and relevant, it is important to dedicate resources purposely to engage the services of specialists during the initial stages of the adoption of social media.

\section{Policy Implication 2: Community-Based Nonprofit Organizations Must Train Internal} Staff Specialists to Manage Organization's Social Media Profile

While engaging the services of social media expert in the early stages of adoption of social media is important and should be a requirement for all small nonprofit organization, it is not financially sustainable to maintain the cost of an external consultant or a team of social media specialists for daily use of the organization's social media profile. The quantitative results show the use of external consultant to manage the social 
media account is positively associated with the adoption of social media, but negatively associated with use of social media. Social media specialists to manage the social media account shows dualistic results - it is positively related to use of Facebook, but negatively related to the use of Twitter. Clearly, external consultant may not be significant for social media use. However, internal social media managers could be helpful for enhanced use if small nonprofits use them strategically. The nonprofits can train internal staff members to manage the social media profile during the daily use of the platform.

One of the major challenges confronting smaller nonprofit organizations operating at the grassroots in various communities is revenue. Many of the local nonprofits can barely afford the services of professionals. The budgetary constraint is a major problem such that engaging the services of a social media specialist to manage the social media account for daily use is not financially sustainable. Instead of using social media experts in the day-to-day usage of the social media platforms, smaller nonprofits should rather train their internal staffs to take up the role of the social media experts after the social media expert has assisted the organization to adopt the platform.

One lesson shared by one of the nonprofit organizations during the interviews was the use of internal staff for different purposes. Instead of employing staff with the purely accounting background for financial activities, the organization employed someone with combined knowledge in both accounting and ICT. The strategy leads to cuts in the cost of engaging social media specialist or employing a staff purposely to manage the social media platforms. Training internal staff to manage the social media account for daily use will save the organization payroll expenditure as well as leverage the use of social media 
for various activities. As many organizations indicated, frontline personnel (secretaries and receptionists) handle such tasks, and they should have adequate training for handling social media.

\section{Policy Implication 3: Community-Based Nonprofit Organizations must train Leadership} in the role of Social Media for Nonprofit Engagement

The impact of leadership knowledge in the efficient administration of the nonprofit organization is without question. Observation from the study shows several of the community-based nonprofit organizations have serious staff challenges. With limited staff, many of the staffs take up multiple roles within the organization. The leadership's knowledge of social media is imperative in the digital age. As the clients and the donors become intensive social media users, the nonprofits have to use social media to engage with their constituencies.

Several studies on the adoption and use of information technology confirm that the role of leadership is very crucial in the adoption and use of technologies in nonprofit organizations (Nah and Saxton, 2012; Waters et al., 2007; Zorn et al., 2011).

Surprisingly, the results of the study demonstrate the impact of leadership on the adoption and use of social media in community-based nonprofit organizations is not significant. Some organizations even mentioned that they are using social media despite not having the support of the leadership. While the success and failures of an organization hang on the effectiveness of leadership, leadership knowledge in the area of technology is very crucial if the organization want to remain technologically inclined and possess the ability to deploy the best tools to garner resources that will improve the health and wealth of the 
organization. Elliott, Katsioloudes, and Weldon (1998) also advise nonprofit organizations to use ICT and the internet to target funding, market and advertise programs and activities and enhance communication with donors and communities.

The face of every organization largely relies on the leadership style, knowledge, and skills. For community-based nonprofits to harness the opportunities presented by social media, it is important to dedicate resources to growing the skills and knowledge of those in management so that effective policies regarding the use of various technology platforms can be implemented to the advantage of the organization. As Zorn et al. (2011) argue, “decision makers' IT knowledge and leadership expertise are the most consistent predictors of ICT adoption and use" (p. 25).

\section{Policy Implication 4: Donors must encourage best practices of social media use in Community-Based Nonprofit Organizations}

While nonprofit organizations are independent organizations, they cannot be detached from donors. Nonprofit organizations primarily rely on charitable donations and grants from government and private foundations to undertake various activities. It is interesting that although there is a cordial relationship between United Way and the community-based nonprofit organizations, United Way does not have a significant role in the adoption and use of social media. United Way and another organized network of nonprofit organizations could do more to encourage best practices in the affiliated nonprofit organizations. Supporting related nonprofit organizations to undertake best practices will significantly improve the performance of the affiliated nonprofit 
organizations and will yield better values for the dollars invested in social media in these affiliated nonprofit organizations.

Previous studies like Hikmet et al. (2008) found that system membership (i.e. a nonprofit organization's affiliation with a network of other nonprofit organizations) was a significant predictor of the adoption of ICT. They demonstrated the influence of the federated organization have on the activities of affiliated nonprofit organizations. Similarly, resource dependence theory posits that external resources of organizations affect the behavior of organizations (Pfeffer and Salancik, 1978). Several scholars including Nah and Saxton (2012) and Zorn et al. (2011) reaffirm that the reliance on donations by nonprofit organizations make donors influence the activities and decisions of nonprofit organizations. Their studies show that donors affect the adoption and use of ICT and social media in particular (Nah and Saxton, 2012; Zorn et al., 2011).

\section{$\underline{6.5 \text { Limitations of the study }}$}

Although the study highlights several interesting insights, it has a few limitations. However, the limitations are ancillary, and do not pose significant threat to the validity of the findings. The first limitation is scope of the study. The study is limited to communitybased nonprofit organizations affiliated with the United Way of Florida. Hence, the geographical scope of the study is limited to Florida, and may not be generalizable beyond the state. Yet, it is important to note that Florida is the ranked the third in terms of population and has over 70,000 registered nonprofits. Moreover, the study only focused on the community-based nonprofits affiliated with the United Way. Consequently, 
community-based nonprofits that are not affiliated with the United Way are out of the scope of this study.

Second, the quantitative analysis was based on a survey response, and is therefore subject to the typical problems associated with survey research. Responses from the online survey and the interviews conducted poses some limitations in the study. The responses could be subject to self reporting bias. The results are also subject to common source bias. The survey is a cross-sectional design. Although we can make inferences about correlation, we cannot make inferences about causality (which requires a longitudinal design). However, the comments and interviews do rectify for some of the problems attendant with surveys.

The qualitative methods further pose some limitations in the study. The content analysis of the Facebook posts were useful in identifying how the organizations used Facebook. However, the analysis did not have anything to say about the effectiveness of the modes of the use. That is, the impact of the Facebook on other users for participating in the organizations' tasks, donations, volunteering cannot be assessed from the content analysis. The assessment of the impact requires further systematic study that is beyond the scope of this dissertation study.

Lastly, the semi-structured interviews explored the motivation for the adoption of Facebook and how nonprofits use Facebook for organizational activities. Typically, interviews need to be conducted with enough personnel to reach theoretical saturation. The study has only six people, four of whom were interviewed over phone and two sent email responses. More interviewees could have been ideal. However, despite repeated requests, many organizations' leaders were not available for the interviews. Yet, the 
limited number of interviewees were enough to provide insights into the relevance of the broad themes of Facebook use identified through content analysis.

\subsection{Recommendations for Future Research}

The present study fills a literature gap on the adoption and use of social media in community-based nonprofit organizations. It represents a step forward in addressing the research gap by using qualitative and quantitative data. At the same time, the findings also indicate several areas for consideration for future research on social media, information technology, and nonprofit literature. First, the results of this study show that the theorized variables obtained from previous studies on large nonprofits do not fully explain the adoption and use of social media among community-based nonprofits. Hence, future research should consider using additional variables that explain the adoption and use of social media among nonprofits.

Second, this study mainly focused on the already established platforms of Facebook and Twitter Future studies will need to explore other emerging social media platforms such as Instagram, Google+, and YouTube. The use of these three platforms is on the rise in nonprofit organizations. Future studies can explore whether technological factors, external factors, and internal institutional factors play a significant role in the adoption and use of these social media platforms.

Third, future studies could examine federated nonprofit organizations beyond the scope of United Way. Such studies would be important to determine whether donor relationship influences the adoption and use of social media. Nationwide studies could also add to the literature on determinants of social media adoption and use. Fourth, 
although the methodology employed in this study is appropriate, future studies should consider using case studies with in-depth interviews as a way to provide a more detailed analysis on the impact of technological, external, and institutional factors on the adoption and use of social media in local and community-based nonprofit organizations. Fifth, future studies should consider using a random sample of local and community-based nonprofits with no affiliation to larger organizations.

\subsection{Conclusion}

Social media is the way of the future. It will shape how organizations govern themselves, relate to their clients, relate to their donors, and conduct their activities. The stakes are high for nonprofit organizations to do more with limited financial resources. The environments in which nonprofits operate have become very volatile, with several social and humanitarian problems. Amidst all these challenges, grants and funding from both government agencies and private donors are in sharp decline, due to financial challenges facing various levels of government - local, state, and federal governments as well as corporate bodies.

For nonprofit organizations to survive in the current environment, they must use resources strategically in order to support the communities and achieve their missionrelated goals. Information and communication technology applications generally improve management and efficient delivery of services as well as improve resource mobilization among nonprofit organizations (Waters et. Al., 2007; Waters et al., 2009; Zorn et al., 2011). Nonprofits that make use of ICT applications can mobilize more resources than organizations that make little or no use of ICT applications (Nah and Saxton, 2012). 
Studies also show that if nonprofit organizations implement efficient technologies, they can achieve their mission to improve the wellbeing of their communities (Quinn and Berry, 2010; Saxton and Wang, 2014). Social media is the latest member of the ICT family. Nonprofit organizations should have strategic means to use the technology effectively. This study highlighted how nonprofits can adopt and use social media effectively in the process of achieving their mission. 


\section{LIST OF REFERENCES}

Abramson, A., and McCarthy, R. (2002). "Infrastructure Organizations.” In L. Salamon (ed.). The State of Nonprofit America. Washington D.C.: Brookings Institution Press.

Ackerman, S. R. (1980). United Charities: An Economic Analysis. Public Policy, 28(3), 323-350.

Alexander, J., Brudney, J. L., and Yang, K. (2010). Measurement: The evolving role of nonprofits in the hollow state. Nonprofit and Voluntary Sector Quarterly, 39(2), 565.

Arnaout, Z. H. (2015). Diffusion of Technology in Small to Medium Medical Providers in Saudi Arabia (Doctoral dissertation). Retrieved from ProQuest Dissertations and Theses. (UMI No. 3734015).

Ash, J. S. (1997). Factors for information technology innovation diffusion and Infusion in health sciences organizations: A systems approach (Doctoral dissertation). Retrieved from ProQuest Dissertations and Theses. (UMI No. 9724464).

Au, Y. A. (2005). A Rational Expectations Perspective On Information Technology Adoption (Doctoral dissertation). Retrieved from ProQuest Dissertations and Theses. (UMI No. 3192002).

Auger, G. A. (2013). Fostering democracy through social media: Evaluating opposed nonprofit advocacy organizations' use of Facebook, Twitter, and YouTube. Public Relations Review, 39(1), 369-376.

Avery, E., Lariscy, R., Amador, E., Ickowitz, T., Primm, C., and Taylor, A. (2010). Diffusion of social media among public relations practitioners in health departments across various community population sizes. Journal of Public Relations Research, 22(3), 336-358.

Barman, E. (2008). With Strings Attached: Nonprofits and the Adoption of Donor Choice. Nonprofit and Voluntary Sector Quarterly, 37(1), 39-56.

Behn, B.K., DeVries, D., and Lin, J. (2010). The determinants of transparency in nonprofit organizations: an exploratory study. Advanced Accounting, 26(2), 6-12.

Benjamin, L. M. (2008). Account Space: How Accountability Requirements Shape Nonprofit Practice. Nonprofit and Voluntary Sector Quarterly, 37(2), 201-223.

Blum, D. E. (1999). Moving Away from Donor Designation. Chronicle of Philanthropy, 11(24), 33-35. 
Bortree, and Seltzer, T. (2009). Dialogic strategies and outcomes: An analysis of environmental advocacy groups' Facebook profiles. Public Relations Review, 35(3), 317-319.

Boyd, D. (2007). Social Network Sites: Definition, History, and Scholarship. Computer. Mediated Communication, 1(2), 3-20.

Brainard, L. A. and Siplon, P. D. (2004). Toward nonprofit organization reform in the voluntary spirit: Lessons from the Internet. Nonprofit and Voluntary Sector Quarterly, 33(3), 44-57.

Brinkerhoff, J. (2002). Government-nonprofit partnership: A defining framework. Public Administration and Development, 22(1), 19-30.

Briones, R. L, Kuch, B., Liu, B. F. and Jin, Y. (2011). Keeping up with the digital age: How the American Red Cross uses social media to build relationships. Public Relations Review, 37(2), 37-43.

Brown, L. K., and Troutt, E. (2004). Funding relations between nonprofits and government: A positive example. Nonprofit and Voluntary Sector Quarterly, 33(1), 5-27.

Bryce, H. J. (2006). Nonprofits as social capital and agents in the public policy process: Toward a new paradigm. Nonprofit and Voluntary Sector Quarterly, 35(2), 311318.

Burt, E. and Taylor, J. (2003). New technologies, embedded values, and strategic change: Evidence from the U.K. voluntary sector. Nonprofit and Voluntary Sector Quarterly, 32(1), 115-127.

Campbell, D. (2002). Outcomes Assessment And The Paradox Of Nonprofit Accountability. Journal of Nonprofit Management and Leadership, 12(3), 1-17.

Campbell, D., Jacobus, B., and Yankey, J.A. (2006). Creating and managing strategic alliances. In R.L. Edwards and J.A. Yankey (Eds.), Effectively managing nonprofit organizations (pp. 391-406). Washington, DC: NASW Press.

Carman, J. G. (2011). What You Don't Know Can Hurt Your Community Lessons from a Local United Way. Nonprofit Management \& Leadership, 21(4), 433-448.

Chan, J. G., Beckman, S. L., and Lawrence, P. G. (2007). Workplace design: A new managerial imperative. California Management Review, 49(2), 1-18.

Child, C. D., and Gronbjerg, K. A. (2007). Nonprofit advocacy organizations: Their characteristics and activities. Social Science Quarterly, 88(1), 259-281. 
Chin, T. M. (2011). Mobile Technology for Nonprofits: Harnessing the Power of Crowdsourcing (Master's Thesis). Retrieved from ProQuest Dissertations and Theses. (UMI No. 1506070).

Cho, M., Schweickartb, T. and Haasec, A. (2014). Public engagement with nonprofit organizations on Facebook. Public Relations Review, 40(1), 565-567.

Cho, S., and Gillespie, D. (2006). A conceptual model exploring the dynamics of government nonprofit service delivery. Nonprofit and Voluntary Sector Quarterly, 35(2), 493-509.

Corder, K. (2001). Acquiring new technology: Comparing nonprofit and public sector agencies. Administration \& Society, 33(2), 194-219.

Cords, J. J., Henig, J. R., and Twombly, E.C. (1999). The Effects of Expanded Donor Choice in United Way Campaigns on Nonprofit Human Service Providers in the Washington, D.C., Metropolitan Area. Nonprofit and Voluntary Sector Quarterly, 28(2), 127-151.

Coston, J. (1998). A model and typology of government-NGO relationships. Nonprofit and Voluntary Sector Quarterly, 27(1), 358-382.

Cummings, L., Dyball, M., and Chen, J.H. (2010). Voluntary disclosures as a mechanism for defining entity status in Australian not-for-profit organisations. Australian Accounting Review, 20(1), 154-164.

Curtis, L., Carrie Edwards, Kristen L. Fraser, Sheryl Gudelsky, Jenny Holmquist, Kristin Thornton, Kaye D. Sweetser. (2010). Adoption of social media for public relations by nonprofit organizations. Public Relations Review, 36(2), 90-92.

Digital Trends (2016). The History of Social Networking. Available at http://www.digitaltrends.com/features/thehistoryofsocialnetworking/. Accessed on $11 / 04 / 2016$.

DiMaggio, P. J., and Powell, W. W. (1983). The iron cage revisited: Institutional isomorphism and collective rationality in organizational fields. American Sociological Review, 48(2), 147-160.

DiStasio, M. W., McCorkindale, T., and Wright, D. K. (2011). How public relations executives perceive and measure the impact of social media in their organizations. Public Relations Review, 37(3), 325-328.

Doolin, B., and Lawrence, S. (1998). Managerialism, information technology, and health reform in New Zealand. Journal of Management in Medicine, 12(4), 302-316. 
Duchak, G. D. (2015). Some determinants of information technology adoption factors By rural electric cooperatives (Doctoral dissertation). Retrieved from ProQuest Dissertations and Theses. (UMI No. 3731393).

Edwards, H. R., and Hoefer, R. (2010). Are social work advocacy groups using Web 2.0 effectively? Journal of Policy Practice, 9(2), 220-239.

Edosomwan, S., Sitalaskshmi, K. P., Doriane, K., Jonelle, W. and Seymour, T. (2011). The History of Social Media and its Impact on Business. The Journal of Applied Management and Entrepreneurship, 16(3), 1-13.

Eng, T., Liu, C., and Sekhon, Y. (2012). The role of relationally embedded network ties in resource acquisition of British nonprofit organizations. Nonprofit and Voluntary Sector Quarterly, 41(2), 1092-1115.

Etim, S. A. (2010). The Adoption and Diffusion of Information and Communication Technology in the Base of the Pyramid Population of Sub-Saharan Africa: A Study of Nigerian University Students (Doctoral dissertation). Retrieved from ProQuest Dissertations and Theses. (UMI No. 3408791).

Eyrich, N., Padman, M. L., and Sweetser, K. D. (2008). PR practitioners' use of social media tools and communication technology. Public Relations Review, 34(4), 412414.

Finn, S., Maher, J. K., and Forster, J. (2006). Indicators of information and communication technology adoption in the nonprofit sector: Changes between 2000 and 2004. Nonprofit Management and Leadership, 16(3), 277-295.

Flanagin, A. J. (2000). Social pressures on organizational website adoption. Human Communication Research, 26(4), 618-646.

Flood, A. and Scott, R. (1987). Hospital structure and performance. Baltimore: Johns Hopkins University Press.

Francis, J., and Perlin, J. (2006). Improving performance through knowledge translation in the Veterans Health Administration. Journal of Continuing Education in the Health Professions, 26(1), 63-71.

Fryer, D., and Granger, M. J. (2008). Closing the Digital Divide: The Role of Community-Based Non-Profit Organizations. The Journal of Global Information Technology Management, 11(1), 1-5.

Galaskiewicz, J. (1997). An urban grants economy revisited: Corporate charitable contributions in the Twin Cities, 1979-81, 1987-89. Administrative Science Quarterly, 42(2), 445-471. 
Gálvez-Rodriguez, M. D., Caba-Perez, C. and López-Godoy, M. (2014). Facebook: A new communication strategy for non-profit organizations In Colombia. Public Relations Review, 40(1), 868-870.

Gandía, J.L. (2011). Internet disclosure by nonprofit organizations: empirical evidence of nongovernmental organizations for development in Spain. Nonprofit Voluntary Sector Quarterly, 40(1), 57-78.

Gazley, B. (2008). Beyond the contract: The scope and nature of informal governmentnonprofit partnerships. Nonprofit and Voluntary Sector Quarterly, 68(2), 141-154.

Gazley, B. (2010). Why not partner with local government? Nonprofit managerial perceptions of collaborative disadvantage. Nonprofit and Voluntary Sector Quarterly, 39(2), 51-76.

Gazley, B., and Brudney, J. R. (2007). The purpose (and perils) of government-nonprofit partnership. Nonprofit and Voluntary Sector Quarterly, 36(2), 389-415.

Gilbelman, M. and Gelman, S. R. (2001). Very Public Scandals: Nongovernmental Organizations in Trouble. Voluntas: International Journal of Voluntary and Nonprofit Organizations, 12(1), 49-66.

Gilbelman, M., Gelman, S. R., and Pollack, D. (1997). The Credibility of Nonprofit Boards: A View from the 1990s and Beyond. Administration in Social Work, 21(2), 21-40.

Goecks, J., Voida, A., Voida, S., and Mynatt, E. (2008). Charitable technologies: Opportunities for collaborative computing in nonprofit fundraising. Proceedings of the 2008 ACM Conference on Computer Supported Cooperative Work (CSCW '08), 21(1), 689-698.

Gordon, T., Knock, C., and Neely, D. G. (2009). The role of rating agencies in the market for charitable contributions. Journal of Accounting and Public Policy, 28(1), 469484 .

Gormley, W. T., and Cymrot, H. (2006). The strategic choices of child advocacy groups. Nonprofit \& Voluntary Sector Quarterly, 35(1), 102-122.

Graddy, E. A. and Morgan, D. L. (2006). Community foundations, organizational strategy, and public policy. Nonprofit and Voluntary Sector Quarterly, 35(2), 605-630. 
Greenberg, J., and MacAulay, M. (2009). NPO 2.0? Exploring the web presence of environmental nonprofit organizations in Canada. Global Media JournalCanadian Edition, 2(1), 63-88.

Greiling, D. (2007). Trust and performance management in non-profit organizations. Innovation Journal: Public Sector Innovation Journal, 12(3), 1-16.

Grønbjerg, K. A., and Paarlberg, L. (2001). Community variations in the size and scope of the nonprofit sector: Theory and preliminary findings. Nonprofit and Voluntary Sector Quarterly, 30(2), 684-706.

Grooters, S. (2011). Lessons in Social Media Fundraising: Applying Global Tactics at A Local Level (Master's Thesis). Retrieved from ProQuest Dissertations and Theses. (UMI No. 1500861).

Grover, V., and Goslar, M. D. (1993). The initiation, adoption, and implementation of telecommunications technologies in U.S. organizations. Journal of Management Information Systems, 10(1), 141-163.

Guo, C. (2007). When government becomes the principal philanthropist: The effect of public funding on patterns of nonprofit governance. Public Administration Review, 67(2), 456-471.

Guo, C., and Brown, W. A. (2006). Community foundation performance: Bridging community resources and needs. Nonprofit and Voluntary Sector Quarterly, 35(1), 267-287.

Guo, C., and Musso, J. A. (2007). Representation in nonprofit and voluntary organizations: A conceptual framework. Nonprofit and Voluntary Sector Quarterly, 36(1), 308-326.

Guo, C., and Saxton, G. D. (2010). Voice-in, voice-out: Constituent participation and nonprofit advocacy. Nonprofit Policy Forum, 1(1), 221-234.

Guo, C., and Saxton, G. D. (2014). Tweeting Social Change: How Social Media Are Changing Nonprofit Advocacy. Nonprofit and Voluntary Sector Quarterly, 43(1), $57-79$.

Guthrie, K., Preston, A., and Sbarbaro, C. (2004). Examining the landscape of Indiana's nonprofit sector: Does what you know depend on where you look? Nonprofit and Voluntary Sector Quarterly, 34(1), 232-259.

Hackler, D. and Saxton, G. (2007). The Strategic use of information technology by nonprofit organizations: increasing capacity and untapped potential. Public Administration Review, 67(3), 474-484. 
Hailu, A. (2012). Factors influencing cloud-computing technology adoption in developing countries (Doctoral dissertation). Retrieved from ProQuest Dissertations and Theses. (UMI No. 3549131).

Hall, M. R. (2006). Corporate philanthropy and corporate community relations: Measuring relationship-building results. Journal of Public Relations Research, $18(1), 1-21$.

Handley, A., and Chapman, C.C. (2011). Content Rules: How to create killer blogs, podcasts, videos, ebooks, webinars, and more that engage customers and ignite your business. Hoboken, NJ: John Wiley \& Son's, Inc.

Handy, F., Seto, S., Wakaruk, A., Mersey, B. A., Mejia, and Copeland L. (2010). The discerning consumer: Is nonprofit status a factor? Nonprofit and Voluntary Sector Quarterly, 39(1), 866-883.

Hart, T. (2002). ePhilanthropy: Using the Internet to Build Support. International Journal of Nonprofit and Voluntary Sector Marketing, 7(4), 353-360.

Haunschild, P. R., and Miner, A. S. (1997). Modes of inter-organizational imitation: The effects of outcome salience and uncertainty. Administrative Science Quarterly, $42(3), 472-500$.

Haveman, H, (1993). Follow the leader: Mimetic isomorphism and entry into new markets. Administrative Science Quarterly, 38(4), 593-635.

Hendricks, M., Plantz, M. C., and Pritchard, K. J. (2008). "Measuring Outcomes of United Way-Funded Programs: Expectations and Reality." In J. G. Carman and K. A. Fredericks (eds.), Nonprofits and Evaluation. New Directions for Evaluation, no. 119. San Francisco: Jossey-Bass.

Hikmet, N., Bhattacherjee, A., Menachemi, N., Kayhan, V. O., and Brooks, R. G. (2008). The role of organizational factors in the adoption of healthcare information technology in Florida hospitals. Health Care Management Science, 11(1), 1-9.

Holcombe, J. S. (2007). The diffusion of information technology to non-traditional Students in institutions of higher education. (Doctoral dissertation). Retrieved from ProQuest Dissertations and Theses. (UMI No. 3264294).

Hrywna, M. (2016). Charities Spent $4 \varnothing$ On Advertising For Each $\$ 1$ Raised Online. The Nonprofit TImes. Available at http://www.thenonprofittimes.com/news-articles/1digital-donors-cost-charities-4\%C2\%A2/. Accessed on April 20, 2017. 
Hughes, A. L., and Palen, H. (2009). Twitter adoption and use in mass convergence and emergency events. International Journal of Emergency Management, 6(2), 248260 .

Ingenhoff, D. and Koelling, M. A. (2009). The potential of Web sites as a relationship building tool for charitable fundraising NPOs. Public Relations Review, 35(1), $66-73$.

Jaskyte, K. (2011). Predictors of Administrative and Technological Innovations in Nonprofit Organizations. Public Administration Review, 71(1), 77-86.

Jones, G. (2001). Organizational theory Text and cases. Upper Saddle River, New Jersey: Prentice Hall.

Jordan, E. A. (2015). Enterprise information technology adoption in government Institutions: a quantitative study (Doctoral dissertation). Retrieved from ProQuest Dissertations and Theses. (UMI No. 3727498).

Kang, S., and Norton, H. E. (2004). Nonprofit organizations' use of the World Wide Web: are they sufficiently fulfilling organizational goals? Public Relations Review, 30(3), 279-284.

Kanter, B., and Fine, A. H. (2010). The Networked Nonprofit: Connecting with social media to drive change. San Francisco, CA: Jossey-Bass.

Kaplan, A. M., and Haenlein, M. (2010). Users of the world, unite! The challenges and opportunities of Social Media. Business Horizons, 53(1), 59-68.

Kent, M. L., and Taylor, M. (1998). Building dialogic relationships through the World Wide Web. Public Relations Review, 24(3), 321-334.

Kilpelainen, A., Paykkonen, K., and Sankala, J. (2011). The use of social media to improve social work education in remote areas. The Journal of Technology in Human Services, 29(1), 1-12.

Kim, D. (2010). Determinants of Corporate Web Services Adoption: A Survey of Companies in Korea (Doctoral dissertation). Retrieved from ProQuest Dissertations and Theses. (UMI No. 3399126).

Kim, H. (2004). Factors influencing the adoption of New information technology in College and University Foodservices (Doctoral dissertation). Retrieved from ProQuest Dissertations and Theses. (UMI No. 3153679). 
Klug, W. E. (2014). The Determinants of Cloud Computing Adoption by Colleges and Universities (Doctoral dissertation). Retrieved from ProQuest Dissertations and Theses. (UMI No. 3617041).

Knox, K. J., Blankmeyer, E. C., and Stutzman, J. R. (2006). Comparative performance and quality among nonprofit nursing facilities in Texas. Nonprofit and Voluntary Sector Quarterly, 35(2), 631-667.

Koenig, R. (2015). Charities Lost 103 Donors for Every 100 They Gained in 2014, Says Study. Chronicle of Philanthropy, Retrieved from https://www.philanthropy.com/article/Charities-Lost-103-Donorsfor $/ 233589$ ? cid $=$ pt\&utm source=pt\&utm medium $=$ en\&elq $=b 186 \mathrm{~d} 3$ cedbfb4f2996 01ed6af4b5459f\&elqCampaignId $=1514$ \&elqaid $=6389$ \&elqat $=1$ \&elqTrackId $=$ bbf daf516e7a4935a26adb99142d7987 Accessed on April 19, 2017.

LaCasse, K., Quinn, L.S., and Bernard, C. (2010). Using social media to meet nonprofit goals: The results of a survey. Idealware, Portland: ME.

Lamothe, S., and Lamothe, M. (2006). The dynamics of local service delivery arrangements and the role of nonprofits. International Journal of Public Administration, 29(1), 769-797.

Lampkin, L., and Boris, E. (2002). Nonprofit organization data: What we have and what we need. American Behavioral Scientist, 45(1), 1675-1715.

LeRoux, K. and Wright, N. S. (2010). Strategic Decision Making? Findings from a National Survey of Nonprofit Social Service Agencies. Nonprofit and Voluntary Sector Quarterly, 39(4), 1-17.

LeRoux, K., and Goerdel, H.T. (2009). Political advocacy by nonprofit organizations: A strategic management explanation. Public Performance \& Management Review, 32(1), 514-536.

Lord, M. L. (2009). How and why fundraisers use social media: a national survey of the practice (Doctoral dissertation). Retrieved from ProQuest Dissertations and Theses. (UMI No. 3496125).

Lovejoy, K., and Saxton, G. D. (2012). Information, Community, and Action: How Nonprofit Organizations Use Social Media. Journal of Computer-Mediated Communication, 17(1), 337-353.

Lovejoy, K., Waters, R. D., and Saxton, G. D. (2012). Engaging stakeholders through Twitter: How nonprofit organizations are getting more out of 140 characters or less. Public Relations Review, 38(1), 313-318. 
Lumpp, T. G. (2014). The Effects of Social Media on National Security within the United States (Doctoral dissertation). Retrieved from ProQuest Dissertations and Theses. (UMI No. 1571545).

Mansfield, H. (2011). Social media for social good: A how-to guide for nonprofits. United States: McGraw-Hill.

Mao, E. (2001). Organizational use and diffusion of information technology In China and international comparative assessment (Doctoral dissertation). Retrieved from ProQuest Dissertations and Theses. (UMI No. 3017964).

Marshall, C. and Rossman, G. B. (2011). Designing Qualitative Research (5th ed). Thousand Oaks, CA: Sage Publications.

McConnell, W. S. (2009). Technology adoption: influence of Availability and Accessibility (Doctoral dissertation). Retrieved from ProQuest Dissertations and Theses. (UMI No. 3448397).

McNutt, J. (2007). Adoption of New-Wave Electronic Advocacy Techniques by Nonprofit Child Advocacy Organizations. In M. Cortes and K. M. Rafter (Eds.), Nonprofits \& Technology: Emerging Research for Usable Knowledge (pp. 33-48). Chicago: Lyceum.

McNutt, J. G., and Boland, K. M. (1999). Electronic advocacy by nonprofit organizations in social welfare policy. Nonprofit and Voluntary Sector Quarterly, 28(4), 432451 .

McNutt, J., and Boland, K. (2007). Astroturf, Technology, and the Future of Community Mobilization: Implications for Nonprofit Theory. Journal of Sociology \& Social Welfare, 34(3), 165-178.

McNutt, J.G., and Menon, G. M. (2008). The rise of cyberactivism: Implications for the future of advocacy in the human services. Families in Society: The Journal of Contemporary Social Services, 89(1), 33-38.

Melendez, S. E. (2001). The nonprofit sector and accountability. New Directions for Philanthropic Fundraising, 31(2), 121-132.

Meyer, J. and. Rowan, B. (1977). Institutionalized organizations: Formal structure as myth and ceremony. American Journal of Sociology, 83(3), 40-63.

Miller, D. (2011). Nonprofit Organizations and the Emerging Potential of Social Media and Internet Resources. SPNHA Review, 6(1), 34-52.

Miller, J. L. (2002). Who “owns” your nonprofit? Nonprofit Quarterly, 9(3), 62-65. 
Moore, G. C. and I. Benbasat. (1991). Development of an instrument to measure the perceptions of adopting an information technology innovation. Information Systems Research, 2(3), 192-222.

Mosley, J. E. (2011). Institutionalization, privatization, and political opportunity: What tactical choices reveal about the policy advocacy of human service nonprofits. Nonprofit \& Voluntary Sector Quarterly, 40(2), 435-457.

Muralidharan, S., Rasmussen, L., Patterson, D., and Jae-Hwa, S. (2011). Hope for Haiti: An analysis of Facebook and Twitter usage during the earthquake relief efforts. Public Relations Review, 37(2), 175-177.

Nah, S. and Saxton, G. D. (2012). Modeling the adoption and use of social media by nonprofit organizations. New media \& society, 15(2), 294-313.

Nah, S. (2010). Media publicity and civil society: Nonprofit organizations, local newspapers, and the Internet in a Midwestern community. Mass Communication and Society, 13(1), 1-27.

National Center for Charitable Statistics. (2010). NCCS all registered nonprofits table wizard. Retrieved from http://nccsweb.urban.org/tablewiz/showreport.php Accessed on August 25, 2015.

Neff, D. J., and Moss, R. C. (2011). The Future of Nonprofits: Innovate and Thrive in the digital age. Hoboken, NJ: John Wiley \& Sons, Inc.

Nelson, R. and Gopalan, S. (2003). Do organizational cultures replicate national cultures? Isomorphism, rejection and reciprocal opposition in the corporate values of three countries. Organization Studies, 24(7), 1115-1151.

Nguyen, T. (2009). Information technology adoption in SMEs: An integrated framework. International Journal of Entrepreneurial Behavior \& Research, 15(2), 162-186.

Norton, H. E. (2004). Nonprofit organizations' use of the World Wide Web: are they sufficiently fulfilling organizational goals? Public Relations Review, 30(3), 279284.

O'Connor, M. K. and Netting, F. E. (2009). Organization practice: A social worker's guide to understanding human services. Hoboken, NJ: John Wiley Sons, Inc.

Obar, J. A., Zube, P., and Lampe, C. (2012). Advocacy 2.0: An analysis of how advocacy groups in the United States perceive and use social media as tools for facilitating civic engagement and collective action. Journal of Information Policy, 2(1), 1-15. 
Olson, D. E. (2000). Agency theory in the not-for-profit sector: Its role at independent colleges. Nonprofit and Voluntary Sector Quarterly, 29(1), 280-296.

Oster, S. M. (1996). Nonprofit organizations and their local affiliates: A study in organizational forms. Journal of Economic Behavior \& Organization, 30(2), 8395.

Parsons, L. M. (2003). Is accounting information from nonprofit organizations useful to donors? A review of charitable giving and value relevance. Journal of Accounting Literature, 22(2), 104-129.

Pearce, K. E. (2011). Accessible, Useful, and Conspicuous: Socioeconomic and Cultural Determinants of Information and Communication Technology Adoption in the Republic of Armenia (Doctoral dissertation). Retrieved from ProQuest Dissertations and Theses. (UMI No. 3473783).

Petray, T. L. (2011). Protest 2.0: Online interaction and aboriginal activists. Media, Culture, \& Society, 33, 923-940.

Pew Research Center Internet, Science \& Tech. (2015). Social Media Usage: 2005-2015. Retrieved January 25th, 2016, from http://www.pewinternet.org/2015/10/08/social-networking-usage-2005-2015/

Pfeffer, J. and Salancik G. R. (1978). The External Control of Organizations. New York: Harper.

Philpot, E. L. (2013). Social media adoption and use of information Technology professionals and implications for leadership (Doctoral dissertation). Retrieved from ProQuest Dissertations and Theses. (UMI No. 3570894).

Plantz, M. C., Greenway, M. T., and Hendricks, M. (1997). Outcome measurement: Showing results in the nonprofit sector. In K. E. Newcomer (Ed.), Using performance measurement to improve public and nonprofit programs (pp. 1530). San Francisco: Jossey-Bass.

Poole, D. L., Nelson, J., Carnahan, S., Chepenik, N. G., and Tubiak, C. (2000). Evaluating Performance Measurement Systems in Nonprofit Agencies: The Program Accountability Quality Scale (PAQS). American Journal of Evaluation, 21(1), 15-26.

Provan, K. G., Beyer, J. M., and Kruytbosch, C. 1980. Environmental linkages and power in resource dependence relations between organizations. Administrative Science Quarterly, 25(2), 200-225. 
Quinn, L., and Berry, A. (2010). The nonprofit social media decision guide. The New Organizing Institute and Idealware. Retrieved from http://www.idealware.org/reports/nonprofitsocial- media-decision-guide. Accessed on October 23, 2015.

Repack, D. L. (2006). Adoption and Use of Information Systems Technology In A Business-Format Franchise (Doctoral dissertation). Retrieved from ProQuest Dissertations and Theses. (UMI No. 3221524).

ybalko, S., and Seltzer, T. (2010). Dialogic communication in 140 characters or less: How Fortune 500 companies engage stakeholders using Twitter. Public Relations Review, 36(1), 336-341.

Safko, L. (2010). The social media bible: Tactics, tools, \& strategies for business success (2nd ed.). Hoboken, NJ: John Wiley \& Son's, Inc.

Salamon, L. M. (1992). America's nonprofit sector: A primer. New York: The Foundation Center.

Salamon, L. M. (1995). Partners in public service: Government-nonprofit relations in the modern welfare state. Baltimore, MD: The John Hopkins University Press.

Salamon, L. M. (Ed.). (2002). The state of nonprofit America. Washington, DC: Brookings.

Salamon, L. M., and Geller, S. L. (2007). Nonprofit fiscal trends and challenges. Baltimore, MD: The John Hopkins Center for Civic Society Studies.

Salamon, L. M., Sokolowsky, S. W., and List, R. (2003). Global civil society: An overview. Baltimore, MD: The John Hopkins Center for Civic Society Studies.

Salamon, L.M. (1999). America's nonprofit sector: A primer (2nd ed.). New York: The Foundation Center.

Salamon, L.M. (2005). The changing context of American nonprofit management. In R.D. Herman \& Associates (Eds.), The Jossey-Bass handbook of nonprofit leadership \& management (pp.81-101). San Francisco, CA: Wiley \& Sons.

Santos, L. M. (2003). An Investigation of which Electronic Media Have Had The Most Impact On Athletic Fundraising At Select NCAA Institutions (Master's thesis). Retrieved from ProQuest Dissertations and Theses. (UMI No. EP21703).

Sargeant, A., Ford, J., and Hudson, J. (2008). Charity brand personality: The relationship with giving behavior. Nonprofit and Voluntary Sector Quarterly, 37(2), 468-441. 
Saxton, G. D. and Wang, L. (2014). The Social Network Effect: The Determinants of Giving Through Social Media. Nonprofit and Voluntary Sector Quarterly, 43(5), $1-19$.

Saxton, G. D., and Benson, M. A. (2005). Social capital and the growth of the nonprofit sector. Social Science Quarterly, 86(1), 16-35.

Saxton, G. D., and Guo, C. (2011). Accountability Online: Understanding the Web-Based Accountability Practices of Nonprofit Organizations. Nonprofit and Voluntary Sector Quarterly, 40(2), 270-295.

Saxton, G. D., and Waters, R. D. (2014). What do Stakeholders Like on Facebook? Examining Public Reactions to Nonprofit Organizations' Informational, Promotional, and Community-Building Messages. Journal of Public Relations Research, 26(2), 280-299.

Saxton, G. D., Guo, C., and Brown, W. (2007). New dimensions of nonprofit responsiveness: The application and promise of Internet-based technologies. Public Performance and Management Review, 31(1), 144-173.

Saxton, G. D., Niyirora, J. N., Guo, C., and Waters, R. D. (2015). \#AdvocatingForChange: The Strategic Use of Hashtags in Social Media Advocacy. Advances in Social Work, 16(1), 154-169.

Schmid, H., Bar, M., and Nirel, R. (2008). Advocacy activities in nonprofit human service organizations: Implications for policy. Nonprofit \& Voluntary Sector Quarterly, 37(3), 581-602.

Schneider, J. A. (2003). Small, minority-based nonprofits in the information age. Nonprofit Management and Leadership, 13(4), 383-399.

Scott, R., and Meyer, J. (1994). Institutional environments and organizations: Structural complexity and individualism. Thousand Oaks, CA: Sage Publications.

Scott, W. R. (1995). Institutions and organizations. Thousand Oaks, CA: Sage.

Scott, W. R., and Christensen, S. (Eds.). (1995). The Institutional Construction of Organizations: International and Longitudinal Studies. Thousand Oaks, CA: Sage.

Sheridan, B. A. (2004). Key Components of Successful Higher Education Online Fundraising Programs (Doctoral dissertation). Retrieved from ProQuest Dissertations and Theses. (UMI No. 3139721). 
Smith, D. H. (1993). Public benefit and member benefit nonprofit, voluntary groups. Nonprofit and Voluntary Sector Quarterly, 22(2), 53-68.

Smitko, K. (2012). Donor engagement through Twitter. Public Relations Review, 38, $633-635$.

Suárez, D. F. (2009). Nonprofit Advocacy and Civic Engagement on the Internet. Administration \& Society, 41(3), 267-289.

Suárez, D. F. and Hwang, H. (2008). Civic engagement and nonprofit lobbying in California, 1998-2003. Nonprofit and Voluntary Sector Quarterly, 37(2), 93-112.

Thompson, T. (2010). Assessing the Determinants of Information Technology Adoption in Jamaica's Public Sector Using the Technology Acceptance Model (Doctoral dissertation). Retrieved from ProQuest Dissertations and Theses. (UMI No. 3421216).

Tillquist, J., King, J.L. and Woo, C. (2002). A representational scheme for analyzing information technology and organizational dependency. M.I.S. Quarterly, 26(2), 91-118.

Tinkelman, D., and Neely, D. (2011). Some econometric issues in studying nonprofit revenue interactions using NCCS data. Nonprofit and Voluntary Sector Quarterly, 40(1), 751-761.

Tomatzky, L.G. and Klein, K.J. (1982). Innovation Characteristics and Innovation Adoption- implementation: A Meta-Analysis of Findings. IEEE Transactions on Engineering Management, 29(1), 28-45.

Ulrich, D., and Barney, J. B. 1984. Perspectives in organizations: Resource dependence, efficiency, and population. Academy of Management Review, 9(1), 471-481.

Vanderwarren, K. R. (2001).Financial Accountability in Charitable Organizations: Mandating an Audit Committee Function. Chicago-Kent Law Review, 77(1), 963 988.

Vishwanath, A. and Goldhaber, G. M. (2003). An examination of the factors contributing to adoption decisions among late-diffused technology products. New Media \& Society, 5(2), 547-572.

Walfall, C. S. (2014). The Use and Adoption of Information Communication and Technologies (ICTs) by Jamaican Micro, Small and Medium-Sized Enterprises (MSMEs) (Doctoral dissertation). Retrieved from ProQuest Dissertations and Theses. (UMI No. 3641768). 
Wang, L., and Graddy, E. (2008). Social capital, volunteering and charitable giving. Voluntas: International Journal of Voluntary and Nonprofit Organizations, 19(1), 23-42.

Waters, R. D. (2007). Nonprofit organizations' use of the Internet: A content analysis of communication trends on the Internet sites of the Philanthropy 400. Nonprofit Management and Leadership, 18(1), 59-76.

Waters, R. D., and Jamal, J. Y. (2011). Tweet, tweet, tweet: A content analysis of nonprofit organizations' Twitter updates. Public Relations Review, 37(4), 321324.

Waters, R. D., and Bortree, D. S. (2010). Building a better workplace for teen volunteers through inclusive behaviors. Nonprofit Management \& Leadership, 20(3), 337355.

Waters, R. D., Burnett, E., Lamm, A., and Lucas, J. (2009). Engaging stakeholders through social media: How nonprofit organizations are using Facebook. Public Relations Review, 35(2), 102-106.

Weisbrod, B., and Dominguez, N. (1986). Demand for collective goods in private nonprofit markets: Can fundraising expenditures help overcome free-rider behavior? Journal of Public Economics, 30(1), 83-96.

Werner, S., Konopaske, R., and Gemeinhardt, G. (2000). The Effects of United Way Membership on Employee Pay in Nonprofit Organizations. Nonprofit Management \& Leadership, 11(1), 35-48.

Westcott, S. (2007) Face time: Charities flock to social-networking Web sites to reach out to new people, spark discussion, and help raise money. The Chronicle of Philanthropy. Available at http://philanthropy.com/free/articles/v19/107/07t000201.htm Accessed on April 20, 2016.

Wilcox-Ugurlu, C. C. (2011). Social Media, Existence, Identity Dynamics and Experiential Consumption (Doctoral dissertation). Retrieved from ProQuest Dissertations and Theses. (UMI No. 3454990).

Yeon, H. M., Choi, Y. and Kiousis, S. (2007). Interactive communication features on nonprofit organizations' webpages for the practice of excellence in public relations. Journal of Website Promotion, 1(2), 61-83.

Young, D. R. (2001). Organizational Identity and the Structure of Nonprofit Umbrella Associations. Nonprofit Management \& Leadership, 11(3), 289-304. 
Young, J. (2010). Exploring and Understanding the Use of Social Media and How It Relates to Capacity Building in Nonprofit Organizations. Paper presented at the Association for Research on Nonprofit Organizations and Voluntary Action (ARNOVA) Conference, Alexandria, Virginia.

Young, J. A. (2012). The Current Status of Social Media uses among Nonprofit Human Service Organizations: An Exploratory Study (Doctoral dissertation). Retrieved from ProQuest Dissertations and Theses. (UMI No. 3507810).

Zhou, Y. (2008). Voluntary adopters versus forced adopters: Integrating the diffusion of innovation theory and the technology acceptance model to study intraorganizational adoption. New Media \& Society, 10(2), 475-496.

Zorn, E. Z., Flanagin, A. J. and Shoham, M. D. (2011). Institutional and Noninstitutional Influences on Information and Communication Technology Adoption and Use among Nonprofit Organizations. Human Communication Research, 37(2), 1-33. 


\section{APPENDICES}

Appendix A: Correlations Matrix, Model 1: The Adoption of Social Media Appendix B: Correlations Matrix, Model 2: The Use of Social Media Appendix C: Open-Ended Interview Questions Appendix D: Survey Questions

Appendix E: IRB Participant Consent 
Appendix A: Correlations Matrix, Model 1: The Adoption of Social Media

\begin{tabular}{|c|c|c|c|c|c|c|c|c|c|c|}
\hline & & 1 & 2 & 3 & 4 & 5 & 6 & 7 & 8 & 9 \\
\hline 1 & Years on Facebook & - & & & & & & & & \\
\hline 2 & Years on Twitter & 0.67 & - & & & & & & & \\
\hline 3 & Relative Advantage & 0.04 & 0.09 & - & & & & & & \\
\hline 4 & Compatibility & -0.14 & -0.11 & 0.58 & - & & & & & \\
\hline 5 & Ease of Use & 0.06 & 0.12 & 0.23 & 0.33 & - & & & & \\
\hline 6 & Observability & 0.01 & 0.01 & 0.40 & 0.47 & 0.21 & - & & & \\
\hline 7 & Source of Funding & -0.13 & -0.13 & 0.42 & 0.37 & 0.31 & 0.28 & - & & \\
\hline 8 & Public Dependence & 0.05 & 0.10 & 0.47 & 0.43 & 0.07 & 0.38 & 0.43 & - & \\
\hline 9 & Donor Dependence & -0.22 & -0.22 & 0.26 & 0.61 & 0.14 & 0.23 & 0.43 & 0.27 & - \\
\hline 10 & Peer Practice & -0.09 & -0.11 & 0.08 & 0.31 & 0.18 & 0.21 & 0.36 & 0.15 & 0.42 \\
\hline 11 & Fundraising & -0.20 & -0.17 & 0.32 & 0.35 & 0.44 & 0.22 & 0.70 & 0.16 & 0.39 \\
\hline 12 & Leadership & 0.00 & -0.08 & 0.29 & 0.35 & 0.21 & 0.40 & 0.44 & 0.29 & 0.38 \\
\hline 13 & IT Staff & -0.03 & -0.06 & -0.06 & 0.00 & -0.07 & 0.07 & 0.00 & 0.04 & 0.04 \\
\hline 14 & Revenue (log) & -0.01 & -0.02 & 0.05 & 0.04 & 0.04 & 0.05 & 0.05 & 0.03 & 0.03 \\
\hline 15 & Managers SM & 0.02 & -0.05 & -0.02 & 0.00 & 0.06 & 0.02 & 0.05 & -0.03 & 0.09 \\
\hline 16 & Ext. Consultant & -0.15 & 0.08 & 0.02 & -0.02 & 0.01 & -0.01 & -0.05 & -0.01 & -0.05 \\
\hline 17 & NPO Sector & 0.19 & 0.20 & 0.07 & -0.10 & 0.03 & 0.00 & -0.08 & 0.02 & -0.18 \\
\hline 18 & UW support & 0.11 & 0.09 & -0.11 & -0.10 & -0.08 & -0.08 & -0.11 & -0.07 & -0.08 \\
\hline 19 & IT Budget & -0.03 & -0.07 & 0.07 & 0.15 & 0.06 & 0.00 & 0.15 & 0.00 & 0.14 \\
\hline 20 & Staff $(\log )$ & -0.06 & -0.06 & -0.02 & 0.04 & -0.03 & 0.08 & 0.03 & 0.06 & 0.07 \\
\hline
\end{tabular}




\begin{tabular}{|c|c|c|c|c|c|c|c|c|c|c|c|c|}
\hline & & 10 & 11 & 12 & 13 & 14 & 15 & 16 & 17 & 18 & 19 & 20 \\
\hline 10 & Peer Practice & - & & & & & & & & & & \\
\hline 11 & Fundraising & 0.22 & - & & & & & & & & & \\
\hline 12 & Leadership & 0.39 & 0.26 & - & & & & & & & & \\
\hline 13 & IT Staff & 0.07 & -0.05 & 0.08 & - & & & & & & & \\
\hline 14 & Revenue (log) & 0.08 & -0.01 & 0.00 & 0.06 & - & & & & & & \\
\hline 15 & Managers SM & 0.06 & 0.07 & -0.02 & 0.11 & 0.06 & - & & & & & \\
\hline 16 & Ext. Consultant & -0.08 & 0.02 & -0.07 & -0.04 & 0.00 & -0.06 & - & & & & \\
\hline 17 & NPO Sector & -0.15 & -0.07 & -0.12 & -0.01 & -0.13 & 0.00 & 0.20 & - & & & \\
\hline 18 & UW support & -0.07 & -0.08 & -0.05 & 0.07 & -0.01 & -0.07 & 0.01 & 0.00 & - & & \\
\hline 19 & IT Budget & 0.05 & 0.13 & 0.05 & 0.07 & -0.16 & 0.04 & -0.13 & -0.03 & -0.03 & - & \\
\hline 20 & Staff (log) & 0.08 & -0.02 & 0.03 & -0.04 & 0.00 & 0.03 & -0.01 & -0.04 & -0.02 & -0.07 & - \\
\hline
\end{tabular}


Appendix B: Correlations Matrix, Model 2: The Use of Social Media

\begin{tabular}{|c|c|c|c|c|c|c|c|c|c|c|}
\hline & & 1 & 2 & 3 & 4 & 5 & 6 & 7 & 8 & 9 \\
\hline 1 & Use of Facebook & - & & & & & & & & \\
\hline 2 & Use of Twitter & 0.30 & - & & & & & & & \\
\hline 3 & Rel. Advantage & 0.04 & 0.10 & - & & & & & & \\
\hline 4 & Compatibility & 0.07 & 0.05 & 0.59 & - & & & & & \\
\hline 5 & Ease of Use & 0.00 & 0.02 & 0.14 & 0.26 & - & & & & \\
\hline 6 & Observability & 0.08 & 0.20 & 0.54 & 0.49 & 0.33 & - & & & \\
\hline 7 & Source of Funding & 0.07 & 0.03 & 0.51 & 0.42 & 0.31 & 0.39 & - & & \\
\hline 8 & Public Dependence & 0.03 & -0.04 & 0.19 & 0.38 & 0.47 & 0.20 & 0.24 & - & \\
\hline 9 & Donor Dependence & -0.01 & -0.06 & 0.30 & 0.31 & -0.22 & 0.27 & 0.15 & -0.28 & - \\
\hline 10 & Peer Practice & -0.02 & -0.04 & 0.20 & 0.24 & 0.36 & 0.26 & 0.30 & 0.22 & 0.13 \\
\hline 11 & Fundraising & 0.05 & 0.04 & 0.37 & 0.35 & 0.52 & 0.32 & 0.73 & 0.43 & -0.04 \\
\hline 12 & Leadership & -0.04 & 0.01 & 0.22 & 0.22 & 0.24 & 0.30 & 0.27 & 0.12 & 0.03 \\
\hline 13 & IT Staff & -0.01 & -0.06 & 0.10 & 0.05 & 0.06 & 0.10 & 0.04 & 0.03 & 0.04 \\
\hline 14 & Revenue (log) & 0.07 & -0.03 & 0.06 & 0.07 & -0.04 & 0.08 & 0.03 & 0.01 & 0.07 \\
\hline 15 & Managers SM & 0.14 & -0.06 & -0.04 & -0.05 & -0.08 & -0.02 & -0.07 & -0.11 & -0.05 \\
\hline 16 & Ext. Consultant & -0.07 & -0.06 & -0.03 & -0.05 & -0.09 & 0.03 & -0.05 & -0.13 & -0.06 \\
\hline 17 & NPO Sector & -0.17 & -0.08 & -0.06 & -0.08 & -0.07 & -0.01 & -0.06 & -0.04 & 0.01 \\
\hline 18 & UW support & 0.08 & 0.02 & 0.04 & 0.11 & -0.03 & -0.02 & 0.05 & 0.00 & 0.03 \\
\hline 19 & IT Budget & -0.06 & -0.06 & -0.02 & 0.04 & -0.03 & 0.08 & 0.03 & 0.06 & 0.07 \\
\hline 20 & Staff $(\log )$ & -0.16 & -0.03 & 0.04 & 0.03 & 0.11 & -0.01 & 0.08 & 0.10 & -0.09 \\
\hline
\end{tabular}




\begin{tabular}{|c|c|c|c|c|c|c|c|c|c|c|c|c|}
\hline & & 10 & 11 & 12 & 13 & 14 & 15 & 16 & 17 & 18 & 19 & 20 \\
\hline 10 & Peer Practice & - & & & & & & & & & & \\
\hline 11 & Fundraising & 0.34 & - & & & & & & & & & \\
\hline 12 & Leadership & 0.10 & 0.24 & - & & & & & & & & \\
\hline 13 & IT Staff & 0.04 & 0.03 & 0.03 & - & & & & & & & \\
\hline 14 & Revenue (log) & 0.01 & 0.02 & -0.03 & 0.06 & - & & & & & & \\
\hline 15 & Managers SM & -0.06 & -0.09 & -0.04 & 0.00 & -0.06 & - & & & & & \\
\hline 16 & Ext. Consultant & -0.10 & -0.05 & -0.11 & -0.13 & 0.00 & 0.20 & - & & & & \\
\hline 17 & NPO Sector & 0.00 & -0.06 & 0.01 & -0.01 & -0.07 & 0.01 & 0.00 & - & & & \\
\hline 18 & UW support & -0.06 & 0.08 & -0.03 & -0.16 & 0.04 & -0.13 & -0.03 & -0.03 & - & & \\
\hline 19 & IT Budget & 0.08 & -0.02 & 0.03 & -0.04 & 0.00 & 0.03 & -0.01 & -0.04 & -0.02 & - & \\
\hline 20 & Staff $(\log )$ & 0.09 & 0.13 & 0.02 & 0.00 & 0.03 & -0.01 & -0.04 & -0.02 & -0.02 & -0.07 & - \\
\hline
\end{tabular}




\section{Appendix C: Open-Ended Interview Questions}

1. What were the main reasons to adopt (Facebook, Twitter etc) in your organization?

a. How has the adoption of (Facebook, Twitter etc) changed how activities are organized in your organization?

b. How does the adoption of (Facebook, Twitter etc) help in achieving your organization's mission?

c. How does the adoption of (Facebook, Twitter etc) help your organization in connecting with clients?

d. How does the adoption of (Facebook, Twitter etc) help your organization in connecting with donors?

e. How does the adoption of (Facebook, Twitter etc) help your organization in fundraising activities?

f. How does the adoption of (Facebook, Twitter etc) help your organization in the dayto-day administration of your organization?

2. Which technologies were you using prior to the adoption of (Facebook, Twitter etc) for the above activities in your organization?

3. What were the main challenges in the adoption of (Facebook, Twitter etc)?

a. What were the technical challenges?

b. What were the human resource challenges?

c. What were the financial challenges?

d. What were the leadership challenges?

4. How did you overcome these challenges? 
5. Which other social media platform(s) do you intend to adopt and use between the next 12 and 24 months?

6. How was your organization introduced to Social Media? Were you working in the organization before social media was adopted?

7. What are your main duties and responsibilities in your organization?

8. What is your level of education?

9. What is your age?

10. What is your gender

11. How many years have you been working in your current organization? 


\section{Appendix D: Survey Questions}

Social Media Diffusion in Nonprofit Organizations. I am conducting a study on the adoption and use of Social Media in Nonprofit Organizations (typically 501(c)(3) organizations) in Florida. The survey is open to the nonprofits which receive funding from United Way (often called "funded partners"). Your responses will help in identifying the opportunities and challenges of social media use among nonprofits. The survey should take no more than ten minutes. Your responses will remain confidential. I can share the final copy of my study, if you give your email address at the end of survey. Your consent is automatically given if you proceed with the survey. If you have any questions or concerns about this research, please feel free to contact the Principal Investigator, Sukumar Ganapati (ganapati@fiu.edu) or me (Elvis Asorwoe, easor001@fiu.edu). We sincerely appreciate your participation in this survey. Elvis Asorwoe Ph.D. Candidate in Public Affairs Florida International University Miami, Florida 33199 1. Does your organization have an account with a social media platform (e.g. Facebook, Twitter, etc.)?

O Yes

O No If No Is Selected, Then Skip To Why did your organization not adopt s...

\section{SOCIAL MEDIA ADOPTION}

2. How many years ago did your organization create an account with the following Social Media platforms?
a) Facebook
b) Twitter
c) Other (please specify) 
3. How often has your organization posted (e.g., texts, pictures, links or videos) to the Social Media platforms during the last two years?

\begin{tabular}{|c|c|c|c|c|c|}
\hline $\begin{array}{c}\text { Facebook } \\
(4)\end{array}$ & Hourly (1) & Daily (2) & Weekly (3) & Monthly (6) & Yearly (7) \\
$\begin{array}{c}\text { Twitter } \\
(5)\end{array}$ & 0 & 0 & 0 & 0 & 0 \\
$\begin{array}{c}\text { Other } \\
\text { (please specify) } \\
(7)\end{array}$ & 0 & 0 & 0 & 0 & 0 \\
\hline
\end{tabular}

4. Why did your organization adopt social media? Rate the importance of the following factors for your organization to adopt social media. 


\begin{tabular}{|c|c|c|c|c|c|c|}
\hline & $\begin{array}{c}\text { Very } \\
\text { important } \\
\text { (1) }\end{array}$ & $\begin{array}{l}\text { Important } \\
\text { (2) }\end{array}$ & $\begin{array}{l}\text { Moderately } \\
\text { important } \\
\text { (3) }\end{array}$ & $\begin{array}{l}\text { Slightly } \\
\text { Important } \\
\text { (4) }\end{array}$ & $\begin{array}{c}\text { Not } \\
\text { important } \\
\text { (5) }\end{array}$ & $\begin{array}{c}\text { Not } \\
\text { Applicable } \\
\text { (6) }\end{array}$ \\
\hline $\begin{array}{l}\text { To accomplish our } \\
\text { mission }\end{array}$ & 0 & 0 & 0 & 0 & 0 & 0 \\
\hline $\begin{array}{l}\text { Social media offers } \\
\text { relative advantage } \\
\text { over existing } \\
\text { technologies our } \\
\text { organization }\end{array}$ & $\mathrm{O}$ & $\mathrm{O}$ & 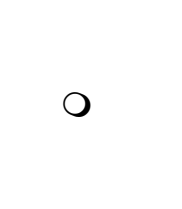 & 0 & 0 & 0 \\
\hline $\begin{array}{l}\text { Social media fulfils } \\
\text { the needs of our } \\
\text { organizational } \\
\text { activities }\end{array}$ & 0 & 0 & O & 0 & 0 & $O$ \\
\hline $\begin{array}{l}\text { Social media is easy } \\
\text { to adopt in our } \\
\text { organization }\end{array}$ & 0 & 0 & 0 & 0 & 0 & 0 \\
\hline $\begin{array}{c}\text { Social media } \\
\text { adoption has resulted } \\
\text { in tangible } \\
\text { organizational } \\
\text { benefits }\end{array}$ & 0 & 0 & 0 & 0 & 0 & 0 \\
\hline $\begin{array}{l}\text { Our organization } \\
\text { adopted social media } \\
\text { for fundraising } \\
\text { purposes }\end{array}$ & 0 & 0 & 0 & 0 & 0 & 0 \\
\hline $\begin{array}{l}\text { Our organization } \\
\text { adopted social media } \\
\text { to diversify our } \\
\text { funding sources }(28)\end{array}$ & 0 & 0 & 0 & 0 & 0 & 0 \\
\hline $\begin{array}{l}\text { Our organization } \\
\text { adopted social media } \\
\text { to generate public } \\
\text { awareness (29) }\end{array}$ & 0 & 0 & 0 & $O$ & 0 & $O$ \\
\hline $\begin{array}{l}\text { Our donors required } \\
\text { us to adopt social } \\
\text { media }(30)\end{array}$ & 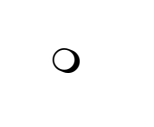 & 0 & 0 & 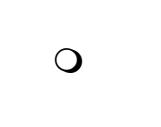 & 0 & 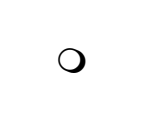 \\
\hline $\begin{array}{l}\text { Our organization } \\
\text { adopted social media } \\
\text { because other } \\
\text { nonprofits have } \\
\text { adopted it (14) }\end{array}$ & 0 & 0 & 0 & 0 & 0 & 0 \\
\hline $\begin{array}{c}\text { Our leadership } \\
\text { championed the } \\
\text { adoption of social } \\
\text { media (16) }\end{array}$ & 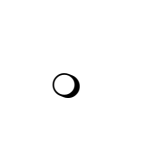 & 0 & 0 & 0 & 0 & 0 \\
\hline
\end{tabular}




\section{Q7 SOCIAL MEDIA USE}

Q8 Why has your organization been using social media? Rate the importance of the following factors for your organization to use social media.

\begin{tabular}{|c|c|c|c|c|c|c|}
\hline Question & $\begin{array}{l}\text { Very } \\
\text { important } \\
\text { (1) }\end{array}$ & $\begin{array}{l}\text { Important } \\
\text { (2) }\end{array}$ & $\begin{array}{l}\text { Moderately } \\
\text { important } \\
\text { (3) }\end{array}$ & $\begin{array}{l}\text { Slightly } \\
\text { Important } \\
\text { (4) }\end{array}$ & $\begin{array}{l}\text { Not } \\
\text { important } \\
\text { (5) }\end{array}$ & $\begin{array}{c}\text { Not } \\
\text { Applicable } \\
\text { (6) }\end{array}$ \\
\hline $\begin{array}{l}\text { Our organization uses } \\
\text { social media to } \\
\text { accomplish our } \\
\text { mission (9) }\end{array}$ & 0 & 0 & 0 & 0 & 0 & 0 \\
\hline $\begin{array}{l}\text { Social media is better } \\
\text { than existing } \\
\text { technologies used in } \\
\text { our organization }(27)\end{array}$ & 0 & 0 & $\mathrm{O}$ & 0 & 0 & 0 \\
\hline $\begin{array}{c}\text { Our organization uses } \\
\text { social media to } \\
\text { conduct our activities } \\
(10)\end{array}$ & 0 & 0 & 0 & 0 & 0 & 0 \\
\hline $\begin{array}{l}\text { Social media has been } \\
\text { easy to use in our } \\
\text { organization (11) }\end{array}$ & 0 & 0 & 0 & 0 & 0 & 0 \\
\hline $\begin{array}{l}\text { Social media use has } \\
\text { resulted in tangible } \\
\text { organizational benefits } \\
\text { (19) }\end{array}$ & 0 & 0 & $\mathrm{O}$ & O & 0 & 0 \\
\hline $\begin{array}{l}\text { Our organization has } \\
\text { been using social } \\
\text { media for fundraising } \\
\text { purposes (13) }\end{array}$ & O & 0 & $\mathrm{O}$ & $\mathrm{O}$ & $\mathrm{O}$ & $\mathrm{O}$ \\
\hline $\begin{array}{l}\text { Our organization has } \\
\text { been using social } \\
\text { media to diversify our } \\
\text { funding sources }(28)\end{array}$ & 0 & $\mathrm{O}$ & $\mathrm{O}$ & O & 0 & $\mathrm{O}$ \\
\hline $\begin{array}{l}\text { Our organization has } \\
\text { been using social } \\
\text { media to generate } \\
\text { public awareness }(29)\end{array}$ & $\mathrm{O}$ & $\mathrm{O}$ & 0 & 0 & 0 & 0 \\
\hline $\begin{array}{l}\text { Our donors required us } \\
\text { to use social media } \\
\text { (30) }\end{array}$ & O & $\mathrm{O}$ & O & $\mathrm{O}$ & $\mathrm{O}$ & $\mathrm{O}$ \\
\hline $\begin{array}{l}\text { Our organization has } \\
\text { been using social } \\
\text { media since other } \\
\text { nonprofits have been } \\
\text { using it (14) }\end{array}$ & $\mathrm{O}$ & O & $\mathrm{O}$ & $\mathrm{O}$ & 0 & $\mathrm{O}$ \\
\hline $\begin{array}{l}\text { Our leadership has } \\
\text { championed the use of } \\
\text { social media (16) }\end{array}$ & $\mathrm{O}$ & 0 & $\mathrm{O}$ & 0 & 0 & 0 \\
\hline
\end{tabular}


Q9 How many people manage the social media account(s) of your organization?

$\begin{array}{ll} & 1(4) \\ & 2(5) \\ & 3(6) \\ O & \text { More than } 3(7) \\ O & \text { Prefer not to answer (8) }\end{array}$

Q10 Who manages the social media account(s) of your organization? Check all that apply

- Frontline Employees (e.g. secretary, receptionist) (6)

口 Middle Administrators (e.g. supervisors) (5)

- Senior Management (e.g. President, CEO, Directors) (4)

- External consultant (7)

口 Prefer not to answer (8)

Display This Question:

If SOCIAL MEDIA ADOPTION Is Not Displayed

Q12 SOCIAL MEDIA NON-ADOPTION THIS SECTION ASKS ABOUT WHY YOUR

ORGANIZATION HAVE NOT ADOPTED SOCIAL MEDIA Why did your organization not adopt social

media? Rate the importance of the following factors for your organization to not adopt social media. 


\begin{tabular}{|c|c|c|c|c|c|c|}
\hline & $\begin{array}{c}\text { Very } \\
\text { important } \\
\text { (1) }\end{array}$ & $\begin{array}{l}\text { Important } \\
\text { (2) }\end{array}$ & $\begin{array}{l}\text { Moderately } \\
\text { important } \\
\text { (3) }\end{array}$ & $\begin{array}{l}\text { Slightly } \\
\text { Important } \\
\text { (4) }\end{array}$ & $\begin{array}{l}\text { Not } \\
\text { important } \\
\text { (5) }\end{array}$ & $\begin{array}{c}\text { Not } \\
\text { Applicable } \\
\text { (6) }\end{array}$ \\
\hline $\begin{array}{l}\text { Social media does not } \\
\text { help accomplish our } \\
\text { mission (9) }\end{array}$ & 0 & 0 & 0 & 0 & 0 & 0 \\
\hline $\begin{array}{l}\text { Social media offers no } \\
\text { relative advantage over } \\
\text { existing technologies } \\
\text { our organization }(27)\end{array}$ & 0 & 0 & 0 & 0 & 0 & 0 \\
\hline $\begin{array}{l}\text { Social media does not } \\
\text { fulfill the needs of our } \\
\text { organizational activities } \\
\text { (10) }\end{array}$ & 0 & 0 & 0 & O & 0 & O \\
\hline $\begin{array}{l}\text { Social media is not easy } \\
\text { to adopt in our } \\
\text { organization (11) }\end{array}$ & 0 & 0 & 0 & 0 & 0 & 0 \\
\hline $\begin{array}{l}\text { Social media adoption } \\
\text { has not resulted in } \\
\text { tangible organizational } \\
\text { benefits (19) }\end{array}$ & 0 & 0 & 0 & 0 & 0 & 0 \\
\hline $\begin{array}{l}\text { Social media does not } \\
\text { help our organization in } \\
\text { fundraising (13) }\end{array}$ & 0 & $\mathrm{O}$ & $\mathrm{O}$ & $\mathrm{O}$ & 0 & $\mathrm{O}$ \\
\hline $\begin{array}{l}\text { Social media does not } \\
\text { help our organization to } \\
\text { diversify our funding } \\
\text { sources }(28)\end{array}$ & 0 & $\mathrm{O}$ & 0 & 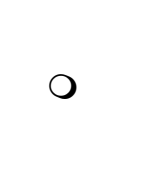 & 0 & 0 \\
\hline $\begin{array}{l}\text { Social media does not } \\
\text { help in generating } \\
\text { public awareness (29) }\end{array}$ & 0 & $\mathrm{O}$ & $\mathrm{O}$ & $\mathrm{O}$ & 0 & $\mathrm{O}$ \\
\hline $\begin{array}{l}\text { Our donors did not } \\
\text { require us to adopt } \\
\text { social media (30) }\end{array}$ & 0 & 0 & 0 & $\mathrm{O}$ & 0 & 0 \\
\hline $\begin{array}{l}\text { Our organization did not } \\
\text { want to adopt social } \\
\text { media just because other } \\
\text { nonprofits have adopted } \\
\text { it (14) }\end{array}$ & 0 & 0 & 0 & O & 0 & 0 \\
\hline $\begin{array}{l}\text { Our leadership does not } \\
\text { see value in the adoption } \\
\text { of social media (16) }\end{array}$ & 0 & 0 & 0 & O & 0 & $\mathrm{O}$ \\
\hline
\end{tabular}




\section{Q13 ORGANIZATIONAL CHARACTERISTICS}

Q14 What is the name of your organization?

O Name (8)

Prefer not to answer (2)

Q15 What are the major activities of your organization? Check all that apply.

Education (4)

口 Environment (5)

- Health (6)

a Human Services (7)

Mutual Benefits (8)

Other (Please specify) (9)

Q16 In which city is your organization located?

Q17 What was the organization's total revenue for 2015 Fiscal year?

Q18 What were the percentage shares of the organization's revenues from following sources for 2015 Fiscal year?

Government (federal, state, local) (8)

Private entities (e.g. philanthropies, corporations) (4)

Fee for service (6)

United Way Chapter (7)

Q19 What percentage of your organization's revenue was spent on information technology (software, hardware, website, and social media) in 2015 Fiscal year?

Q20 How many employees work in your organization?

\begin{tabular}{|c|c|c|}
\hline & Total Staff (1) & IT Staff (2) \\
Full time (4) & & \\
Part time (5) & & \\
Volunteers (6) & & \\
\hline
\end{tabular}


Q21 Please provide any comments you may have on the adoption and use of social media in your organization.

Q22 If you are interested in obtaining the results of this study, please indicate your email address below.

O Email Address: (1)

Prefer not to receive results of the study (2) 
Appendix E: IRB Participant Consent

FIU IRB Approval: 99/12/2016 FIU IRB Expiration:09/12/2017

\begin{tabular}{|l|l|}
\hline & \\
\hline FIU IRB Number: & IRB-15-0390 \\
\hline
\end{tabular}

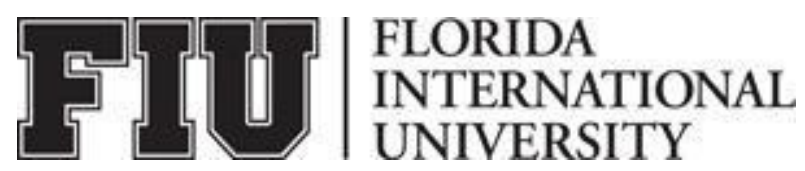

\section{ADULT ONLINE CONSENT TO PARTICIPATE IN A RESEARCH STUDY THE DIFFUSION OF SOCIAL MEDIA IN NONPROFIT ORGANIZATIONS}

\section{PURPOSE OF THE STUDY}

You are being asked to be in a research study. The purpose of this study is to gain a better understanding of the use of social media in nonprofit organizations.

\section{NUMBER OF STUDY PARTICIPANTS}

If you decide to be in this study, you will be one of 1000 people in this research study.

\section{DURATION OF THE STUDY}

Your participation will require 20 minutes to complete this survey.

\section{PROCEDURES}

If you agree to be in the study, we will ask you to do the following things:

1. You will be asked to complete several questions regarding the factors that influence the use of ICT for fundraising purposes in nonprofits. Total time for your participation is estimated to be 20 minutes.

2. If you agree to participate in this study, and you cannot accurately answer the questions, please pass this survey on to the person who can best answer them in your organization.

\section{RISKS AND/OR DISCOMFORTS}

There is no risk/discomfort to you from responding to this survey. The participation in this study is voluntary and refusal to participate involves no penalty or loss of benefits to which you are entitled. You may discontinue participation at any time without penalty or loss of benefits. 


\section{BENEFITS}

This study will deepen our understanding of the use of ICT for fundraising purposes in nonprofit organizations. If you would like to know the results of this study, I will share my findings with you.

\section{ALTERNATIVES}

There are no known alternatives available to you other than not taking part in this study. However, any significant new findings developed during the course of the research which may relate to your willingness to continue participation will be provided to you. 


\begin{tabular}{|l|l|}
\hline FIU IRB Approval: & $09 / 12 / 2016$ \\
\hline FIU IRB Expiration: & $09 / 12 / 2017$ \\
\hline FIU IRB Number: & IRB-15-0390 \\
\hline
\end{tabular}

\section{CONFIDENTIALITY}

The records of this study will be kept private and will be protected to the fullest extent provided by law. In any sort of report we might publish, we will not include any information that will make it possible to identify a subject. Research records will be stored securely and only the researcher team will have access

to the records. However, your records may be reviewed for audit purposes by authorized University or other agents who will be bound by the same provisions of confidentiality.

\section{COMPENSATION \& COSTS}

I will randomly select 5 respondents and send them 1 \$20 starbucks gift card and 4 $\$ 10$ starbucks gift cards as a thank you for participating in the survey. You will not be responsible for any costs to participate in this study.

\section{RIGHT TO DECLINE OR WITHDRAW}

Your participation in this study is voluntary. You are free to participate in the study or withdraw your consent at any time during the study. Your withdrawal or lack of participation will not affect any benefits to which you are otherwise entitled. The investigator reserves the right to remove you without your consent at such time that they feel it is in the best interest.

\section{RESEARCHER CONTACT INFORMATION}

If you have any questions about the purpose, procedures, or any other issues relating to this research study you may contact Elvis Asorwoe, at Department of Public Administration, Florida International University, Modesto A. Maidique PCA 250B, 11200 SW 8th Street, Miami, FL 33199, Email: easor001@fiu.edu Cell: 305-549-0913, Fax: 305$348-5848$

\section{IRB CONTACT INFORMATION}

If you would like to talk with someone about your rights of being a subject in this research study or about ethical issues with this research study, you may contact the FIU Office of Research Integrity by phone at 305-348-2494 or by email at ori@fiu.edu.

\section{PARTICIPANT AGREEMENT}

I have read the information in this consent form and agree to participate in this study. I have had a chance to ask any questions I have about this study, and they have been answered for me. By clicking on the "consent to participate" button below I am providing my informed consent.

\section{(Insert Consent to Participate Button Here on the Website) \\ Consent to Participate (1)}




\section{Qualitative / Interview}

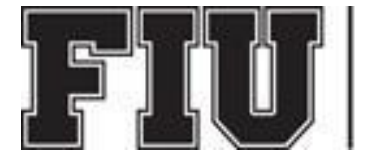

\section{FLORIDA}

\begin{tabular}{|l|l|}
\hline FIU IRB Approval: & $09 / 12 / 2016$ \\
\hline FIU IRB & $09 / 12 / 2017$ \\
\hline FIU IRB Number: & IRB-15-0390 \\
\hline
\end{tabular}

INTERNATIONAL

UNIVERSITY

\section{ADULT CONSENT TO PARTICIPATE IN A RESEARCH STUDY THE DIFFUSION OF SOCIAL MEDIA IN NONPROFIT ORGANIZATIONS}

\section{PURPOSE OF THE STUDY}

You are being asked to be in a research study. The purpose of this study is to gain a better understanding of the adoption and non-adoption of social media in nonprofit organizations

\section{NUMBER OF STUDY PARTICIPANTS}

If you decide to be in this study, you will be one of 10 people in this research study.

\section{DURATION OF THE STUDY}

Your participation will require $20-45$ minutes to complete.

\section{PROCEDURES}

If you agree to be in the study, we will ask you to do the following things:

3. You will be asked to answer several questions regarding the use of technology for fundraising purposes in nonprofits. The interview will be recorded for transcription for report compilation.

4. If you agree to participate in this study, and you cannot accurately answer the questions, you are allowed to ask a colleague to answer.

\section{RISKS AND/OR DISCOMFORTS}

There is no risk/discomfort to you from responding to this survey. The participation in this study is voluntary and refusal to participate involves no penalty or loss of benefits to which you are entitled. You may discontinue participation at any time without penalty or loss of benefits.

\section{BENEFITS}

This study will deepen our understanding of the use of ICT for fundraising purposes in nonprofit organizations. If you would like to know the results of this study, I will share my findings with you.

\section{ALTERNATIVES}

There are no known alternatives available to you other than not taking part in this study. However, any significant new findings developed during the course of the research which may relate to your willingness to continue participation will be provided to you. 


\begin{tabular}{|l|l|}
\hline FIU IRB Approval: & $09 / 12 / 2016$ \\
\hline FIU IRB Expiration: & $09 / 12 / 2017$ \\
\hline FIU IRB Number: & IRB-15-0390 \\
\hline
\end{tabular}

\section{CONFIDENTIALITY}

The records of this study will be kept private and will be protected to the fullest extent provided by law. In any sort of report we might publish, we will not include any information that will make it possible to identify a subject. Research records will be stored securely and only the researcher team will have access to the records. However, your records may be reviewed for audit purposes by authorized University or other agents who will be bound by the same provisions of confidentiality.

\section{COMPENSATION \& COSTS}

There is no compensation for participating in this study. You will not be responsible for any costs to participate in this study.

\section{RIGHT TO DECLINE OR WITHDRAW}

Your participation in this study is voluntary. You are free to participate in the study or withdraw your consent at any time during the study. Your withdrawal or lack of participation will not affect any benefits to which you are otherwise entitled. The investigator reserves the right to remove you without your consent at such time that they feel it is in the best interest.

\section{RESEARCHER CONTACT INFORMATION}

If you have any questions about the purpose, procedures, or any other issues relating to this research study you may contact Elvis Asorwoe, at Department of Public Administration, Florida International University, Modesto A. Maidique PCA 250B, 11200 SW 8th Street, Miami, FL 33199, Email: easor001@fiu.edu Cell: 305-549-0913, Fax: 305$348-5848$

\section{IRB CONTACT INFORMATION}

If you would like to talk with someone about your rights of being a subject in this research study or about ethical issues with this research study, you may contact the FIU Office of Research Integrity by phone at 305-348-2494 or by email at ori@fiu.edu. 


\section{PARTICIPANT AGREEMENT}

I have read the information in this consent form and agree to participate in this study. I have had a chance to ask any questions I have about this study, and they have been answered for me. I understand that I will be given a copy of this form for my records.

Signature of Participant

Printed Name of Participant

Signature of Person Obtaining Consent
Date

Date 


\section{ELVIS ASORWOE}

2001

2013

2003-2011

2011-2013

2013-Present

\section{PRESENTATIONS}

BA, Political Science

University of Ghana, Legon

Accra, Ghana

Master of Public Administration

Indiana State University

Terre Haute, Indiana

Business Development Officer

Business Advisory Center

National Board for Small Scale Industries

Ministry of Trade and Industries

Accra, Ghana

Teaching and Research Assistant

Indiana State University

Terre Haute, Indiana

Teaching and Research Assistant

Florida International University

Miami, Florida

Asorwoe, E. (2017). Why Do Local Nonprofits use Social Media? Understanding the Determinants of Social Media use among Local Nonprofits in Florida. Paper presented at the American Society for Public Administration (ASPA) Annual Conference, Atlanta, Georgia.

Asorwoe, E. (2016). The Impact of Employee Status on Donations and Financial Performance of Nonprofit Organizations. Paper to be presented at the South Eastern Conference for Public Administration (SECoPA) Annual Conference, Raleigh, North Carolina.

Asorwoe, E. (2016). Freedom of Opinion and Freedom of Expression: The Threat of Internet Freedom on the Strength of Global Civil Society. Presented at the 74th Midwest Political Science Association (MPSA) Annual Conference, Chicago, Illinois.

Asorwoe, E and Ganapati, S. (2015). The State of Global Smart Cities. Presented at the Urban Affairs Association (UAA) 45th Annual Conference, Miami, FL. 
Asorwoe, E. (2014). Factors Affecting Africa's eGovernment Development. Presented at the 72nd Midwest Political Science Association (MPSA) Annual Conference, Chicago, Illinois. 